\title{
ANALYSIS OF BIMETALLIC ADHESION AND INTERFACIAL TOUGHNESS OF KINETIC METALLIZATION COATINGS
}

\author{
A Thesis \\ presented to \\ the Faculty of California Polytechnic State University, \\ San Luis Obispo
}

In Partial Fulfillment

of the Requirements for the Degree

Master of Science in Engineering, with a Specialization in Materials Engineering

by

Alec D. Guraydin

May 2013 
(C) 2013

Alec D. Guraydin

ALL RIGHTS RESERVED 


\section{COMMITTEE MEMBERSHIP}

TITLE:

AUTHOR:

DATE SUBMITTED:

COMMITTEE CHAIR:

COMMITTEE MEMBER:

COMMITTEE MEMBER:

\section{ANALYSIS OF BIMETALLIC ADHESION AND INTERFACIAL TOUGHNESS OF KINETIC METALLIZATION COATINGS}

Alec D. Guraydin

May 2013

Dr. Trevor Harding, Professor, Materials Engineering, California Polytechnic State University

Dr. Blair London, Professor, Materials Engineering, California Polytechnic State University

Dr. Ralph Tapphorn, VP of Technology, Innovative Technology, Inc. (dba) Inovati 


\title{
ABSTRACT \\ ANALYSIS OF BIMETALLIC ADHESION AND INTERFACIAL TOUGHNESS OF KINETIC METALLIZATION COATINGS
}

\begin{abstract}
Alec D. Guraydin
Due to their ability to confer enhanced surface properties without compromising the properties of the substrate, coatings have become ubiquitous in heavy industrial applications for corrosion, wear, and thermal protection, among others. Kinetic Metallization (KM), a solid-state impact consolidation and coating process, is well-suited for depositing industrial coatings due to its versatility, low substrate heat input, and low cost. The ability of KM coatings to adhere to the substrate is determined by the quality of the interface. The purpose of this study is to develop a model to predict the interfacial quality of KM coatings using known coating and substrate properties. Of the various contributions to adhesion of KM coatings, research suggests that the thermodynamic Work of Adhesion $\left(\mathrm{W}_{\mathrm{AD}}\right)$ is the most fundamental. It is useful to define interfacial quality in terms of the critical strain energy release rate $\left(\mathrm{G}_{\mathrm{C}}\right)$ at which coating delamination occurs. Studies show that $\mathrm{G}_{\mathrm{C}}$ for a given interface is related to $\mathrm{W}_{\mathrm{AD}}$. This study attempts to develop a theoretical model for calculating $\mathrm{W}_{\mathrm{AD}}$ and understand the relationship between $\mathrm{G}_{\mathrm{C}}$ and $\mathrm{W}_{\mathrm{AD}}$. For a bimetallic interface between two transition metals, $\mathrm{W}_{\mathrm{AD}}$ can be theoretically calculated using known electronic and physical properties of each metal: the molar volume, $\mathrm{V}$, the surface energy, $\gamma$, and the enthalpy of alloy formation, $\Delta \mathrm{H}^{\text {interface }} ; \Delta \mathrm{H}^{\text {interface }}$ is a function of the molar volume, $\mathrm{V}$, the work function, $\varphi$, and the electron density at the boundary of the Wigner-Seitz cell, $\mathrm{n}_{\mathrm{Ws}}$. $\mathrm{W}_{\mathrm{AD}}$ for $\mathrm{Ni}-\mathrm{Cu}$ and $\mathrm{Ni}-\mathrm{Ti}$ interfaces were $3.51 \mathrm{~J} / \mathrm{m}^{2}$ and $4.55 \mathrm{~J} / \mathrm{m}^{2}$, respectively. A modified Four-point bend testing technique was used to experimentally measure $\mathrm{G}_{\mathrm{C}}$ for $\mathrm{Ni}-\mathrm{Cu}$ and $\mathrm{Ni}-\mathrm{Ti}$ specimens produced by KM. These tests yielded mean $\mathrm{G}_{\mathrm{C}}$ values of $50.92 \mathrm{~J} / \mathrm{m}^{2}$ and $132.68 \mathrm{~J} / \mathrm{m}^{2}$ for $\mathrm{Ni}-\mathrm{Cu}$ and $\mathrm{Ni}-\mathrm{Ti}$ specimens, respectively. Plastic deformation and surface roughness are likely the main reasons for the large discrepancy between $\mathrm{G}_{\mathrm{C}}$ and $\mathrm{W}_{\mathrm{AD}}$. At the $95 \%$ confidence level, the mean $\mathrm{G}_{\mathrm{C}}$ of the Ni-Ti interface is significantly higher than that of the Ni-Cu interface. Further testing is recommended to better understand the relationship between $\mathrm{W}_{\mathrm{AD}}$ and $\mathrm{G}_{\mathrm{C}}$.
\end{abstract}

Keywords: thermal spray, cold spray, Kinetic Metallization, work of adhesion, interfacial energy, critical strain energy release rate, interfacial toughness, solid-state wetting 


\section{ACKNOWLEDGEMENTS}

I would like to give special thanks to several individuals whose assistance and guidance were invaluable to me over the course of this project.

Firstly, I would like to acknowledge my thesis advisor Dr. Trevor Harding for helping me define, develop, and complete this project. Over the past two years, Dr. Harding has devoted countless hours during thesis meetings, office hours, and email correspondence to ensure that I succeeded. Dr. Harding had faith in my abilities and encouraged me during difficult times. I am very grateful for his efforts.

From Inovati, I would like to give special thanks to Dr. Ralph Tapphorn, without whom this project would not have come to fruition. Dr. Tapphorn helped me define the scope of this project and offered insight and guidance every step of the way. He also ensured that Inovati provided the necessary testing materials, a vital part of this project. I would also like to thank Howard Gabel and Travis Crowe, also from Inovati. Their assistance was crucial throughout my work on this project.

I would like to thank Dr. Blair London for his assistance in the set-up and operation of the Instron machine for four-point bend testing.

Finally, I would like to thank my friends and fellow students. Trevor Lee, Matt Rudow, Blake Gaspar, and Michael Turovskiy, my fellow MATE graduate students, for their help during thesis meetings. Also, my friends Phil Blacklock, Kevin Stanton, Dave Haskell, and Tala Fatolahzadeh for their advice and assistance. 


\section{TABLE OF CONTENTS}

Page

LIST OF TABLES ...................................................................................

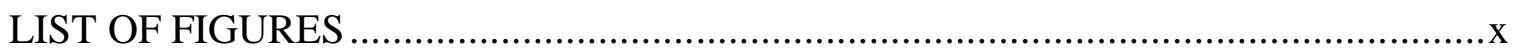

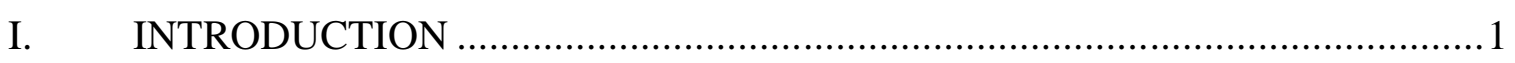

Introduction to Coatings .............................................................. 1

Thermal Spray Coatings ............................................................. 4

Thermal Spray Variants ..................................................... 7

Cold Spray and Kinetic Metallization ............................................... 8

Coating Quality ....................................................................... 10

Failure Location ............................................................ 10

Interfacial Quality .................................................... 11

Measurement Techniques ........................................................ 12

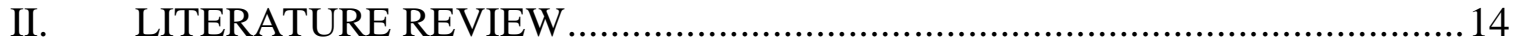

Process-based Approach ....................................................... 14

Adhesive and Elastic Energy ................................................. 14

Capabilities and Limitations ............................................... 16

Mechanistic Approach ......................................................... 17

Mechanisms of Adhesion .................................................... 17

Relevant Mechanisms .....................................................20

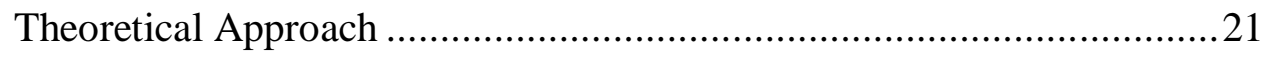

Fracture Mechanics Theory …...........................................2 21

Work of Adhesion...........................................................2 24

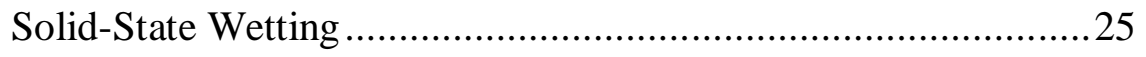

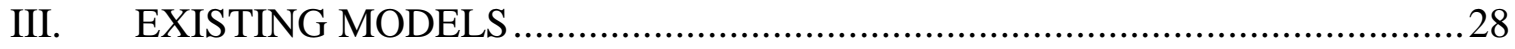

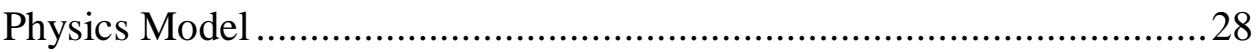

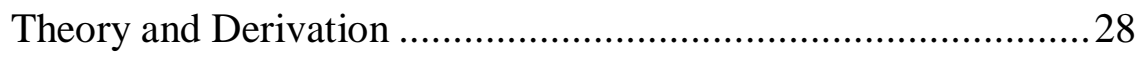

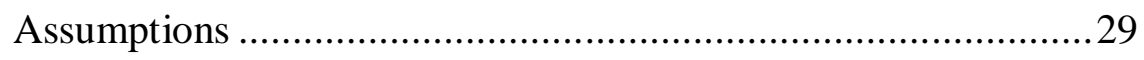




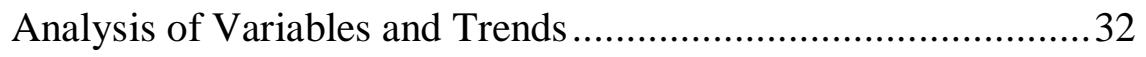

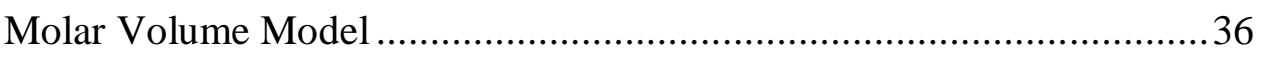

Theory and Derivation ................................................ 36

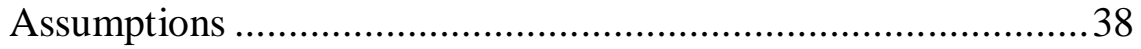

Analysis of Variables and Trends ..........................................39

Cohesion Theory Model ...................................................................... 44

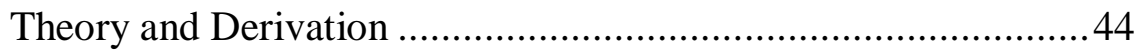

Assumptions and Additional Terms.......................................49

Analysis of Variables and Trends ........................................54

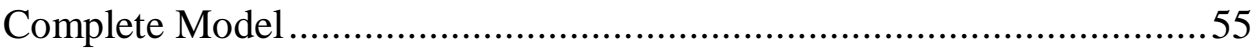

Comparisons between Models .............................................56

Physics Model versus Epitaxial Model.................56

Molar Volume Model versus Mismatch Model ....57

Analysis of Variables and Trends .........................................58

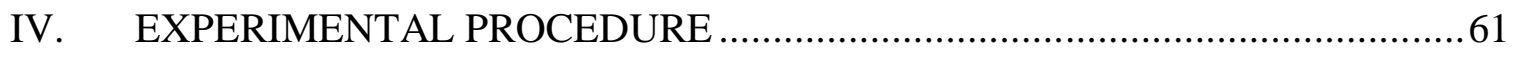

Test Method ..........................................................................6 61

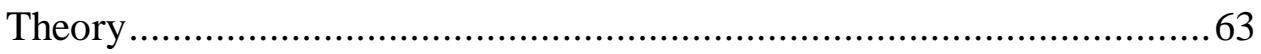

Four-point Bending ...................................................6 63

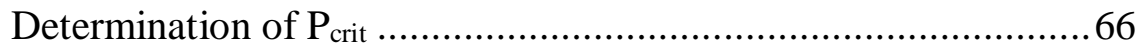

Materials ........................................................................... 71

Sample Preparation................................................................... 72

KM Specimens ......................................................... 72

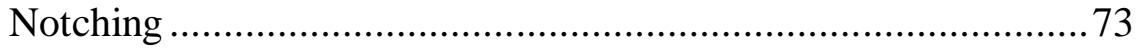

Test Procedure ........................................................................... 76

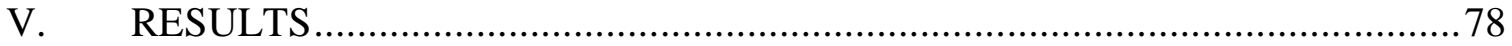

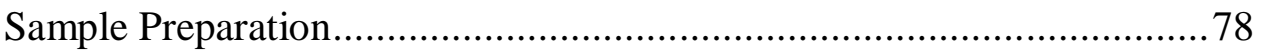

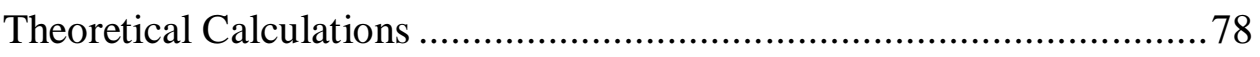

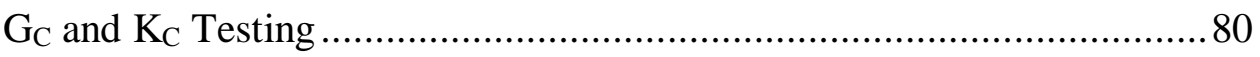

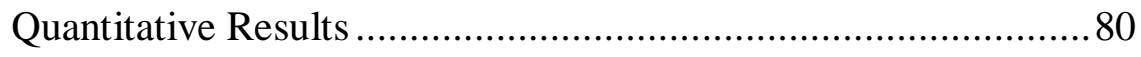

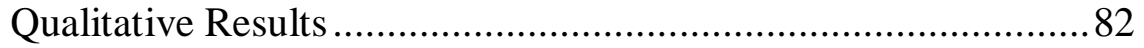

vii 


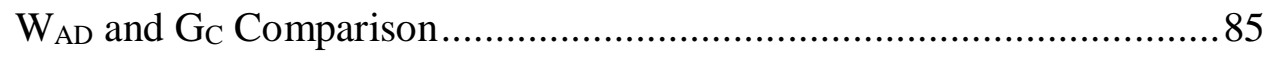

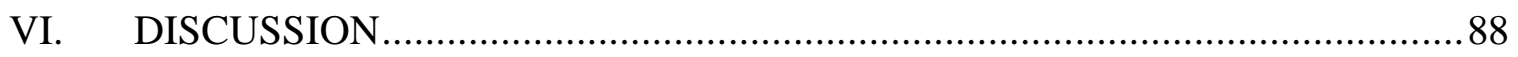

Sample Preparation.................................................................. 88

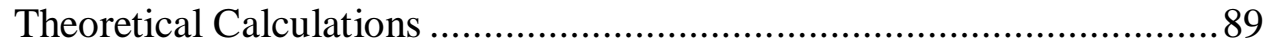

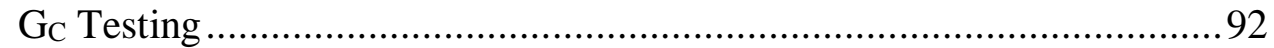

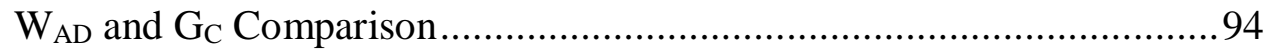

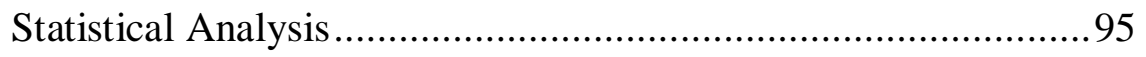

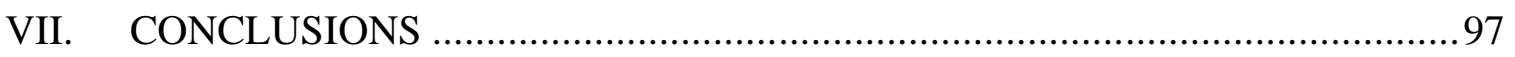

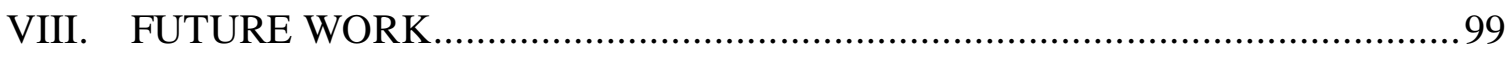

Model Verification: Solid-State Wetting Experiments .......................99

Determination of Elastic Properties of Coating ............................... 101

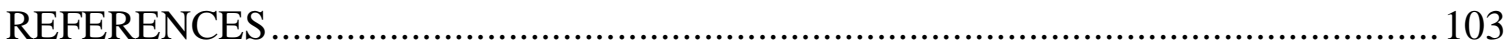

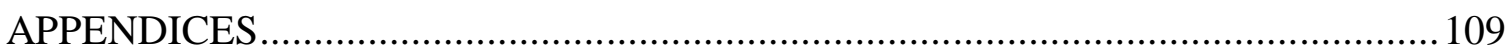

Appendix A: Statistical Analysis of $\mathrm{G}_{\mathrm{C}}$ Data ................................ 109

Test for Difference between Means ........................................ 109 


\section{LIST OF TABLES}

Table

1. Typical values of variation of states (Allan, Lannoo, \& Dobrzynski, 1974) ...........30

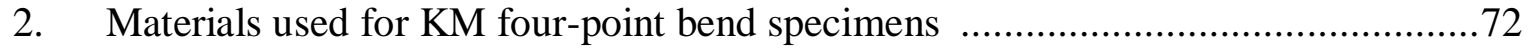

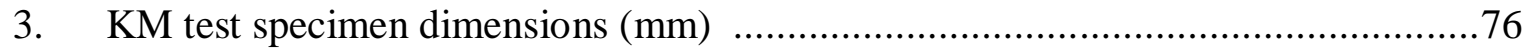

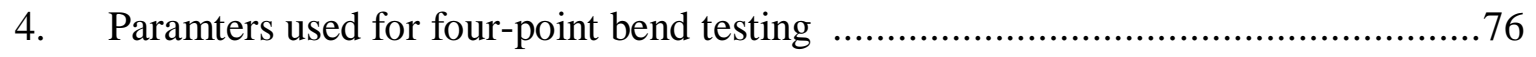

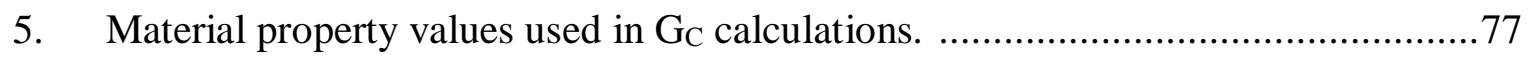

6. Theoretical results for Work of Adhesion. All values are in units of $\mathrm{J} / \mathrm{m}^{2}$. ..........79

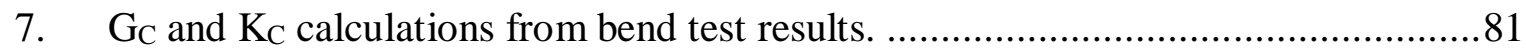

8. $\mathrm{W}_{\mathrm{AD}}$ and $\mathrm{G}_{\mathrm{C}}$ values are compared to attempt to identify a relationship

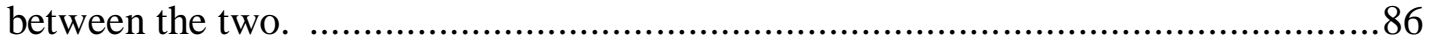

9. Comparison of the magnitudes of interfacial and surface energies. ......................90

10. Interfacial properties of other bimaterial interfaces. All values are in units

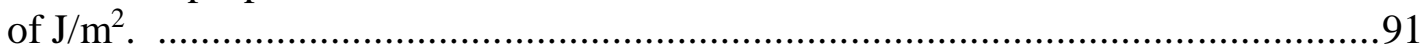

11. Interfacial toughness data for various bimaterial interfaces............................. 93

12. $\mathrm{G}_{\mathrm{C}}$ results for several metal-metal and metal-nonmetal interfaces. .....................94

13. 2-sample t-test for the difference in mean $\mathrm{G}_{\mathrm{C}}$ between the $\mathrm{Ni}$ - $\mathrm{Ti}$ and $\mathrm{Ni}-\mathrm{Cu}$ specimens. 


\section{LIST OF FIGURES}

Figure

1. The general thermal spray process produces a coating with a lamellar structure (Davis, 2002).

2. Schematic of a thermal spray coating showing a characteristically heterogeneous microstructure (Davis, 2002).

3. Cost comparison of 1/8"clad, 1/8" weld overlay, and 15 mil thermal spray coating.

4. Thermal spray process variants differ in their operating temperature and particle velocity (Berndt \& Berndt, 2003).. 8

5. Failure in a coating system is characterized as either adhesive or cohesive depending on where failure occurred.

6. Graph showing adhesive (A) and elastic (R) energies of particles during a cold spray process for several particle sizes $\left(\mathrm{D}_{\mathrm{P}}\right)$. Adhesion occurs within a velocity window where A > R (Wu, Fang, Yoon, Kim, \& Lee, 2006).

7. Wetting is dictated by an energy balance between the solid, liquid, and vapor phases (Kinloch, 1980).

8. Surface roughness can provide crack shielding due to contact between asperities on opposing surfaces (Evans, Ruhle, Dalgleish, \& Charalambides, 1989).

9. Due to roughness-induced shielding, interfacial toughness tends to increase as phase angle increases (Evans, Ruhle, Dalgleish, \& Charalambides, 1989).

10. This study will focus on the thermodynamic contribution to adhesion.

11. Schematic representation of the d band densities of states, Fermi levels $(\mathrm{F})$, and work functions $(\mathrm{W})$ for an interface between two transition metals (Allan, Lannoo, \& Dobrzynski, 1974). 
12. When two dissimilar metals are brought into contact, there is a contact potential $\Delta \mathrm{V}$ created due to the difference in their respective Fermi levels.

(a) Electrons are more energetic in Mo, so they tunnel to the surface of Pt.

(b) Equilibrium is reached when the Fermi levels are aligned (Kasap, 2007).

13. Graphs of work of adhesion results from physics model for (a) Chromium,

(b) Molybdenum, and (c) Tungsten 34

14. Graph of cohesive energies for transition metals 35

15. $\Phi$ increases as the difference between the Molar volumes increases

16. Graphs of molar volume model interfacial energies for (a) Chromium, (b) Molybdenum, and (c) Tungsten.

17. The cohesive and surface energies of the transition metals follow approximately the same trend.

18. Epitaxial energy graphs for (a) Chromium, (b) Molybdenum, and (c)

Tungsten.

19. Mismatch energy graphs for (a) Chromium, (b) Molybdenum, and (c)

Tungsten.

20. Graphs of total energy term for (a) Chromium, (b) Molybdenum, and (c) Tungsten.

21. Complete model interfacial energies for (a) Chromium, (b) Molybdenum, and (c) Tungsten.

22. A typical four-point bend test fixture using a load span-support span ratio of 1:2 (ASTM International, 2010).

23. Modified Four-point Bend test specimen (Watanabe, Owada, Kuroda, \& Gotoh, 2006).

24. The load response of an ideal four point bending specimen. Under these conditions, $\mathrm{P}_{\text {crit }}$ is easy to determine.

25. $\mathrm{G}_{\mathrm{C}}$ is calculated by considering the difference in stored strain energy between the cracked and un-cracked specimen at the critical load when delamination begins. 
26. Preliminary testing resulted in loading behavior that deviated from the ideal, with three distinct load response regions.

27. Inovati KM PCS equipment was used to produce the test specimens (Inovati, 2012).

28. Optical microcopy was used to verify coating thickness: (a) Copper

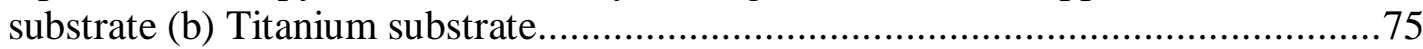

29. Four-point bend test results for Ni-Ti and $\mathrm{Ni}-\mathrm{Cu}$ coating systems...................... 80

30. The notch acted as an initiation site for the vertical crack..................................83

31. Microcracks initiated at the coating surface caused delamination, as seen in literature.

32. High-magnification view of a microcrack that deflected along the interface, causing delamination.

33. There appears to be a positive correlation between $\mathrm{W}_{\mathrm{AD}}$ and $\mathrm{G}_{\mathrm{C}}$.

34. An alternate form of the Young-Dupré equation can be used to calculate interfacial energy experimentally.

35. Normal Probablility plots of the (a) Ni-Cu and (b) Ni-Ti data. Normality tests suggest that the data is approximately normal.

36. Both the tests return p-values $>0.05$, suggesting that there is no significant difference between the variances of the two samples.

37. A 2-sample t-test using a pooled standard deviation indicates that the mean $\mathrm{G}_{\mathrm{C}}$ of the Ni-Ti specimens is significantly greater than the mean $\mathrm{G}_{\mathrm{C}}$ of the $\mathrm{Ni}-\mathrm{Cu}$ specimens. 


\section{INTRODUCTION}

\section{Introduction to Coatings}

As industrial technology has progressed and engineered components are subjected to increasingly varied conditions, the use of coatings has become ever more integral to proper operation. Many advanced coatings systems can be tailored to withstand specific loading conditions or fulfill certain design requirements; often times, these requirements demand surface properties that differ substantially from the bulk properties of the substrate. Coatings and other surface modification techniques allow for improved performance and extended life of components functioning in a variety of environments. A major advantage of engineered coatings is their ability to confer enhanced surface properties without compromising the properties of the substrate (Chalker, Bull, \& Rickerby, 1991). Further, a wide variety of materials can be applied as coatings, and their properties can often be controlled by the application technique and process parameters. These characteristics make coatings attractive for various applications across numerous industries (Davis, 2004).

Coatings can be classified by several different criteria, based on their function, processing, or properties. Thin films, typically on the order of several hundred nanometers, are widespread in such industries as optics, semiconductor device fabrication, and biomedical devices (Lee, 1991). Usually polymeric or metallic, thin films can be tailored to have specialized surface properties. They can be carefully applied to 
small-scale geometries with tight tolerances. However, deposition of these coatings is difficult, and the coatings themselves have minimal mechanical integrity, ruling out use in harsh environments (Campbell, 2008). On the other end of the spectrum are industrial coatings, with thickness on the order of microns to millimeters. These coatings can be metallic, ceramic, or composite, and are generally more robust than thin films due to their compositions and thickness. Industrial coatings are suitable for extreme environments that demand superior properties and can be used on medium- to large-scale parts with relatively minimal geometric restrictions (Weiss, 1995). While the technology of thin films is a subject of great significance, this discussion will focus on industrial coatings.

Coatings see heavy use in the aerospace, petroleum, and automotive industries, among others. It has been estimated that as much as $75 \%$ of the components in modern aircraft engines employ some type of coating (Davis, 2004). Metallic carbide and refractory metal coatings are used for fretting wear protection in certain engine sections. For high-temperature corrosion protection, metallic alloys or ceramic thermal barrier coatings are used. Landing gear components are coated for wear and corrosion resistance or to repair damage (Davis, 2004). Coatings of corrosion resistant alloys, such as 316-L stainless steel or Hastalloy C-276 provide economical solutions to widespread corrosion problems seen in petroleum refineries (Moskowitz, 1992). Coatings are also common in land-based turbine applications. High-temperature coatings are employed for wear, oxidation, and corrosion resistance. In the automotive industry, aluminum metal-matrix composites (MMCs) are used to coat disk brakes, providing strength while significantly 
reducing their weight. Molybdenum coatings are commonly used for wear resistance in high-temperature engine components (Davis, 2004).

Coating deposition techniques vary based on geometry and application; since a coating's properties are highly dependent on processing, choosing the appropriate deposition technique is important for optimal performance. Perhaps the simplest coating method is to simply weld overlay the substrate with a more resistant material. Weld overlay, also known as hardfacing, involves melting the surface of the work piece while applying a molten layer of filler material. This process inputs a large amount of heat into the substrate, so weld overlay is generally only used on large components. Drawbacks of weld overlay include a large heat-affected zone and regions of mixing between the substrate and filler material. Weld overlay can be accomplished by traditional welding techniques such as Tungsten Inert Gas (TIG) welding, Shielded Metal Arc Welding (SMAW), or Metal Inert Gas (MIG) welding (Davis, 2004). Weld overlay is attractive because it produces high quality coatings, can be done on-site, and is relatively simple for small scale applications (Kashani, Amadeh, \& Ghasemi, 2007). For larger coated areas, cladding becomes more economical. In cladding processes, a solid plate of a more wearor corrosion-resistant material is bonded to the base metal. In contrast to weld overlay, cladding is often performed during the original fabrication process. This can be accomplished by one of several techniques, including laser cladding and plasma cladding (Blazynski, 1983; Shepeleva, Medres, Kaplan, Bamberger, \& Weisheit, 2000). 


\section{Thermal Spray Coatings}

An alternative to these techniques is thermal spraying. Thermal spraying encompasses a family of coating deposition techniques that involve the same basic steps. First, an energy source is used to melt the coating material to a molten or semi-molten state. Then, the heated particles are accelerated toward the substrate by process gases or atomization jets. Particle speeds vary from 100 to more than $1000 \mathrm{~m} / \mathrm{s}$. These particles impact the substrate and deform, forming thin lamellae called "splats" that bond to the surface. A coating is produced by subsequent build-up of splats (Figure 1) (Davis, 2004). The resulting coating is a layered structure consisting of melted and partially melted splats, oxide particles, voids, and other defects, the relative amounts of which contribute to the properties of the coating (Figure 2) (Hermanek, 2002).

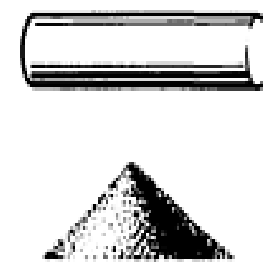
feedstock
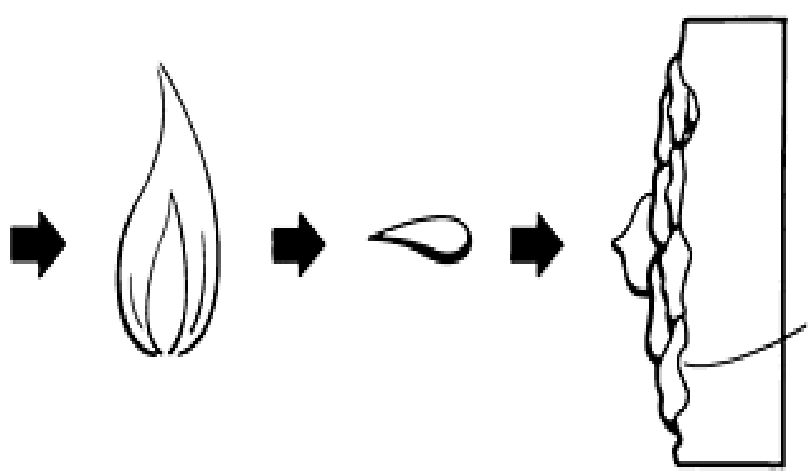

Particles impact on substrate and flatten

Electric or gas heat source melts feedstock

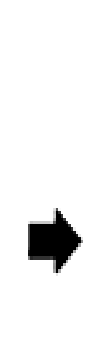

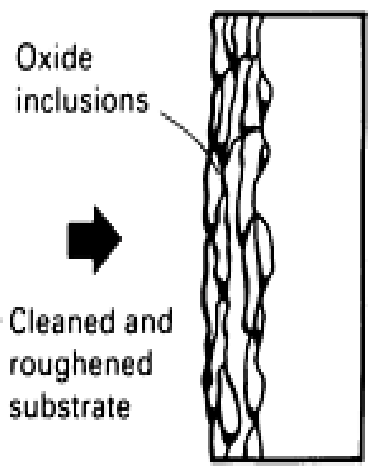

\begin{abstract}
Molten particles are accelerated
\end{abstract}

Figure 1: The general thermal spray process produces a coating with a lamellar structure (Davis, 2002). 


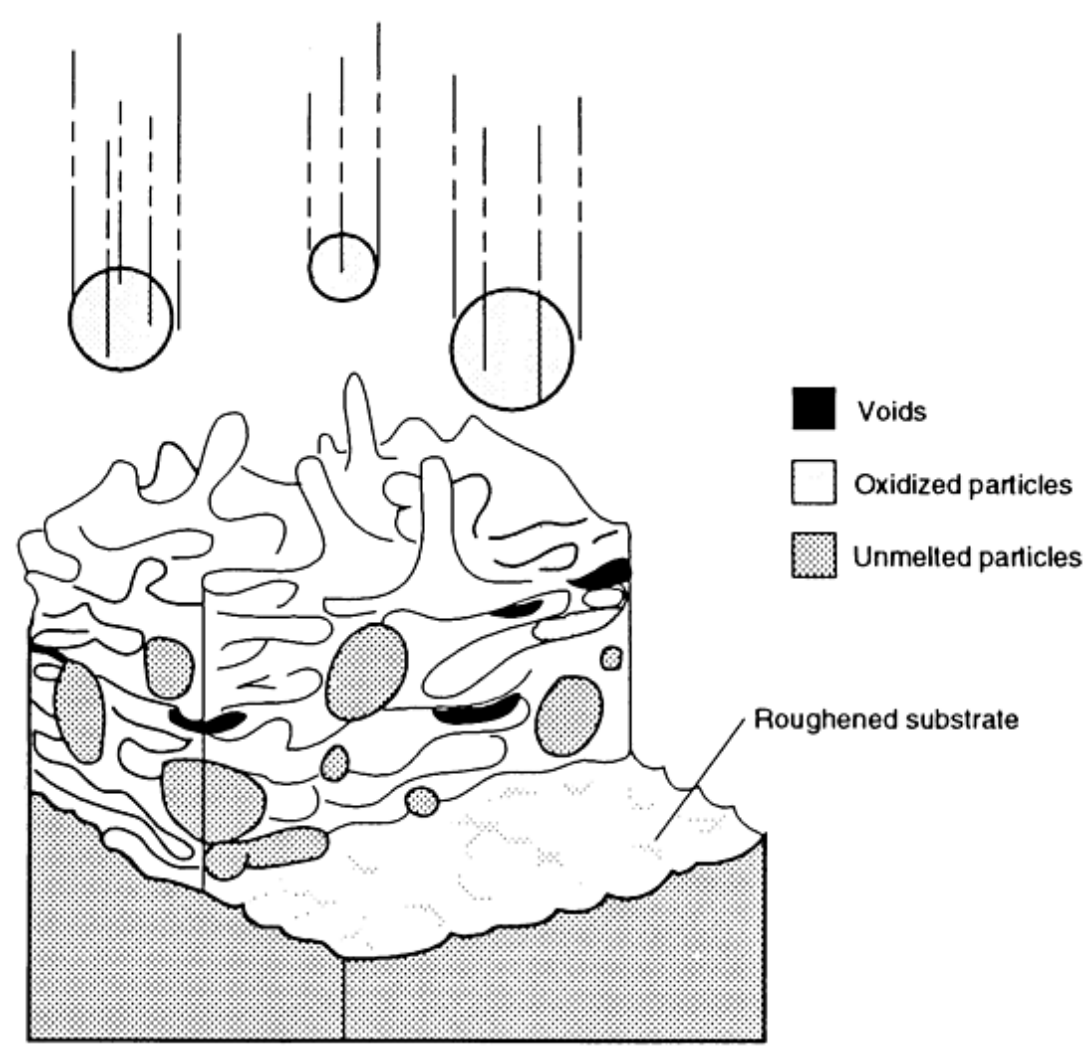

Figure 2: Schematic of a thermal spray coating showing a characteristically heterogeneous microstructure (Davis, 2002).

Thermal spray coatings (TSCs) offer many advantages over other more traditional coating techniques. TSCs are typically on the order of 10 mils in thickness, compared to around 1/8-inch for overlay or cladding. Since coating materials are usually expensive, high-performance materials, this can represent a significant savings in cost. A cost comparison of weld overlay, cladding, and thermal spraying is presented in Figure 3: 


\section{Relative Costs of Overlay, Cladding, and Thermal Spray Coating}

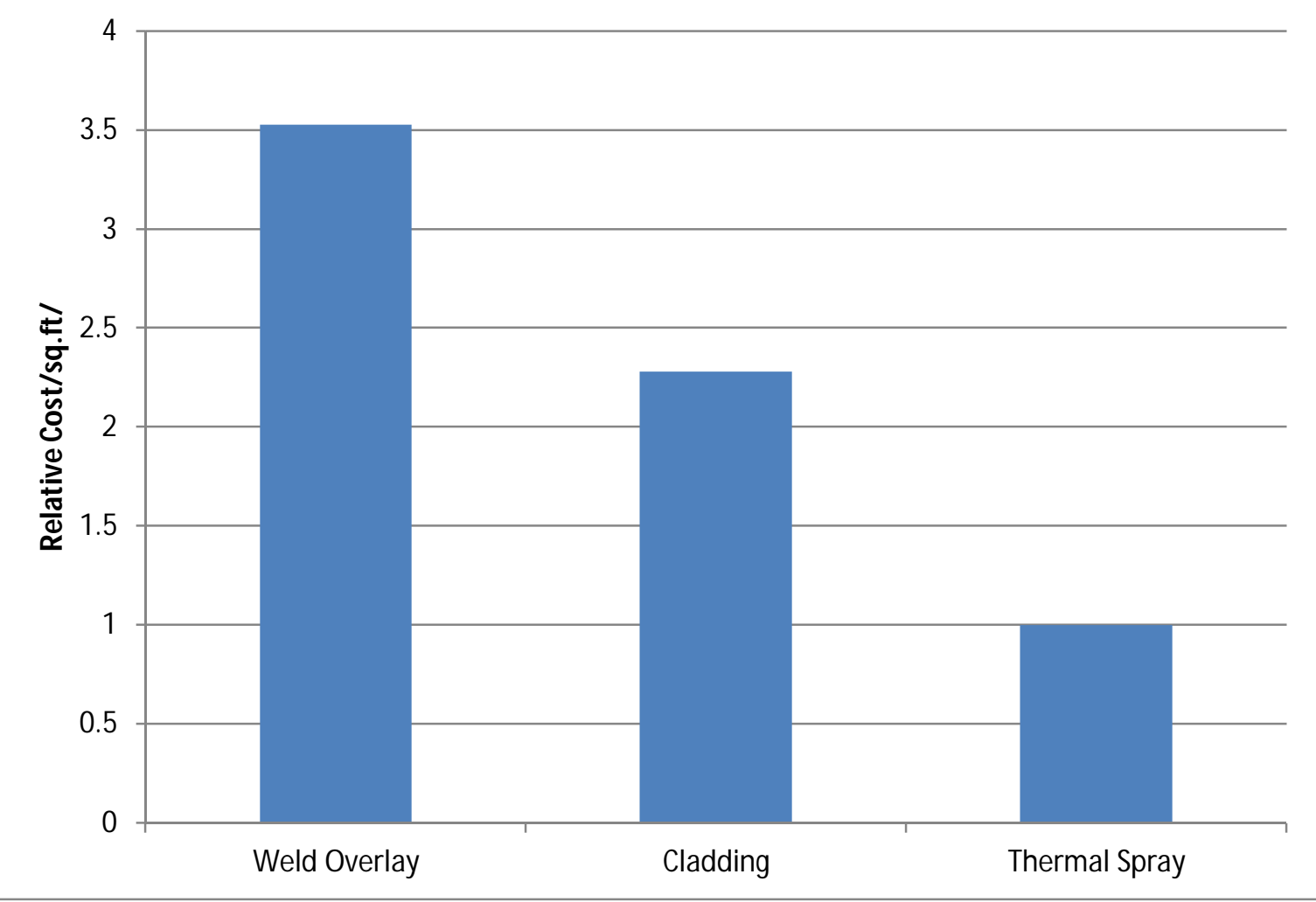

Figure 3: Cost comparison of 1/8"clad, 1/8" weld overlay, and 15 mil thermal spray coating.

Another advantage is the versatility of thermal spraying; many metals, alloys ceramics, and composite materials are compatible with some type of thermal spraying process (Berndt \& Berndt, 2003). Compared to cladding or overlay, thermal spraying inputs a relatively low amount of heat to the substrate. This minimizes thermal distortion of the substrate and allows for deposition on heat-treated components. The ease in which coatings can be repaired or recoated is another advantage of thermal spray technology (Davis, 2004). The main disadvantage of thermal spray coatings arises from the defects that are introduced into the coating during the deposition process. The large amount of 
plastic deformation experienced by the particles reduces the ductility of the coating compared to the bulk material. Formation of oxides and porosity generally results in lower quality coatings, though this depends on the application (Lin \& Berndt, 1994).

\section{Thermal Spray Variants}

Variations of the thermal spray process mainly differ in two parameters-temperature and velocity of the process. These two parameters dictate the types of materials that can be sprayed and the properties of the coating produced (Lin \& Berndt, 1994). Thermal spray processes can be classified into three major categories: flame spray, electric arc spray, and plasma spray. Flame spray processes can be further divided into low- and high-speed processes. Wire and Powder flame processes employ a flame to melt the feedstock material (in wire or powder form, respectively), which is then accelerated by air jets to speeds of around $100 \mathrm{~m} / \mathrm{s}$. High Velocity Oxyfuel (HVOF) and Detonation Gun processes employ much higher temperatures $\left(2500\right.$ to $\left.3100^{\circ} \mathrm{C}\right)$ and particle speeds in the supersonic regime. Electric arc processes use two consumable wire electrodes connected to a current source. An arc is struck and the wires are fed into the gun, which melt and are atomized and accelerated toward the substrate by compressed air. Plasma arc processes operate at extremely high temperatures $\left(6000\right.$ to $\left.15000^{\circ} \mathrm{C}\right)$. A plasma is generated by superheating an inert gas with a DC arc. Powder feedstock is delivered by a carrier gas and accelerated by the plasma jet (Davis, 2004; Hermanek, 2002). These

processes are summarized in Figure 4. Coating processes typically utilize carefully tuned 
process parameters to produce coatings with properties that are optimized for a particular application (Berndt \& Berndt, 2003).

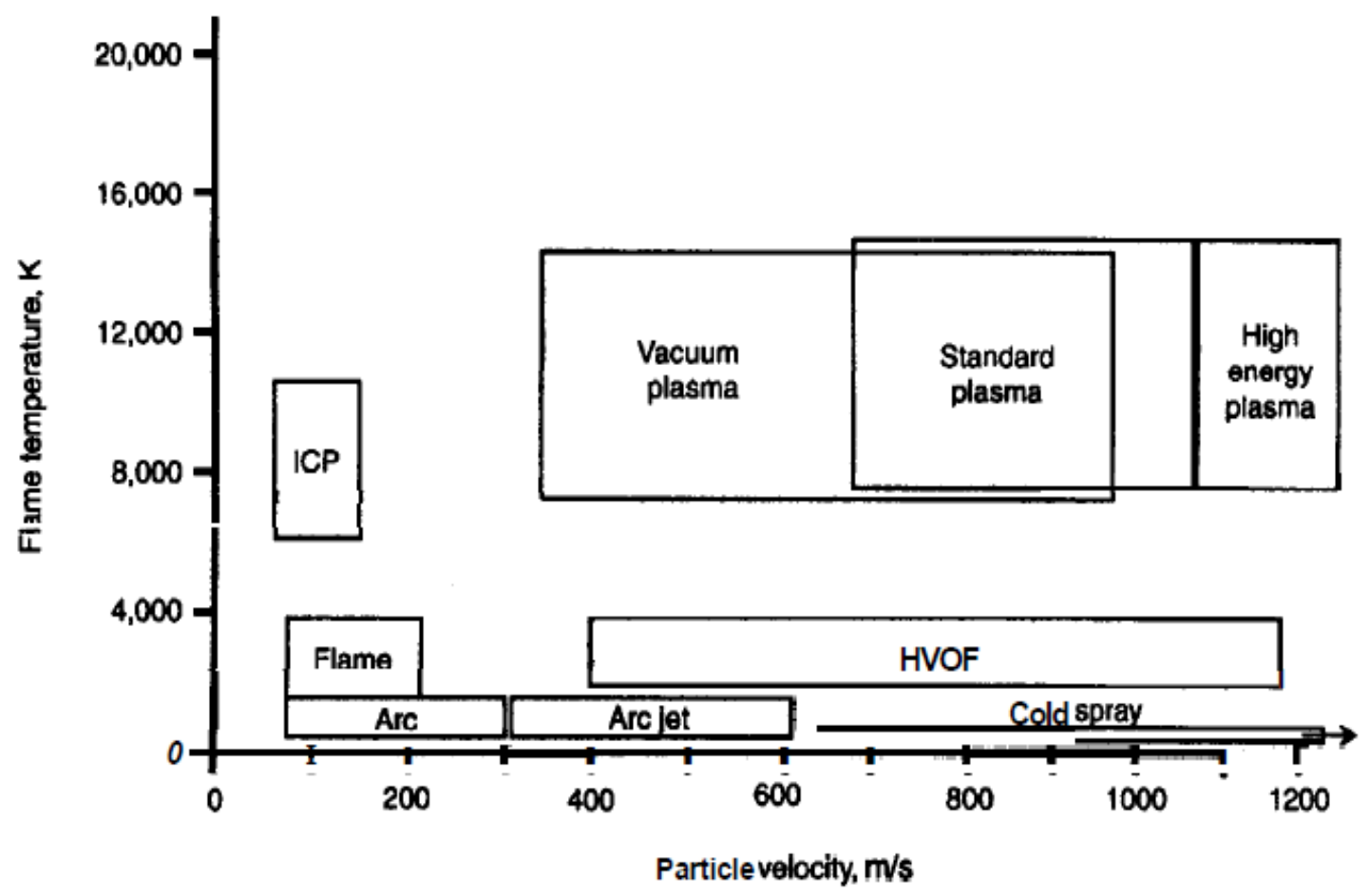

Figure 4: Thermal spray process variants differ in their operating temperature and particle velocity (Berndt \& Berndt, 2003).

\section{Cold Spray and Kinetic Metallization}

Most thermal spray processes rely on a combination of temperature and velocity to provide the particles with sufficient thermal and kinetic energy for coating formation to occur. The higher the particle velocity, the less heat input is needed. In flame spraying, for example, full particle melting is required because particle velocities are relatively low; in HVOF, only partial melting is required because the particle velocities are much higher (Stoltenhoff, Kreye, \& Richter, 2001). The process of Cold Spraying builds on this 
principle, using supersonic particle velocities to supply the necessary kinetic energy for coating formation while keeping heat input to a minimum. Because particle melting does not occur, cold spraying can be used to deposit high melting point metals, cermets, and ceramic coatings that cannot be accomplished with other thermal spray techniques ( $\mathrm{Li}$, Li, \& Liao, 2006). In addition, the properties of the particle feedstock are maintained and thermal oxidation is minimized. The result is a dense coating with mechanical properties comparable to those of the cold-worked bulk material (Schmidt, et al., 2009). Further, the use of low process temperature minimizes substrate heat input, avoiding thermal stresses and making it possible to coat both thick and thin sections (Kurochkin, Demin, \& Soldatenkov, 2002). Cold spray has experienced significant advances in recent years, and progress continues to be made in understanding and modeling the coating formation process.

This paper will focus on Kinetic Metallization (KM), a solid-state impact consolidation and coating process developed and patented by Inovati, Inc. KM enjoys many of the same advantages over conventional thermal spraying, including minimal substrate heat input and particle oxidation. Both processes are solid-state and do not alter the properties of the coating or substrate. The key difference is the gas pressures employed and the resulting particle velocities. Cold spray processes typically uses Helium or Nitrogen gas at pressures between 200 and 500 psi. The particles are accelerated using a De Laval type converging-diverging nozzle to achieve high particle velocities—velocities up to $1200 \mathrm{~m} / \mathrm{s}$ have been reported (Stoltenhoff, Kreye, \& Richter, 
2001; Schmidt, et al., 2009). KM, on the other hand, employs a proprietary two-phase sonic deposition nozzle to accelerate and triboelectrically charge the particles entrained in the carrier gas. At supersonic speeds, the density and pressure of the carrier gas drops, reducing its ability to effectively accelerate particles. Inovati's strategy uses sonic gas speeds to maintain gas density and pressure in an attempt to maximize deposition efficiency. Inovati has demonstrated that their patented KM nozzle and process result in higher quality coatings while operating at a fraction of the cost of other cold spray processes (Inovati, 2012).

\section{Coating Quality}

\section{Failure Location}

The issue of coating quality is important because it is closely related to performance. Good adhesion is necessary, since a coating may need to endure thermal stresses, various types of loading, corrosive media, and other environmental factors. In addition, the coating must be of sufficient quality to overcome any residual stresses that may have been built up during the deposition process. Coating quality can include many characteristics, including splat structure, porosity, oxide content, and cohesive strength (Lee, 1991). While these properties are obviously important, it is the properties of the interface that determine adhesion. To describe the quality of an interface, one must first define the location at which quality is assessed. Generally, failure will occur at one of three locations: within the substrate, within the coating, or at the interface between the 
two. These possible failure locations are shown schematically in Figure 5. The substrate properties are generally known, and those of the coating can readily be measured by experimentation and controlled by processing parameters, but interfacial quality is more difficult to define and determine - the interface properties will be the focus of this paper.

\section{Possible Failure Locations:}

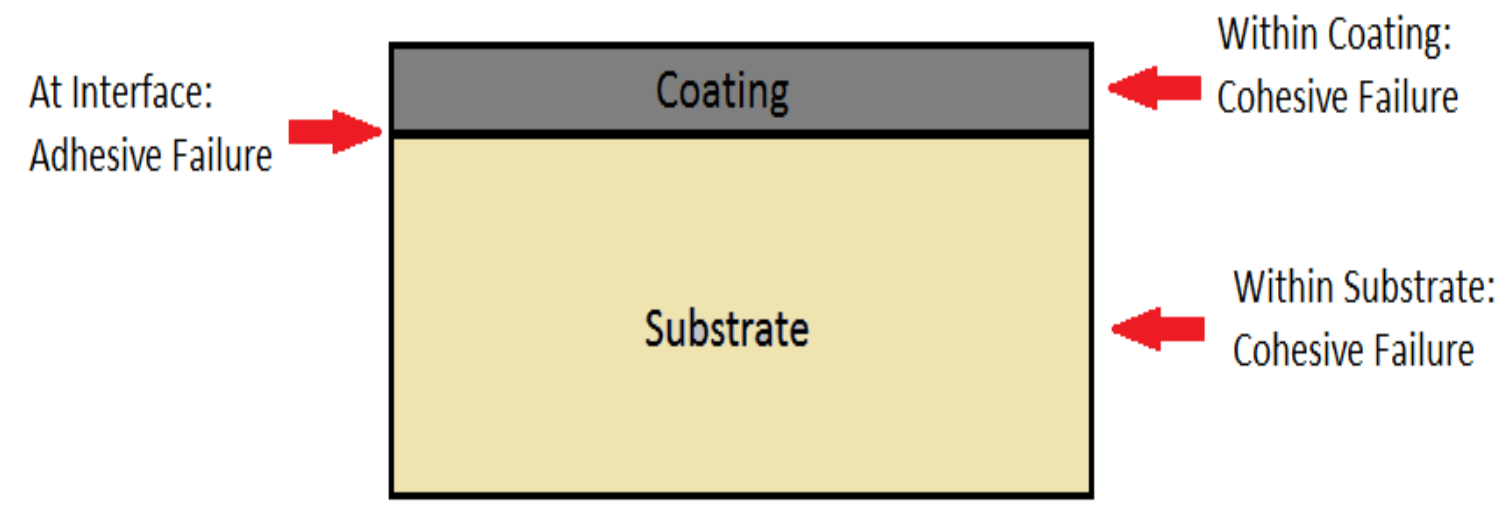

Figure 5: Failure in a coating system is characterized as either adhesive or cohesive depending on where failure occurred.

\section{Interfacial Quality}

Interfacial "quality" can be quantified in a number of ways. The most basic way to define it is in terms of the stress at which the interface separates. This stress is typically called "adhesion strength." This strength is determined solely by the magnitude of the applied tensile force, and can be defined by the average failure stress during tensile testing (Lin \& Berndt, 1994). However, studies have shown that adhesion strength is an inherently stochastic parameter because it includes the effects of defects and stress 
concentrations (Evans, Hutchinson, \& Wei, 1999). Statistical treatments have been attempted to account for the stochastic nature of adhesion strength. Tensile test data can be modeled using a Weibull distribution to more accurately describe the strength of the interface (Shen, Wang, Fan, Ma, \& Yang, 2011). Even so, all measures of strength are test-specific, which limits their usefulness (Lee, 1991). The other common way of quantifying interfacial quality is by the energy dissipated per unit area upon extending a crack along the interface. This energy value, commonly called interfacial fracture energy, is analogous to fracture toughness in a homogeneous material and is generally accepted as the most fundamental, deterministic measure of adhesion. In addition, interfacial fracture energy is more amenable to quantitative comparison with models (Evans, Hutchinson, \& Wei, 1999).

\section{Measurement Techniques}

As mentioned previously, adhesion strength is dependent on how the stress is applied, so numerous test methods exist for determining the strength of an interface under different loading conditions. The ASTM Standard Test Method for Adhesion or Cohesion Strength of Thermal Spray Coatings (C 633) specifies a simple tensile test. However, this test is only useful for comparing strengths of similar coatings under the same loading conditions, and cannot provide a measure of interfacial quality (ASTM International, 2008). The indentation test characterizes the interface in terms of both strength and fracture resistance, and the scratch test can be used to calculate the Work of Adhesion by measuring the strain energy released during coating removal. Both of these methods are 
still victim to random elements such as defects (Chalker, Bull, \& Rickerby, 1991). Best testing techniques, such as three-point bending, four-point bending, and Dual Cantilever Beam (DCB) also characterize interfaces in terms of fracture energy and are generally more accurate and easier to perform. Interfacial fracture energy can be described by $\mathrm{G}_{\mathrm{C}}$, the critical strain energy release rate, or $\mathrm{K}_{\mathrm{C}}$, the interfacial fracture toughness. These metrics are believed to provide a good indication of the mechanical performance and integrity of the interface (Klingbeil \& Beuth, 1997; Katipelli, Agarwal, \& Dahotre, 2000).

Although bend testing provides an accurate, meaningful measure of interfacial quality, it is destructive, and is still dependent on the process used to make the coating. It cannot be used to quantitatively determine the quality of a different substrate-coating system; at most, it can only be used to qualitatively rank the quality of several systems. Most coating-substrate systems are evaluated by a guess-and-check strategy, since there is little way of predicting the quality of the interface. Such prediction, if possible, would be invaluable, because it could tell coating manufacturers the ideal coating material for a given substrate. It is the purpose of this paper to determine whether the quality of Kinetic Metallization coatings-- in terms of quantitative and experimentally verifiable measures of toughness, such as $\mathrm{G}_{\mathrm{C}^{--}}$can be predicted by models incorporating fundamental material properties. These models would give guidance for proper materials selection to maximize adhesion for a given coating system. 


\section{LITERATURE REVIEW}

This paper will now review the various attempts to model the interfacial energy of a bimetallic interface. It will begin by analyzing the theory, capabilities, and limitations of process-based approaches to calculation of adhesion. Next, the various mechanisms of adhesion will be identified and analyzed. After ruling out mechanisms that are irrelevant, or whose contributions are negligible, the significant contributions will be analyzed more fully. A theoretical framework for quantification of these contributions will be developed by reviewing and applying theories of fracture mechanics, wetting, and thermodynamics. This framework will be used to identify the most fundamental parameter associated with adhesion-interfacial energy. Then, several models for the theoretical calculation of interfacial energy will be presented, analyzed and compared.

\section{Process-based Approach}

\section{Adhesive and Elastic Energy}

Plenty of research has been done in an attempt to characterize and model particlesubstrate interaction and coating formation during the cold spray process. Many studies cite the critical velocity, $\mathrm{V}_{\text {critical }}$, as the defining characteristic of a cold spray process. At particle velocities greater than $\mathrm{V}_{\text {critical}}$, particle-substrate bonding will occur (Hussain, McCartney, Shipway, \& Zhang, 2009). $\mathrm{V}_{\text {critical }}$ is a function of particle size, particle and substrate material properties, and contact temperature. The process of coating build-up can be thought of in terms of an "adhesive interaction" between the particle and the 
substrate with bond generation occurring during contact. Some studies suggest that there are two competing processes that occur during particle impact: adhesive bond formation and plastic deformation. The energy of the adhesive bonds can be estimated by the product of $A_{\max }$, the theoretical maximum adhesion energy of a substrate and coating atom, and a\%, the relative bond strength (Kurochkin, Demin, \& Soldatenkov, 2002; Wu, Fang, Yoon, Kim, \& Lee, 2006). The a\% term also represents the probability of particle adhesion. During particle impact, part of the particle's kinetic energy is converted into elastic energy, which tends to detach the particle from the substrate. Analysis of these two terms can be used to find $\mathrm{V}_{\text {critical. }}$ If the adhesive energy (A) of a particle is greater than its elastic energy $(\mathrm{R})$, the particle will adhere to the substrate and coating formation will occur (Figure 6) (Papyrin A. N., 2003; Papyrin, Kosarev, Klinkov, Alkimov, \& Fomin, 2007). 


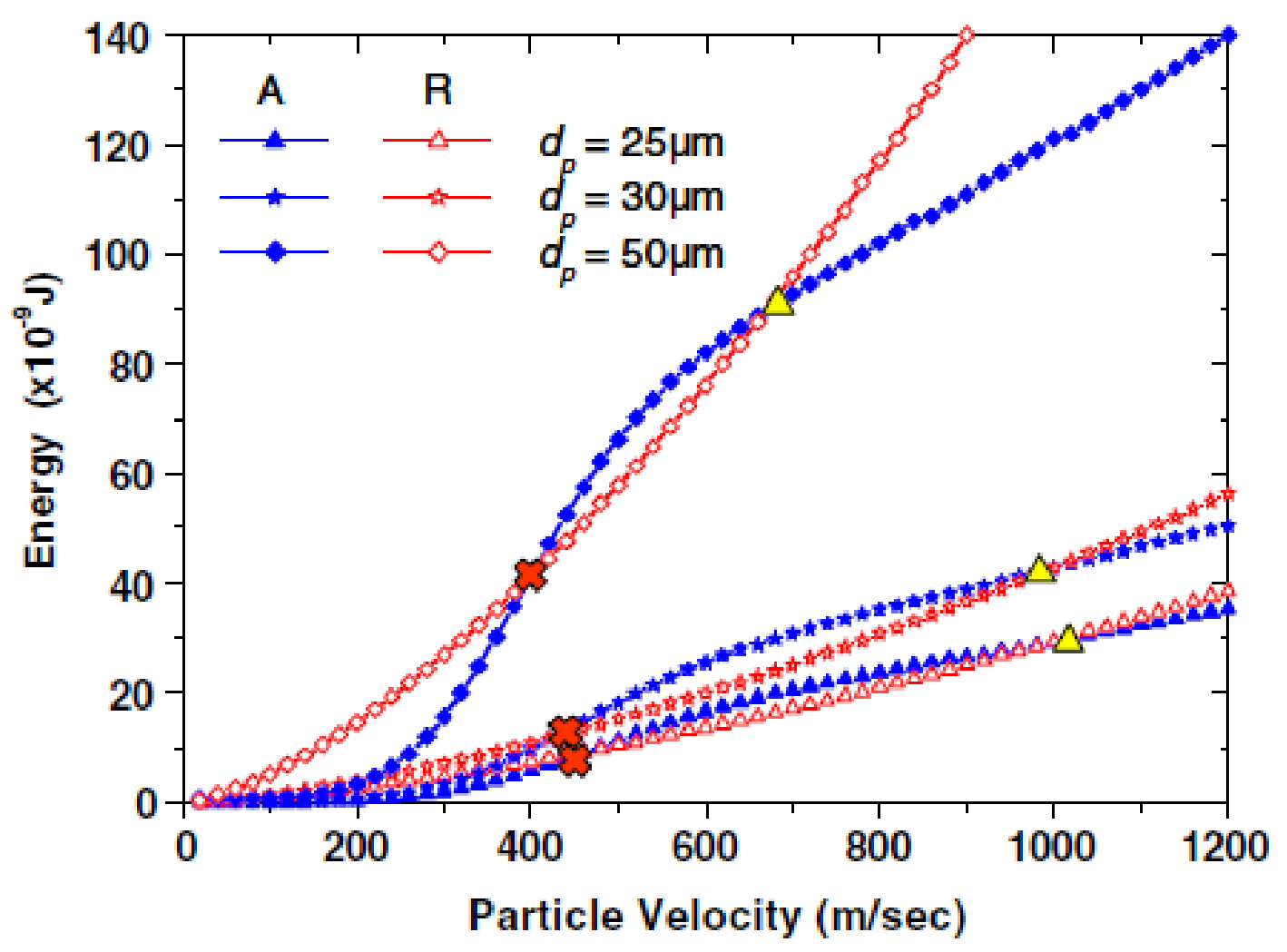

₹ Critical velocity for the particle deposition onto the substrate

$\triangle$ Maximum velocity for the particle deposition onto the substrate

Figure 6: Graph showing adhesive (A) and elastic (R) energies of particles during a cold spray process for several particle sizes $\left(D_{P}\right)$. Adhesion occurs within a velocity window where A > R (Wu, Fang, Yoon, Kim, \& Lee, 2006).

\section{Capabilities and Limitations}

The process-based approach is useful from a processing standpoint because it can be used to estimate $\mathrm{V}_{\text {critical }}$ using material properties and process parameters. It can also be used to determine optimal processing parameters for a given coating-substrate system. However, it has serious limitations. Determining the adhesive and elastic energy relies on accurate calculations of contact temperature, which is highly dependent on impact 
velocity. Controversy exists over the accuracy of the thermal analysis used. Some studies affirm the commonly held belief that Cold Spray is a completely solid state process, but others suggest that local melting can occur at the interface at sufficiently high particle velocities (Papyrin A. N., 2003). Due to the lack of a method to accurately determine the maximum adhesive energy, this model can only provide relative bond strengths, and thus can only be used for comparative purposes (Wu, Yang, Fang, Yoon, \& Lee, 2006). This precludes process based approaches from being used for predictive purposes. To accurately calculate adhesive energy, a quantitative, mechanistic-based approach is needed that includes all contributions to adhesion.

\section{Mechanistic Approach}

\section{Mechanisms of Adhesion}

The science of adhesion is a multi-disciplinary topic that draws on theories from chemistry, materials science, and fracture mechanics. The main mechanisms of adhesion are mechanical, electrostatic, thermodynamic, diffusion, and chemical and metallurgical bonding (Mittal \& Pizzi, 1999). Mechanical adhesion is achieved by interlocking between the two surfaces. Surface roughness, which effectively results in increased surface area, can affect the degree of mechanical interlocking that occurs. Mechanical interlocking is achieved to some degree due to the large amounts of plastic deformation that particles undergo during impact. Numerical models of the particle-substrate interaction during impact have been developed in an attempt to understand the process. 
They suggest that plastic deformation creates interfacial instability, which contributes in three ways: an increase in interfacial surface area, fine length-scale mixing, and mechanical interlocking. The contribution of these effects is usually a significant fraction of the overall adhesion strength (Grujicic, Saylor, Beasley, DeRosset, \& Helfritch, 2003).

If electron transfer occurs between two surfaces brought into contact, then there will be potential energy associated with the electrostatic interactions of the surfaces. This energy can contribute to overall adhesion (Mittal \& Pizzi, 1999). Perhaps the most widely applicable mechanism is that of thermodynamics. Also referred to as adsorption or wettability, the thermodynamic adhesive energy is defined by the Young-Dupré equation:

$$
W_{A d}=\gamma_{L V}(1+\cos \theta) \quad \text { Equation } 1
$$

Where $\mathrm{W}_{\mathrm{AD}}$ is the thermodynamic Work of Adhesion, and $\gamma_{\mathrm{LV}}$ is the surface energy of the liquid vapor interface and $\theta$ is the contact angle as shown in Figure 7. 


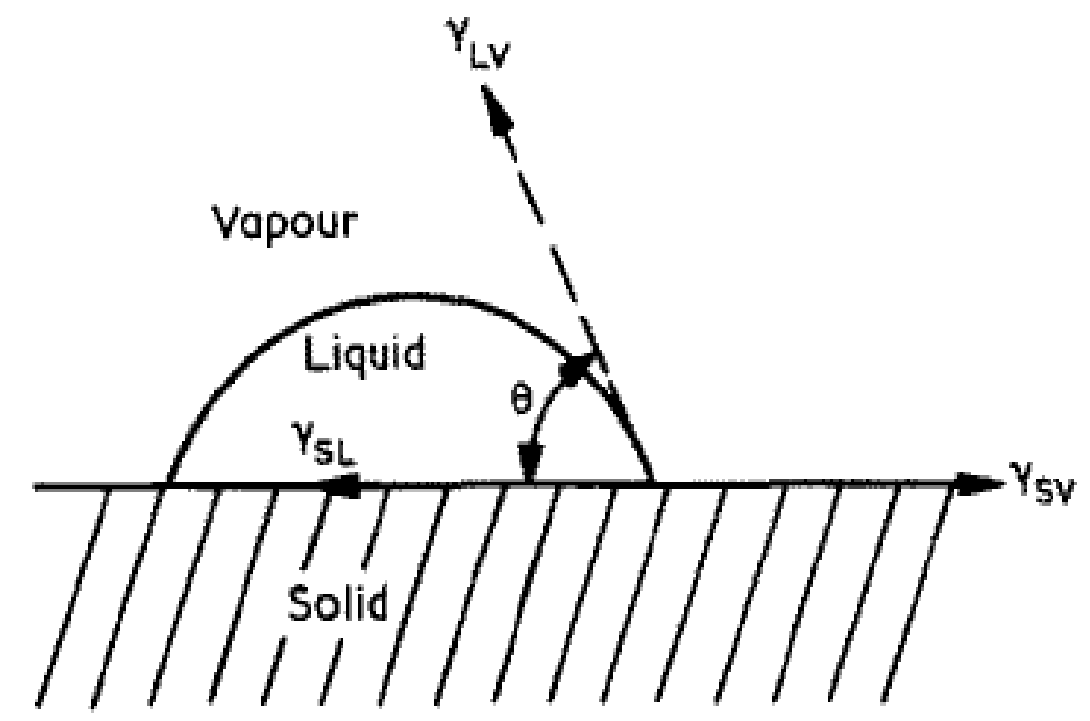

Figure 7: Wetting is dictated by an energy balance between the solid, liquid, and vapor phases (Kinloch, 1980).

Diffusion bonding is based on the theory that when placed in contact, two metals will bond by interdiffusing into each other. This requires a clean surface, free of oxides and other contaminants. In addition, contact must occur at the atomic scale; this requires an atomically smooth surface. Surface asperities will limit the surface contact area and reduce the amount of diffusion bonding that can occur (Ksiazak, Sobczak, Mikulowski, Radziwill, \& Surowiak, 2002).

Chemical bonding occurs when chemical reactions occur at the interface between two metals, producing an intermetallic compound. The adhesive energy involved is associated with the enthalpy of formation of this compound (Sangiorgi, Muolo, Chatain, \& Eustathopolous, 1988). The final mechanism of adhesion is metallurgical bonding. When placed in intimate contact, metallic bonding can occur via electronic interactions at the interface. The extent of these interactions, and the strength of the metallurgical bond, 
depends on the electronic structure of the metals. Studies suggest that the density of free electrons, the work function, and the Fermi energy may affect the strength of metallurgical bonds (Czichos, 1972; Ksiazak, Sobczak, Mikulowski, Radziwill, \& Surowiak, 2002).

\section{Relevant Mechanisms}

Not all of the above mechanisms are relevant for metal-metal systems deposited by KM spraying systems. It is generally accepted that the mechanisms that significantly contribute to the adhesive energy of thermal spray coatings are mechanical, thermodynamic, and metallic interactions (Fukanuma \& Ohno, 2004). The relative contribution due to large-scale electrostatic interactions has been shown to be negligible, although other electronic effects can play a part in adhesion (Mittal \& Pizzi, 1999). In addition, the relatively low temperatures at which cold spray processes are performed and short contact times involved suggest that significant diffusion does not occur $(\mathrm{Wu}$, Yang, Fang, Yoon, \& Lee, 2006; Ajdelsztajn, Zuniga, Jodoin, \& Lavernia, 2006). Chemical bonding is usually undesirable because interfacial reactions and their brittle intermetallic products can have deleterious effects on the mechanical properties of the interface (Liu, Muolo, Valenza, \& Passerone, 2010). This can be avoided by careful materials selection. This leaves mechanical interlocking, thermodynamic, and metallurgical interactions. To quantify and explain the contributions of these mechanisms, a theoretical framework is required. 


\section{Theoretical Approach}

\section{Fracture Mechanics Theory}

Building on the previous definition of interfacial fracture energy, one method to quantitatively describe the various contributions to adhesion is through the use of fracture mechanics theory. Under this theory, the work of adhesion $\left(\mathrm{W}_{\mathrm{AD}}\right)$ represents the most fundamental contribution to interfacial fracture energy. This is evident upon consideration of the Griffith criteria for fracture in elastic solids. Crack growth occurs when the elastic energy released during fracture is greater than or equal to energy of the newly created surfaces (McMahon, 2004; Gross \& Seelig, 2011). This means that in a pure, perfectly brittle material, the critical strain energy release rate is equal to the work of adhesion. Metals, though, undergo a significant amount of plastic deformation during crack extension, resulting in considerable amounts of energy dissipation during fracture. Modeling of the work that goes into plastic deformation is extremely difficult and requires analysis using an elastic-plastic description of solids and an understanding of the dependence on $\psi$, the phase angle of loading (Tvergaard \& Hutchinson, 1993). $\psi$ is used to describe the manner in which the interface is loaded. A phase angle of $0^{\circ}$ represents pure tension, referred to as Mode I loading or "opening”. A phase angle of $90^{\circ}$ represents pure shear, referred to as Mode II loading or "sliding". Often times, loading conditions fall between these two extremes and thus $\psi$ is a value between $0^{\circ}$ and $90^{\circ}$. Such loading conditions are referred to as mixed-mode (Evans, Ruhle, Dalgleish, \& Charalambides, 1989, Callister, 2003) 
Surface roughness can also increase the interfacial fracture energy by changing the apparent contact angle (Butt, Graf, \& Kappl, 2006). This increase can be approximated by the Wenzel equation (Equation 2) (Packham, 2003).

$$
\cos \theta_{\text {apparent }}=R_{\text {roughness }} * \cos \theta \quad \text { Equation } 2
$$

Where $\mathrm{R}$ is the ratio between the actual and the projected surface area. Because $\mathrm{R}$ is always greater than or equal to 1 , surface roughness will decrease $\theta_{\text {apparent }}$ for $\theta<90^{\circ}$ and increase $\theta_{\text {apparent }}$ for $\theta>90^{\circ}$. This will change the work of adhesion (Butt, Graf, \& Kappl, 2006). An additional proposed effect of roughness is that of roughness-induced crack shielding. When $\psi$ is non-zero, interface cracks in elastic materials are "shielded" by contact between asperities, as depicted in Figure 8. The magnitude of this effect depends on $\psi$ as well as the amplitude of the roughness (Evans, Ruhle, Dalgleish, \& Charalambides, 1989). As $\psi$ increases, the ratio of shear to opening increases. As is apparent in Figure 8, contact between asperities produces a resistance to crack propagation due to shear forces. As a result, for a given interfacial profile, interfacial toughness tends to increase as $\psi$ increases, as depicted in Figure 9 (Evans, Ruhle, Dalgleish, \& Charalambides, 1989). 


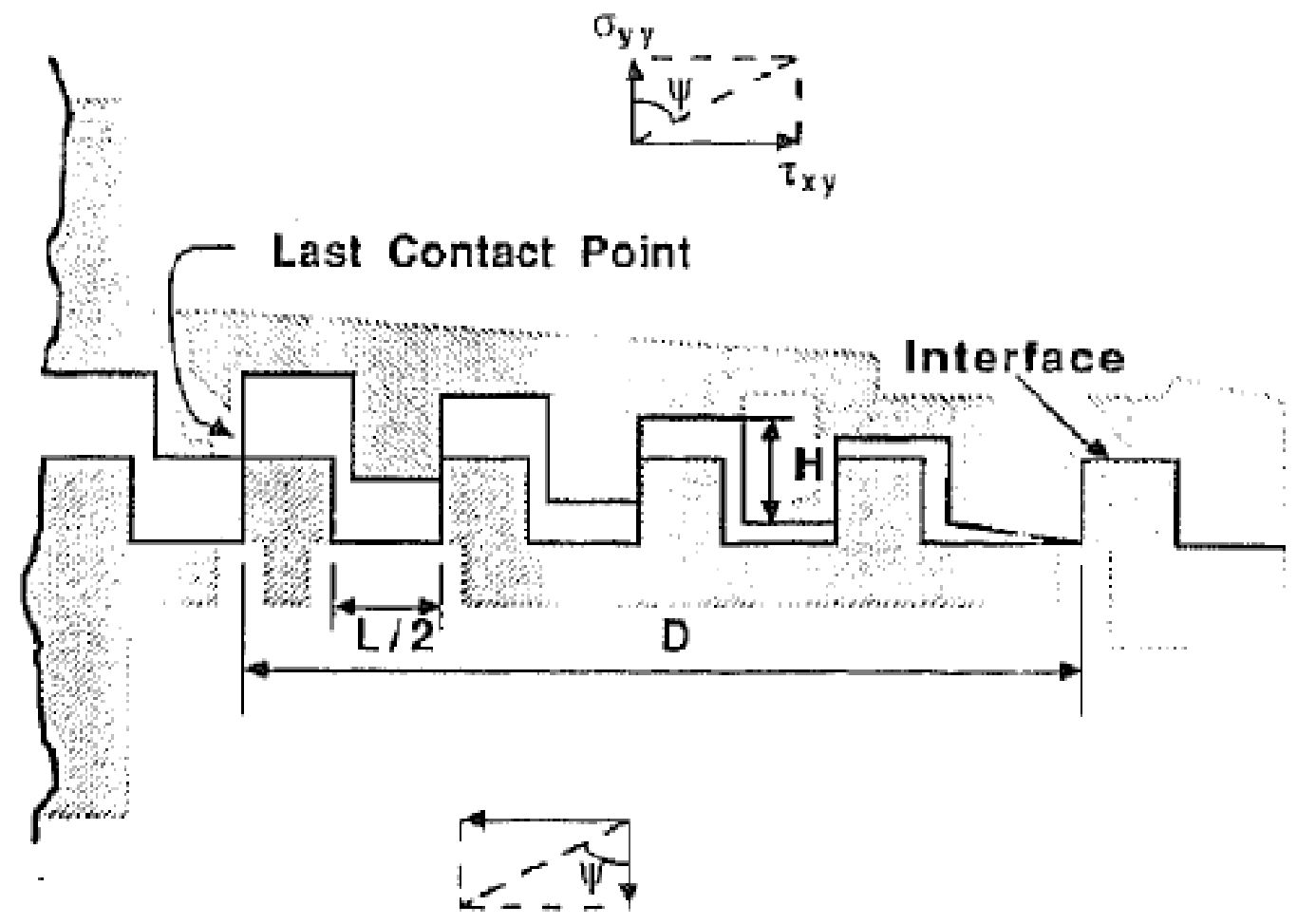

Figure 8: Surface roughness can provide crack shielding due to contact between asperities on opposing surfaces (Evans, Ruhle, Dalgleish, \& Charalambides, 1989). 


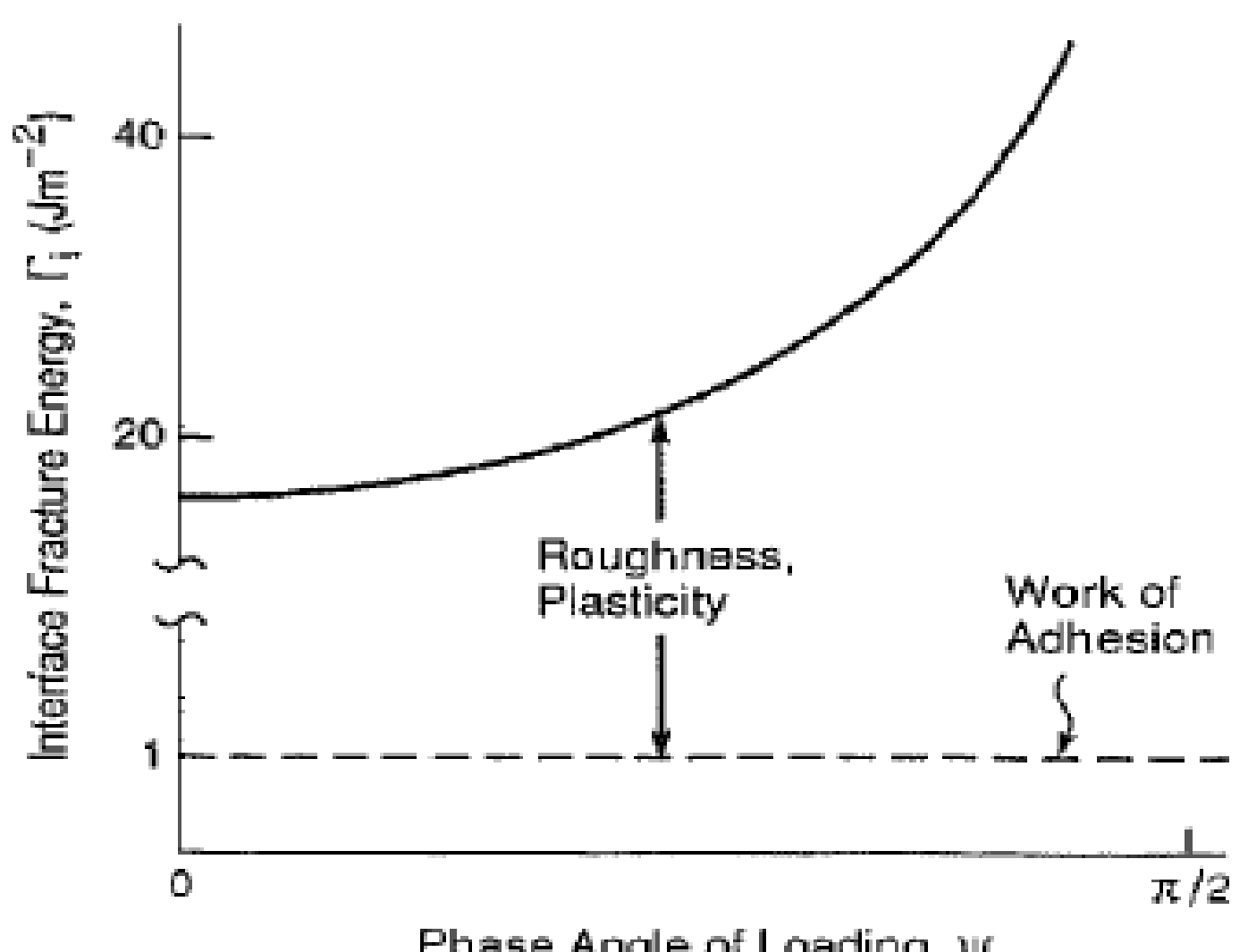

Figure 9: Due to roughness-induced shielding, interfacial toughness tends to increase as phase angle increases (Evans, Ruhle, Dalgleish, \& Charalambides, 1989).

\section{Work of Adhesion}

Although fracture mechanics theory provides a good basis for the contribution of thermodynamics and mechanical effects, it struggles to quantify the effects of plastic deformation and other variables such as residual stresses in the coating. It does, however, emphasize the importance of the work of adhesion in describing the toughness of an interface. Nearly all models based on fracture mechanics include the work of adhesion of a pure interface before other contributions are considered. In reality, though, no surface is pure, and there will be some segregation of impurities to the interface. The work of 
adhesion can also be modified to include the effects of interfacial segregation of impurities by use of the Gibbs adsorption isotherm:

$$
d \gamma=-\sum_{i} \Gamma_{i} d \mu_{i}
$$

\section{Equation 3}

Where $\Gamma_{\mathrm{i}}$ and $\mu_{\mathrm{i}}$ are the adsorption and chemical potential of the $i$ th component, respectively (Wang \& Wynblatt, 1998). The ease in which the work of adhesion can be calculated makes it an ideal metric for the toughness of an interface (Wynblatt, 2000). Granted, the fracture energy of most real interfaces is significantly larger than the work of adhesion, but research strongly suggests that the work of adhesion is proportional to interfacial toughness (Evans, Hutchinson, \& Wei, 1999; Evans, Ruhle, Dalgleish, \& Charalambides, 1989). Thus if the components contributing to the work of adhesion are known, they can be correlated to experimentally determined toughness values, such as $\mathrm{G}_{\mathrm{C}}$ and $\mathrm{K}_{\mathrm{C}}$. In theory, this correlation could be used to predict the interfacial toughness using theoretical work of adhesion calculations.

\section{Solid-State Wetting}

In order to understand the influence of thermodynamics on adhesion of KM coatings, the concept of wetting must be adapted to a solid-state form. The Young-Dupré equation (Equation 1) was developed to describe the situation of a liquid drop on a solid surface, but it can be manipulated and applied to solid-state wetting as well. In this case, the Dupré equation is used: 


$$
W_{A D}=\gamma_{1}+\gamma_{2}-\gamma_{12}
$$

Equation 4

Where $\gamma_{1}$ and $\gamma_{2}$ are the surface energies of the coating and substrate, respectively, and $\gamma_{12}$ is the energy of the interface, a term unique to the coating-substrate combination (Ksiazak, Sobczak, Mikulowski, Radziwill, \& Surowiak, 2002). Experimental evidence from Inovati supports the hypothesis that thermodynamics plays a large role in determining interfacial quality. Strong interfaces are created through strong metallurgical bonding, which is achieved by effective solid-state wetting (Inovati, 2012). For a given coating, a substrate is considered "wetting" if the contact angle is less than $90^{\circ}$. Conversely, it is considered "non-wetting" if the contact angle is greater than $90^{\circ}$. Solidstate wetting experiments under ultra-high vacuum (UHV) conditions verify the results of the Young-Dupré equation (Equation 1); that is, favorable interactions at the interface produce a small contact angle, which results in large work of adhesion values, while unfavorable interactions produce larger contact angles and smaller work of adhesion values (Wynblatt, 2000; Gangopadhyay \& Wynblatt, 1994). It is speculated that the degree of wetting is controlled by the strength of the metallic interactions at the interface (Delannay, Froyen, \& Deruyttere, 1987).

Analysis of the Dupré equation (Equation 4) shows that the work of adhesion is determined by three variables: the surface energies of the two metals $\left(\gamma_{1}\right.$ and $\left.\gamma_{2}\right)$ and the interfacial energy $\left(\gamma_{12}\right)$. Surface energy values for metals are either known or easily determined via the Sessile drop technique or other contact angle experiments (Gangopadhyay \& Wynblatt, 1994). This leaves $\gamma_{12}$ as the key variable for describing the 
interface. If this value and the surface energies of the coating and substrate are known, then the work of adhesion can be calculated. It is a function of various material properties and reflects various aspects of both the two components of the interface and the interface itself, including both electronic and physical properties. For the predictive model to be useful, accurate values of $\gamma_{12}$ are required. To achieve this, several models for the theoretical calculation of $\gamma_{12}$ will now be analyzed.

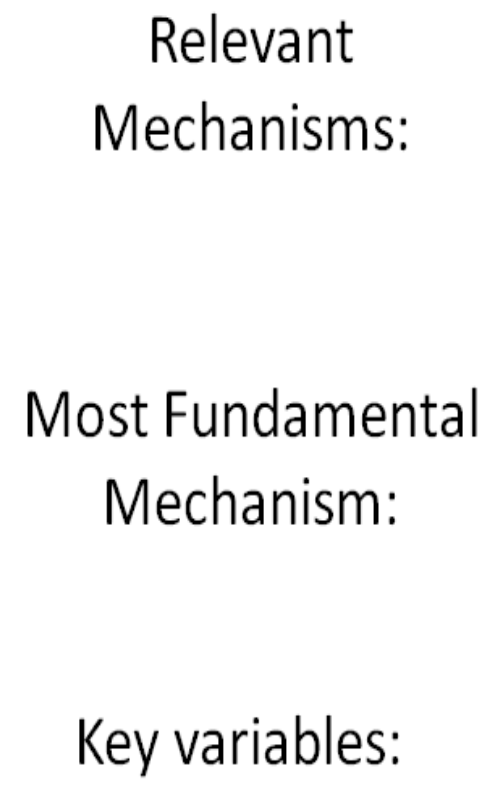

Adhesion Mechanisms:
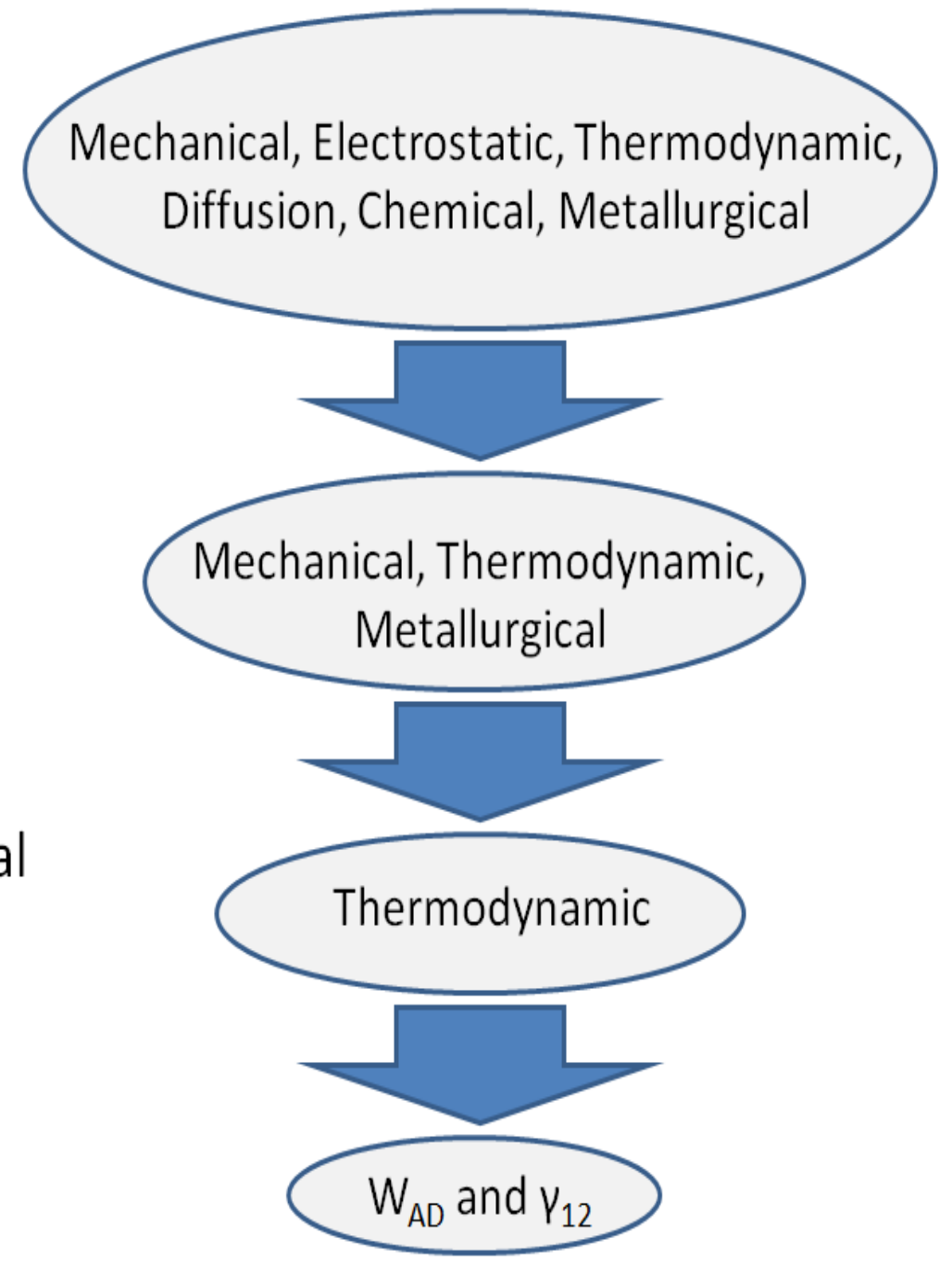

Figure 10: This study will focus on the thermodynamic contribution to adhesion. 


\section{EXISTING MODELS}

\section{Physics Model}

\section{Theory and Derivation}

One model attempts to quantify the interfacial energy between two metals based on metallic bonding due to electronic interactions at the interface. Previous research concerning the electronic contribution to the surface energy of transition metals suggests that the electronic contribution to the interfacial energy is significant as well. When two dissimilar metals are placed in contact, an electrostatic potential is created due to the difference in Fermi energies of the two metals. The contact potential aligns the Fermi energies (Figure 11). When this potential is evaluated over the entire interface, it becomes clear that the interfacial energy is dependent not only on the Fermi levels of the metals but also on their work function, cohesive energy, and density of states (Czichos, 1972). Here, the density of states is approximated by fitting a Gaussian curve to the second moment of the density of states. This analysis is accomplished by means of a linearized Thomas-Fermi approximation of a tight binding model and self-consistent calculations, resulting in Equation 5:

$$
\begin{aligned}
\gamma_{12}=\frac{1}{2} \frac{\epsilon_{0} a}{e^{2}}( & \left.W_{1}-W_{2}\right) \\
& +\frac{\epsilon_{0} a}{e^{2}}\left(W_{1}-W_{2}\right)\left[E_{F 1}-E_{F 2}+\frac{1}{4}\left(E_{F 1}+E_{F 2}\right) \frac{\Delta \mu_{1}}{\mu_{1}}\right] \\
& -\frac{\Delta \mu_{1}}{\mu_{1}}\left(E_{C 1}-E_{C 2}\right)
\end{aligned}
$$


Where $\mathrm{W}$ is the work function, $\mathrm{E}_{\mathrm{F}}$ is the Fermi energy, $\frac{\Delta \mu}{\mu}$ is the relative variation of the density of states, and $E_{C}$ is the cohesive energy. The subscripts refer to the metal of the lower transition series (1) and higher (2). Also included are constants $\varepsilon_{0}$, the permittivity of free space, e, the electronic charge, and a, the lattice parameter (assumed to be approximately 4 Angstroms) (Allan, Lannoo, \& Dobrzynski, 1974).

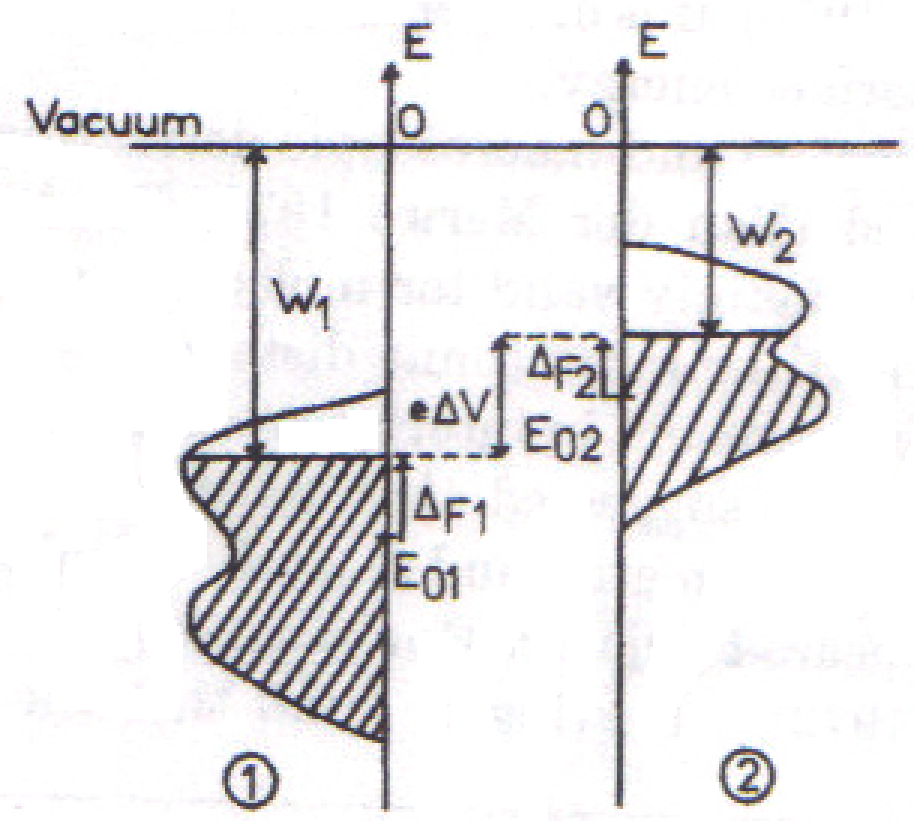

Figure 11: Schematic representation of the $d$ band densities of states, Fermi levels (F), and work functions (W) for an interface between two transition metals (Allan, Lannoo, \& Dobrzynski, 1974).

\section{Assumptions}

This model presents a relatively simple way of calculating the electronic contribution to interfacial energy in units of eV/atom using known properties of each 
metal. This analysis assumes the interface is sharp, flat, and atomically smooth. This means the interface is perfectly coherent with no lattice defects. Further, it is assumed there is no interdiffusion or surface contamination. To achieve quantitative results, several additional assumptions and approximations are made throughout the analysis. The relative variation of the density of states between different metallic elements is approximated in Table 1:

Table 1: Typical values of variation of states (Allan, Lannoo, \& Dobrzynski, 1974)

\begin{tabular}{|c|c|c|c|c|}
\hline \multirow{2}{*}{} & \multicolumn{4}{|c|}{ Interface between metals of: } \\
\cline { 2 - 5 } & Same series & $\begin{array}{c}\mathbf{1}^{\text {st }} \text { and } \mathbf{2}^{\text {nd }} \\
\text { transition } \\
\text { series }\end{array}$ & $\begin{array}{c}\mathbf{1}^{\text {st }} \text { and } \mathbf{3}^{\text {rd }} \\
\text { transition series }\end{array}$ & $\begin{array}{c}\mathbf{2}^{\text {nd }} \text { and } \mathbf{3}^{\text {rd }} \\
\text { transition series }\end{array}$ \\
\hline$\frac{\Delta \boldsymbol{\mu}_{\mathbf{1}}}{\boldsymbol{\mu}_{\mathbf{1}}}$ & 0 & 0.1 & 0.15 & 0.075 \\
\hline
\end{tabular}

To convert $\mathrm{eV} /$ atom to $\mathrm{J} / \mathrm{m}^{2}$, the number of surface atoms per unit area is needed. This value represents the interface; however, it is different for each metal. To account for this fact, the average molar surface area is used in this conversion. Finally, the Fermi energies of transition metals in crystalline form are difficult to define. It is a complex threedimensional surface called the Fermi surface that varies throughout the crystal. However, for calculations, it can be approximated as a single value; in this case the Work function of the metal was used in place of the Fermi level. Consider Figure 11, which simplifies the situation to a one-dimensional approximation: 


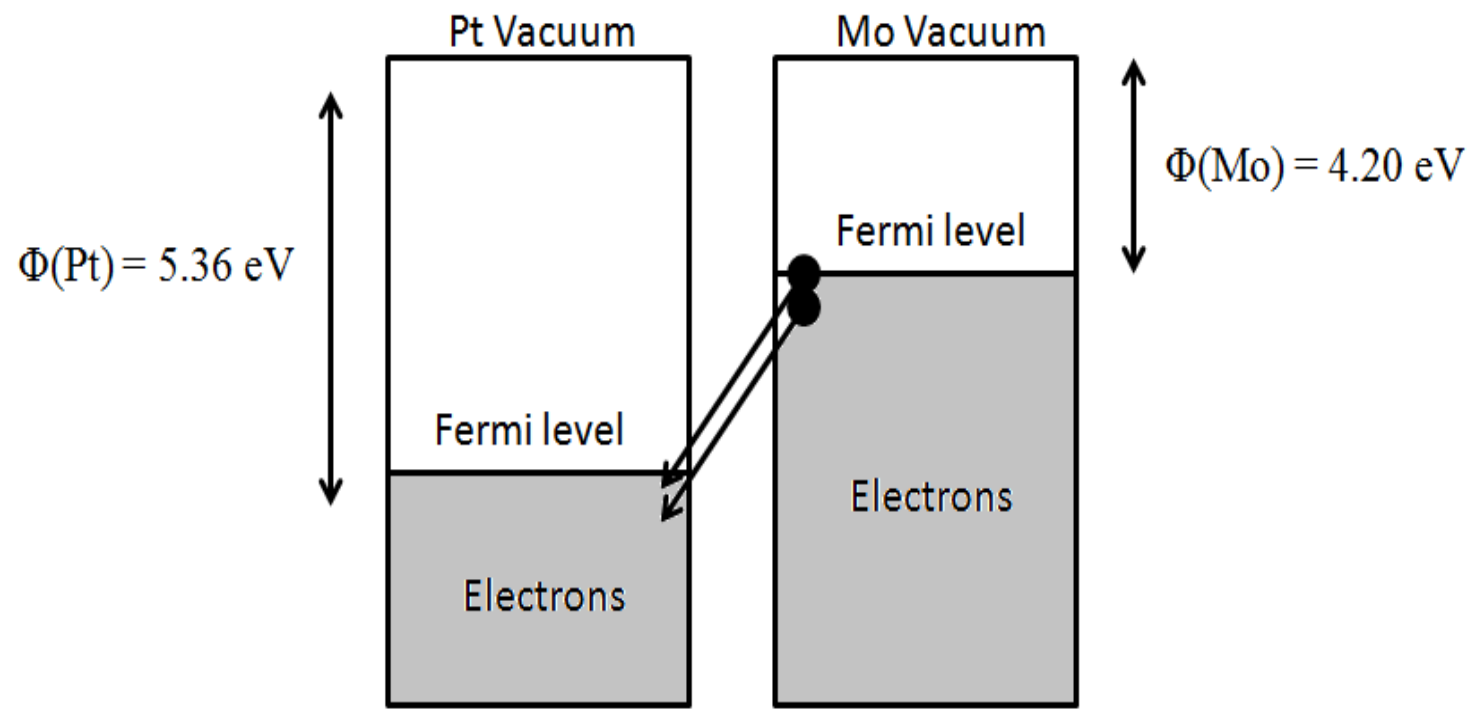

(a)

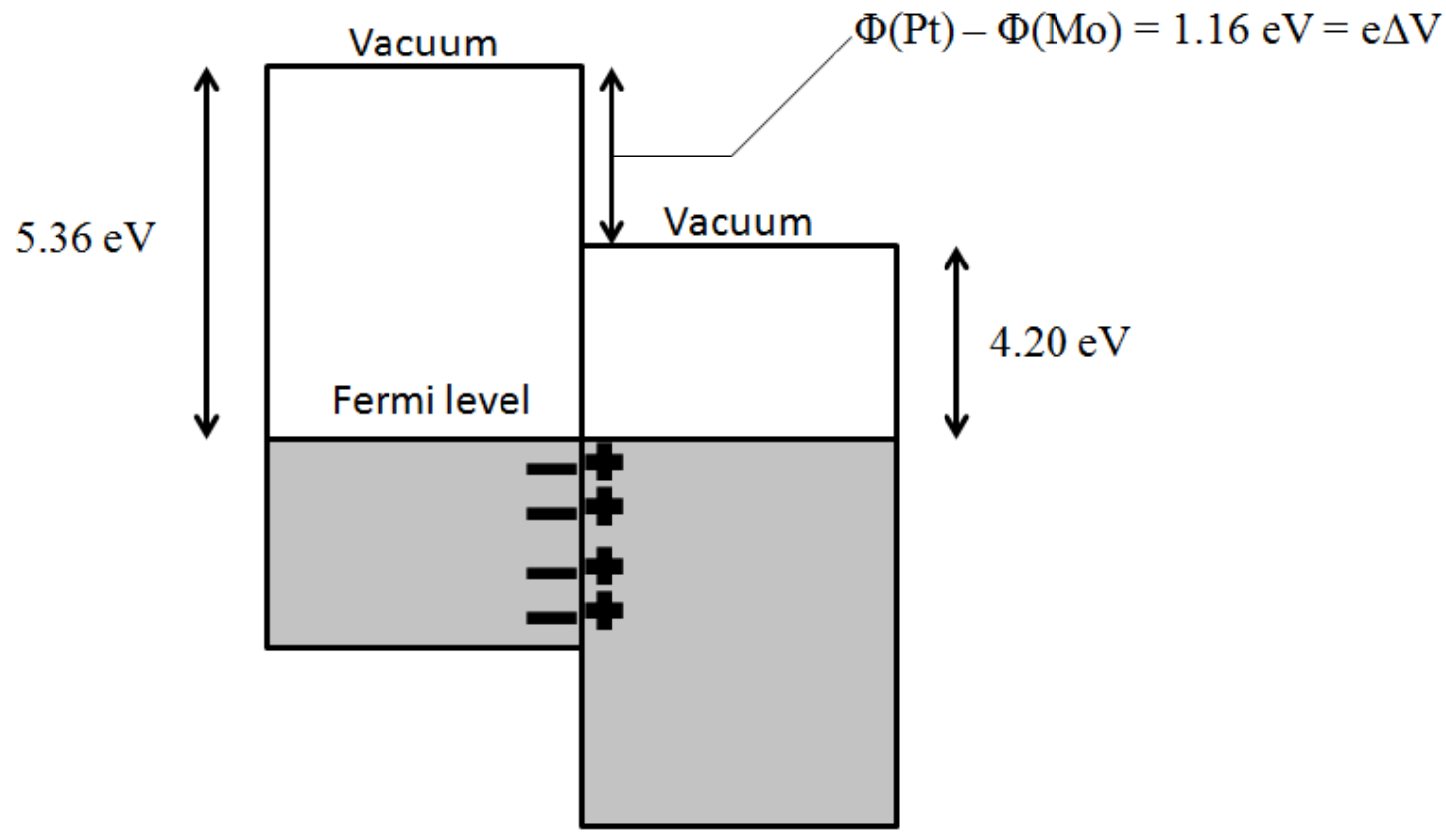

(b)

Figure 12: When two dissimilar metals are brought into contact, there is a contact potential $\Delta \mathrm{V}$ created due to the difference in their respective Fermi levels. (a) Electrons are more energetic in Mo, so they tunnel to the surface of Pt. (b) Equilibrium is reached when the Fermi levels are aligned (Kasap, 2007). 
For metals, the Fermi level $\mathrm{E}_{\mathrm{F}}$ is the highest energy state occupied by electrons at 0 Kelvin. The Work Function $\mathrm{W}$ is the energy required to remove an electron from the Fermi level to the vacuum level. The value of the Fermi level depends on where it is referenced, but it is normally measured from the bottom of the energy band, as depicted in Figure 12. When two dissimilar metals are placed in contact, there will be a net transfer in electrons because the metals have different Fermi levels. This creates a contact potential $\Delta \mathrm{V}$ at the interface, the size of which is determined by the difference in work functions. Thus, if $\Delta \mathrm{E}_{\mathrm{F}}=\Delta \mathrm{V}$ and $\Delta \mathrm{V}=\Delta \mathrm{W}$, then $\Delta \mathrm{E}_{\mathrm{F}}=\Delta \mathrm{W}$ (Kasap, 2007). Because it is the difference between the metals' Fermi levels that matters, the reference energy is not important, as long as it is constant. When referenced to the vacuum level, $\mathrm{E}_{\mathrm{F}}$ is simply equal to $-\Phi$, justifying the assumption made earlier.

\section{Analysis of Variables and Trends}

The details of the analysis used in this model is physics-intensive and beyond the scope of this paper. Nonetheless, analysis of the variables present in Equation 5 reveals the principles and theory involved in the model. The key parameters are the work function $\mathrm{W}$, the Fermi level $\mathrm{E}_{\mathrm{F}}$, the cohesive energy $\mathrm{E}_{\mathrm{C}}$, and the relative variation of the density of states $\frac{\Delta \mu}{\mu}$. The assumption is made that $\mathrm{W}$ and $\mathrm{E}_{\mathrm{F}}$ are equal. They essentially represent the same quantity: the free energy per electron, or the electrochemical potential. During contact, this potential energy results in electron transfer and metallic bonding; essentially, the potential difference represents the adhesive energy between the two metals (Kasap, 2007). The cohesive energy represents the affinity to bond with its own 
atoms as opposed to bond across the interface, and the density of states term represents the number and distribution of electrons available for bonding (Czichos, 1972).

Interfacial energy values were calculated for several metal-metal combinations; the results are shown below in Figure 13.

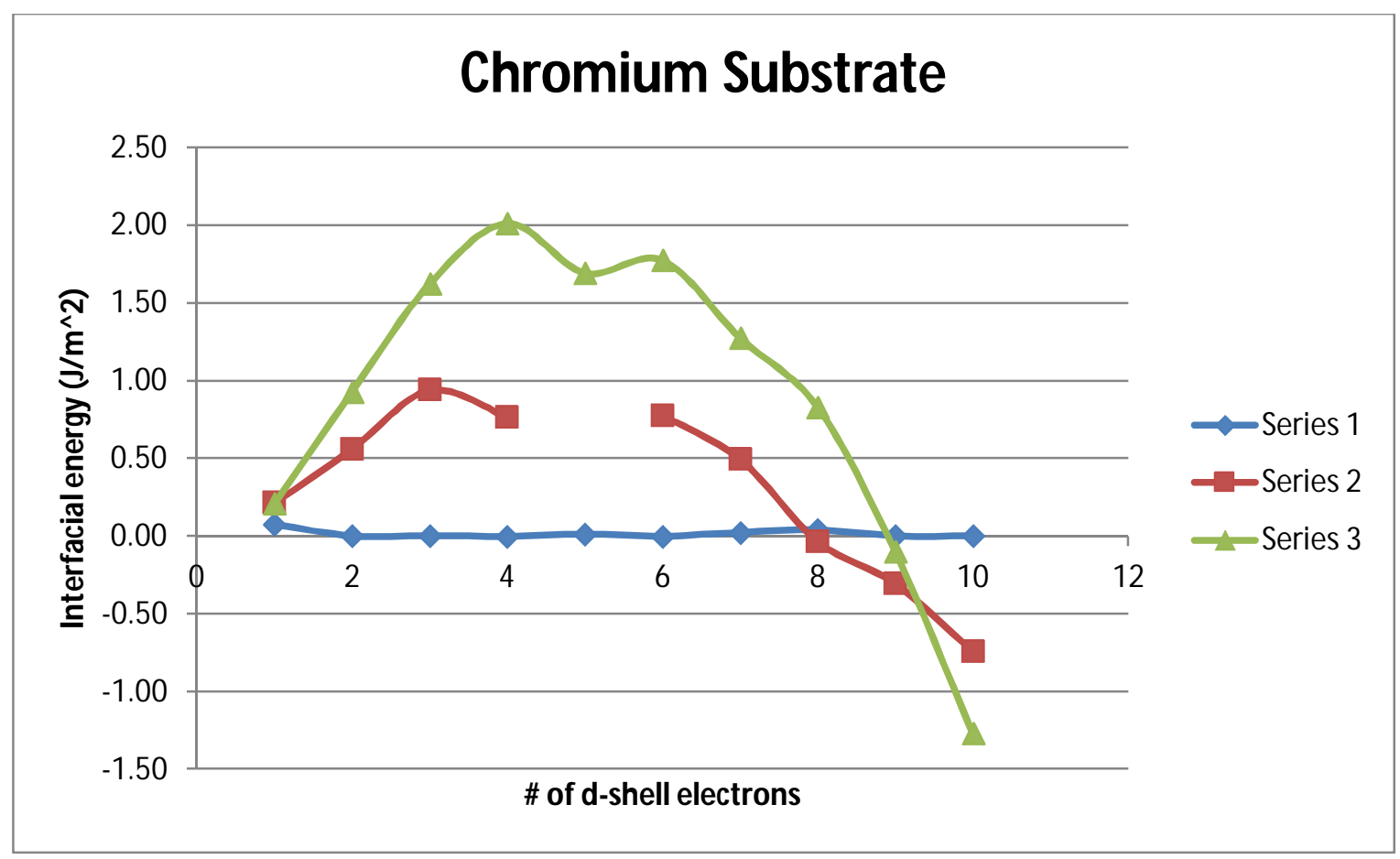

(a) 


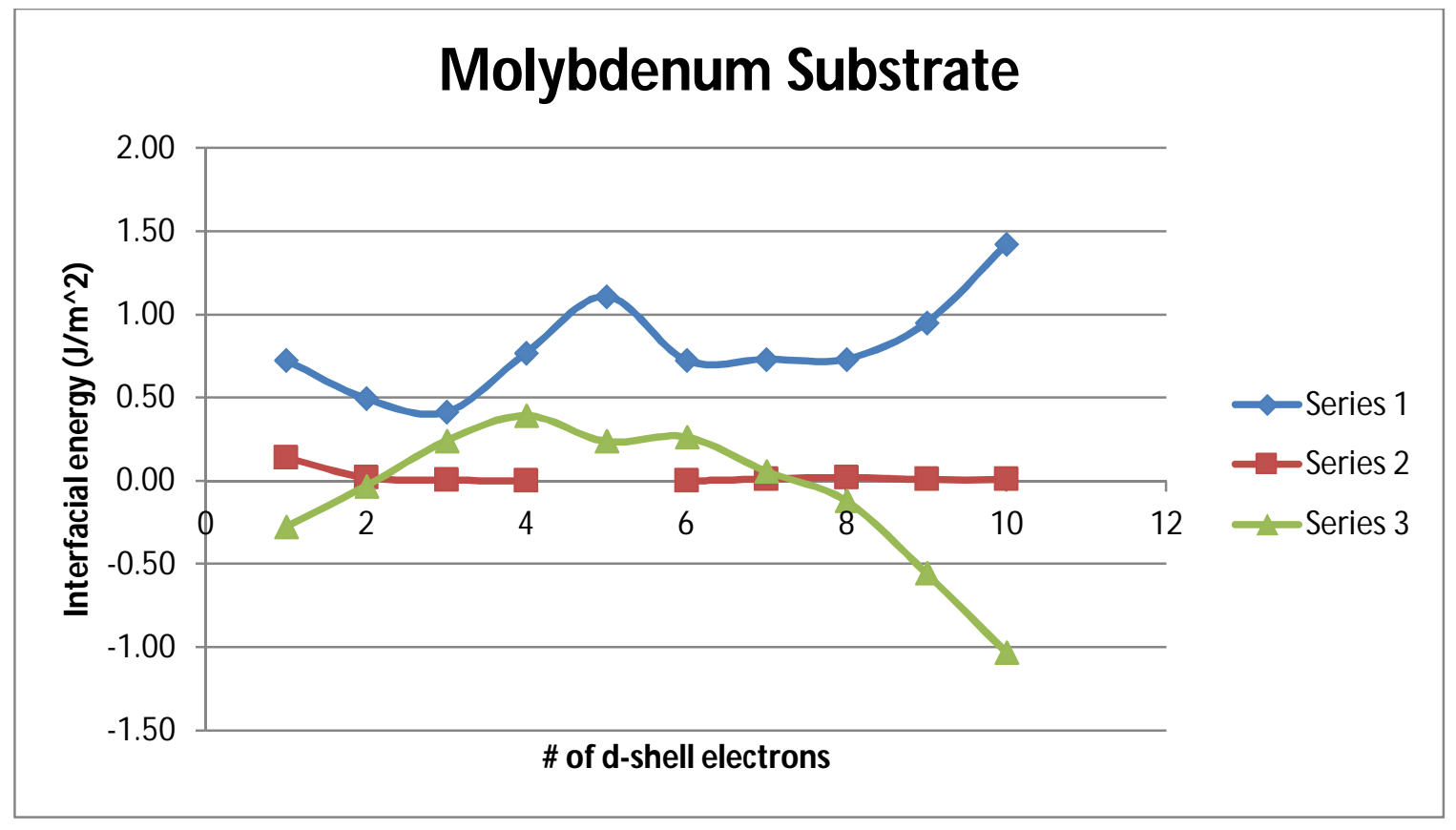

(b)

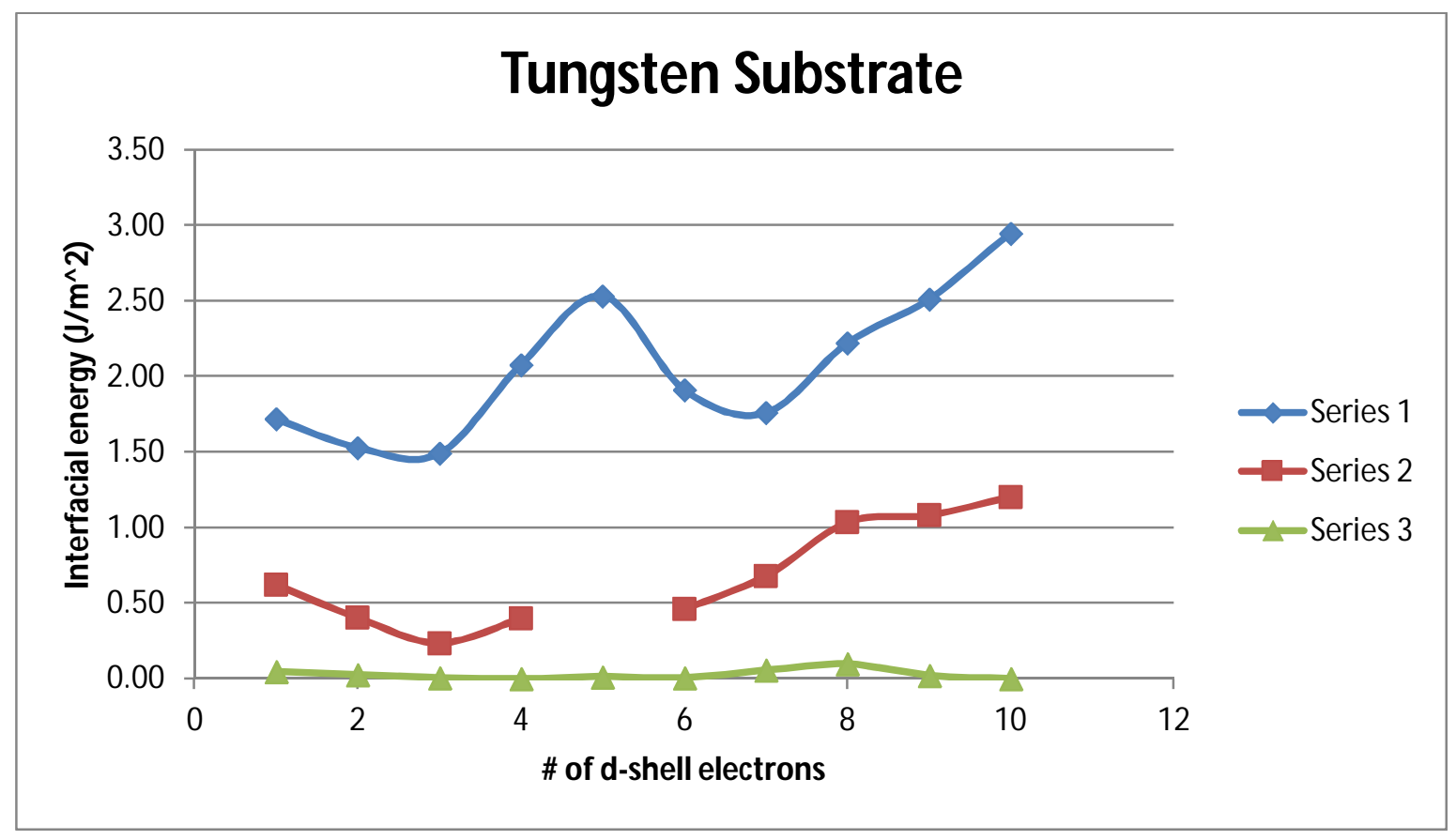

(c)

Figure 13: Graphs of work of adhesion results from physics model for (a) Chromium, (b) Molybdenum, and (c) Tungsten 
When the metals belong to the same transition series, the third term in Equation 5 is zero. The result is an interfacial energy that is small—on the order of $0.05 \mathrm{eV}$. When the metals belong to different transition series, though, the third term is significantly larger than the first two terms. In this case, the interfacial energy is controlled by the difference in cohesive energies of the two metals. This is verified by examining trends in the cohesive energies of transition metals:

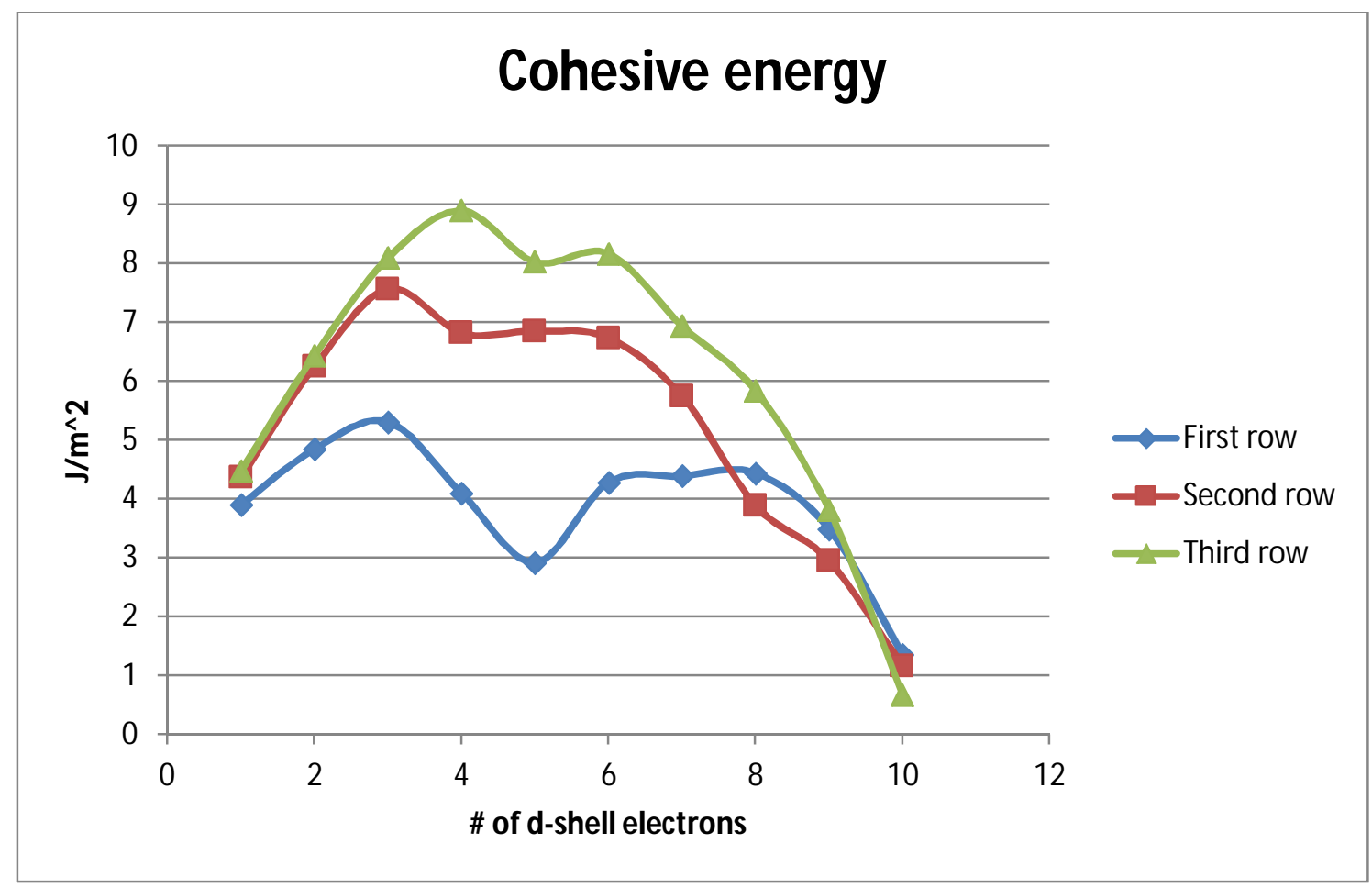

Figure 14: Graph of cohesive energies for transition metals

Moving left to right across a transition row, the cohesive energy shows a parabolic dependence on the number of valence electrons. The cohesive energy increases, reaches a maximum in the middle of the row, then decreases. According to Hund's rule, electrons will singly fill all orbitals before double occupation occurs. This means that a state with 
each d-subshell singly filled is energetically favorable and more stable; one can see how this would result in a higher cohesive energy for elements with these electronic structures (Tro, 2011). The "dip" observed in the middle of the $3 \mathrm{~d}$ transition row can be attributed to magnetic effects due to spin-polarization (Skriver \& Rosengaard, 1992; Kajar \& Mizia, 1977).

For an interface between two metals of the same transition row, the difference in the densities of states is zero. The $\frac{\Delta \mu}{\mu}$ term used in this model represents the variation in electronic structure between a bulk and an interface atom. The more closely these values match between two dissimilar metals, the smaller the interfacial energy will be. According to this model, within the same transition row, the electronic structure of two metals match quite closely, so this term is approximately zero for any same-row pair. In this case, the interfacial energy is determined by the variation of the work function and Fermi level, as described previously. For metals of different series, the electronic structure varies significantly; the $\frac{\Delta \mu}{\mu}$ term quantifies this variation.

\section{Molar Volume Model}

\section{Theory and Derivation}

A different model attempts to model interfacial energy by considering the van der Waals interactions between molecules across an interface. The analysis begins by 
considering the Berthelot relation for the attractive constants between like $\left(A_{a a}\right.$ and $\left.A_{b b}\right)$ and unlike $\left(\mathrm{A}_{\mathrm{ab}}\right)$ molecules:

$$
\frac{A_{a b}}{\left(A_{a a} A_{b b}\right)^{\frac{1}{2}}}=\Phi
$$

Equation 6

Where the variable $\Phi$ is characteristic of the system. By analogy, this ratio can be set up with the free energies of cohesion and adhesion:

$$
\begin{gathered}
-\frac{\Delta F_{a b}}{\left(\Delta F_{a} \Delta F_{b}\right)^{\frac{1}{2}}}=\Phi ; \text { where } \Delta F_{a b}=\gamma_{a b}-\gamma_{a}-\gamma_{b} \\
\text { and } \Delta \mathrm{F}_{\mathrm{N}}=2 \gamma_{\mathrm{N}}
\end{gathered}
$$

\section{Equation 7}

Where $\Delta \mathrm{F}_{\mathrm{ab}}$ and $\Delta \mathrm{F}_{\mathrm{N}}$ are the free energies of adhesion and cohesion between phases $\mathrm{A}$ and $\mathrm{B}$, respectively, and $\gamma_{\mathrm{N}}$ is the surface energy of phase $\mathrm{N}$. These equations can be solved for the interfacial energy $\gamma_{\mathrm{ab}}$ :

$$
\gamma_{a b}=\gamma_{a}+\gamma_{b}-2 \Phi\left(\gamma_{a} \gamma_{b}\right)^{\frac{1}{2}}
$$

Solving for $\Phi$ is performed by setting up expressions for the force required to separate the two phases. These expressions can be integrated over separation distance and solved for the energy required for separation. For a more detailed derivation, see Reference 50 (Girifalco \& Good, 1957). Integrating and solving yields the following expression for $\Phi$ :

$$
\Phi=\frac{4 V_{a}^{\frac{1}{3}} V_{b}^{\frac{1}{3}}}{\left(V_{a}^{\frac{1}{3}}+V_{b}^{\frac{1}{3}}\right)^{2}}
$$


Where $\mathrm{V}_{\mathrm{a}}$ and $\mathrm{V}_{\mathrm{b}}$ are the molar volumes of phase $\mathrm{A}$ and $\mathrm{B}$, respectively.

\section{Assumptions}

The required integration can be performed if certain simplifying assumptions are made. Firstly, the densities of each phase must be constant right up to the interface. Secondly, the molecular pair distribution function must also be constant. This assumption is only important when dealing with polyatomic molecules; in practice, this assumption is justified because errors due to oversimplification tend to cancel out. Finally, it is assumed that the interaction energy can be modeled using a Lennard-Jones potential:

$$
\varepsilon_{a b}=-\frac{A_{a b}}{r^{6}}+\frac{B_{a b}}{r^{m}}
$$

Equation 10

Where $\varepsilon_{a b}$ is the interaction energy, $r$ is distance between atoms, and $A_{a b}, B_{a b}$, and $m$ are constants (Good, Girifalco, \& Kraus, 1958; Good \& Girifalco, 1960). This is a simple approximation that is valid at both long and short distances for neutral atoms and molecules. The $1 / \mathrm{r}^{\mathrm{m}}$ term represents the repulsive potential, with $m$ generally being equal to 12 . The $1 / \mathrm{r}^{6}$ term represents the attractive potential. Systems are considered "regular" if the interaction energy can be described using an equation of this form. These assumptions generally hold true for uncharged, spherical molecules and atoms, making this model applicable to metal-metal interfaces (Atkins \& de Paula, 2009). 


\section{Analysis of Variables and Trends}

Like the previous model, the derivation is relatively complex, but analysis of the variables and trends can highlight the fundamental principles. The Molar Volume model quantifies the effects of physical interactions, as opposed to the Physics Model, which quantified electronic interactions. The key variables in this model are the molar volumes $-V_{a}$ and $V_{b}$ and the surface energies $-\gamma_{a}$ and $\gamma_{b}$ of the coating and substrate materials. If one imagines two metals in contact, there will be a lattice mismatch due to dissimilar atomic size. The greater the differences in molar volume, the greater the mismatch, and the greater the energy associated with this mismatch. This trend is apparent from an independent analysis of Equation 6, which is shown graphically in Figure 15: 


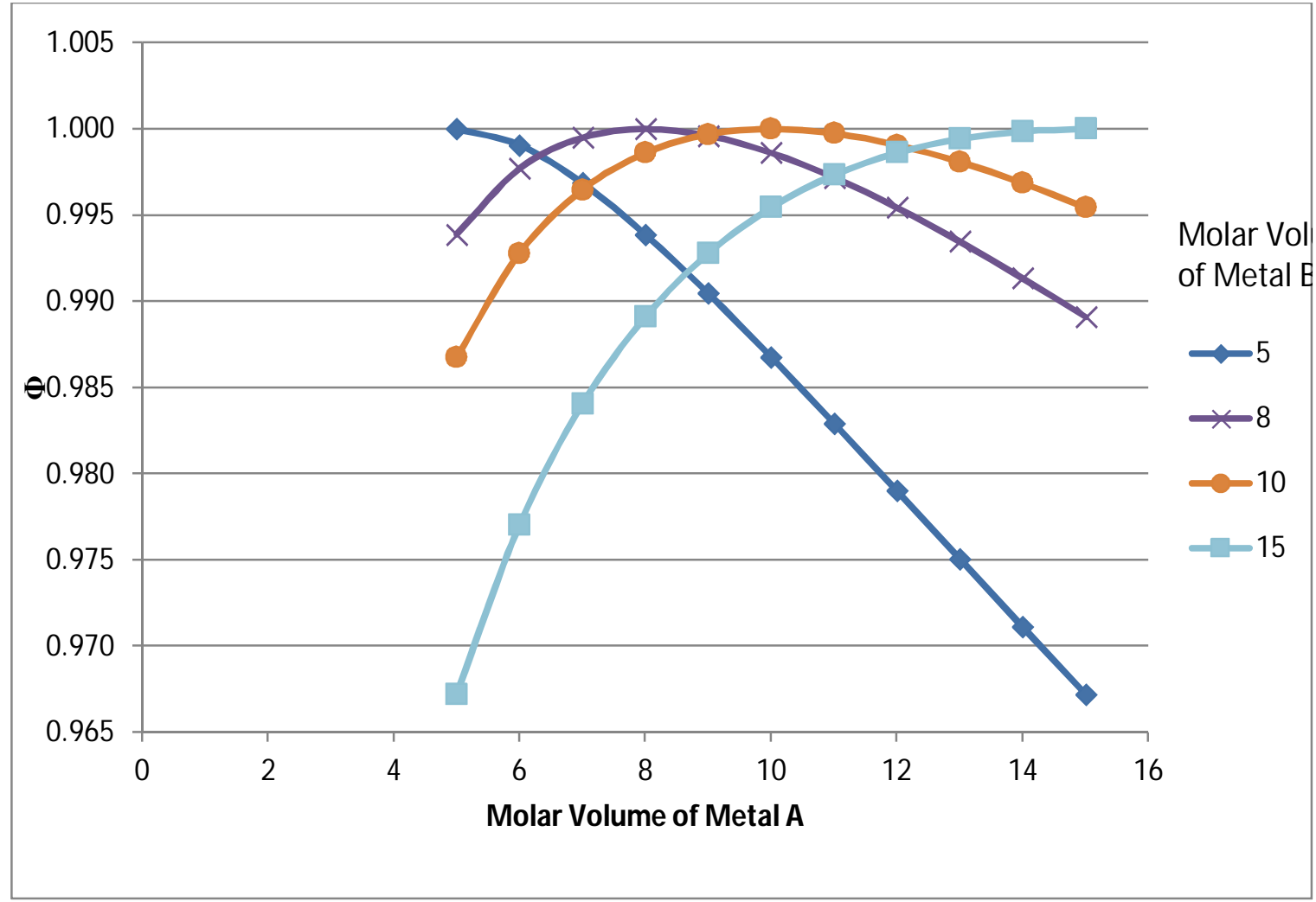

Figure 15: $\Phi$ increases as the difference between the Molar volumes increases

Greater molar volume mismatch results in smaller values of $\Phi$, which increases interfacial energy if the surface energies are held constant. As the difference in molar volume approaches zero, $\Phi$ approaches 1 , and the interfacial energy approaches zero. Conceptually, one can imagine that the more dissimilar the two constituents, the less favorable adhesion will be; this is represented by a large interfacial energy. Conversely, if the metals have identical molar volumes, there will be no lattice mismatch, and the physical contribution to the interfacial energy will be smaller. $\Phi$ varies from 1 to about 0.95, so the effects of molar volume are less significant than those of surface energy. Much like molar volume, large differences in the surface energy of the two constituents results in a higher interfacial energy, while similar surface energies yield small interfacial 
energy. This is clear from investigation of Equation $\mathbf{8}$ for $\gamma_{\mathrm{ab}}$. If $\Phi$ is assumed to be 1, then this equation reduces to the following form:

$$
\gamma_{a b}=\left(\gamma_{a}^{1 / 2}-\gamma_{b}^{1 / 2}\right)^{2}
$$

Equation 11

According to the Lennard-Jones approximation, the interaction energy between unlike atoms is equal to the geometric mean of the attraction energies between like atoms (Atkins \& de Paula, 2009). The surface energies represent the relative affinity of each metal to bond with itself, as opposed to each other. If the surface energies of two dissimilar atoms are equal, then one can imagine that bonding with a like or unlike atom would be equally favorable. There would be no energy barrier to bonding across an interface compared to bonding within itself, hence an interfacial energy of zero. Interfacial energy values were calculated for transition metal pairs (Figure 16). 


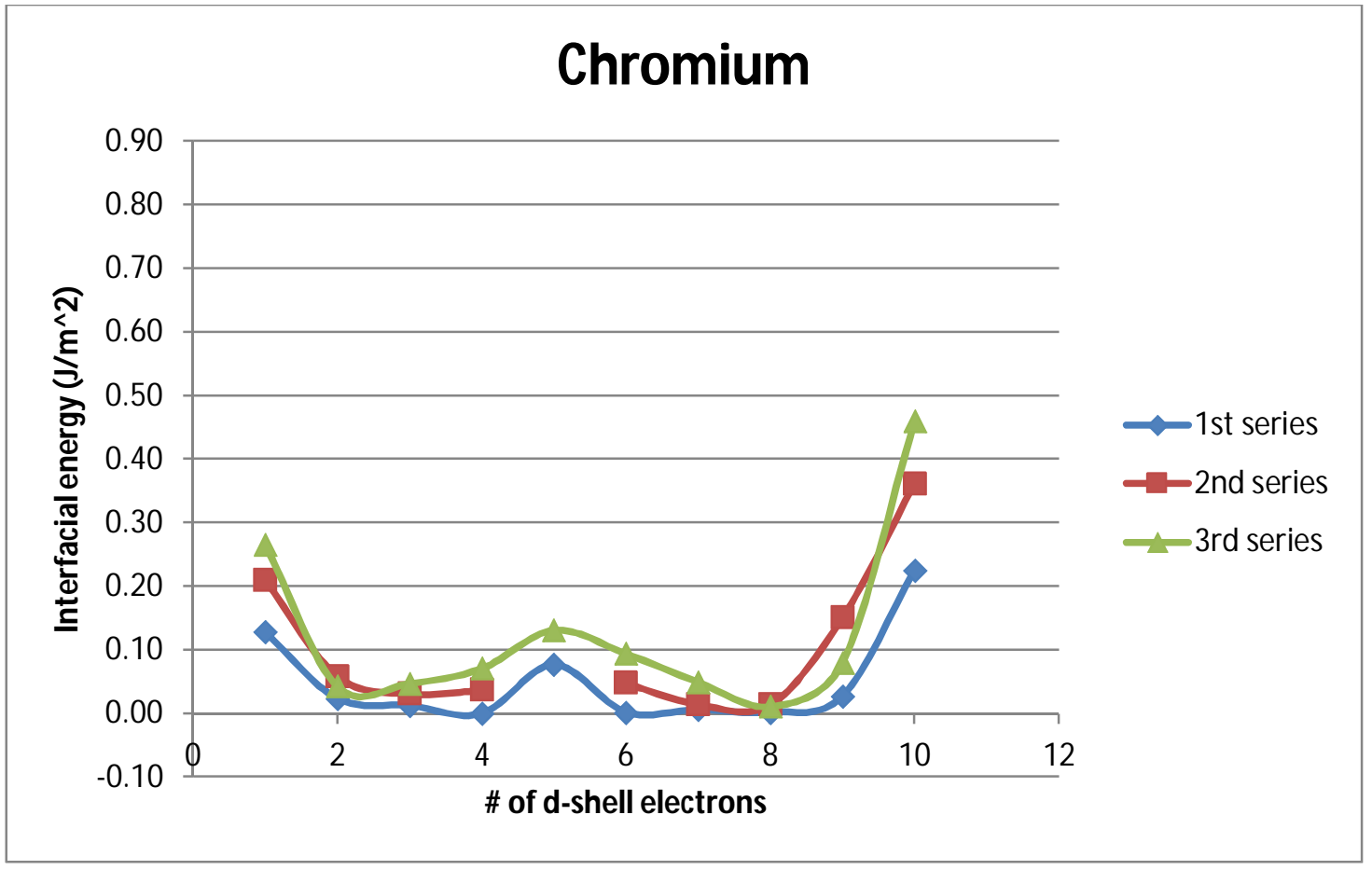

(a)

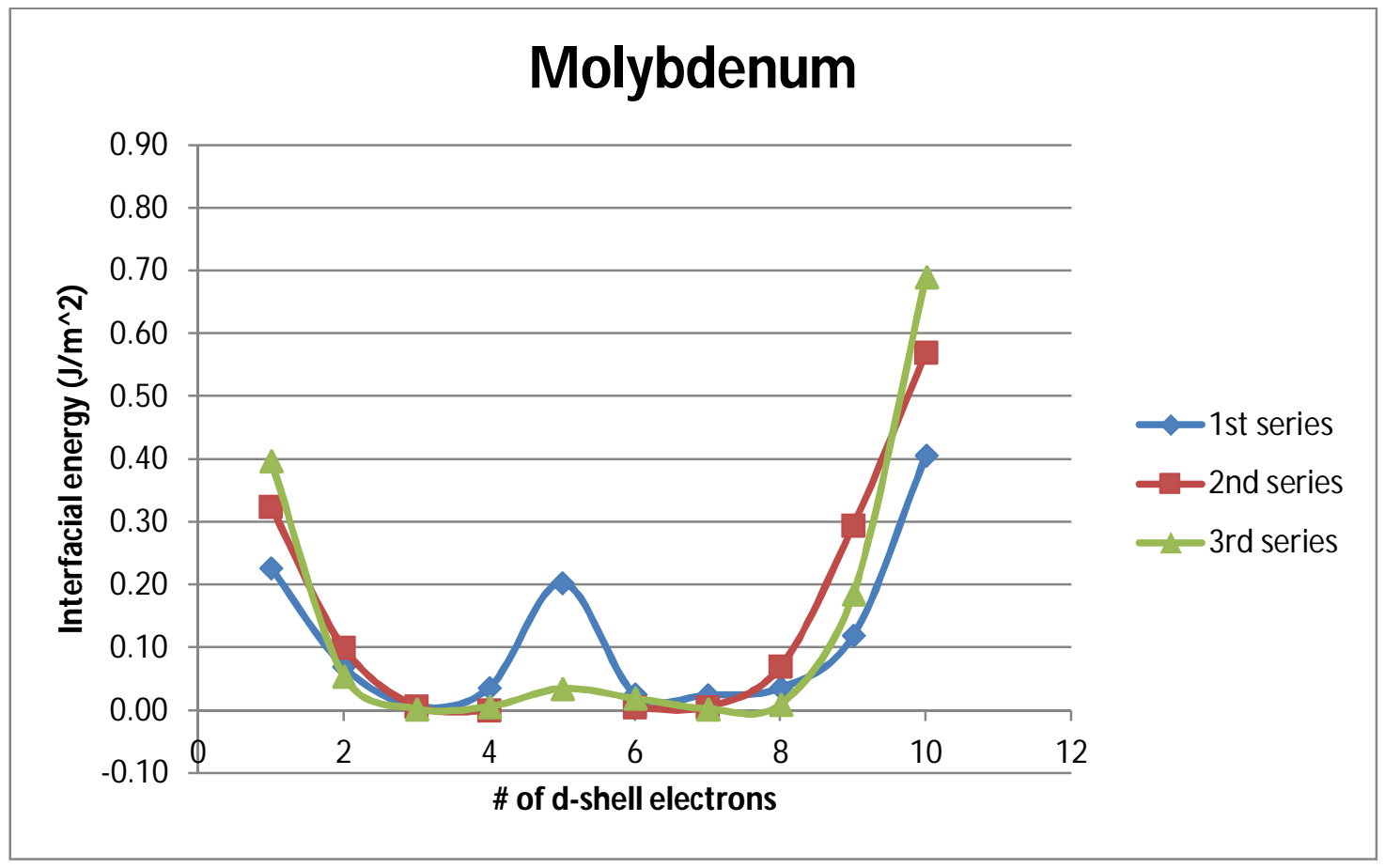

(b) 


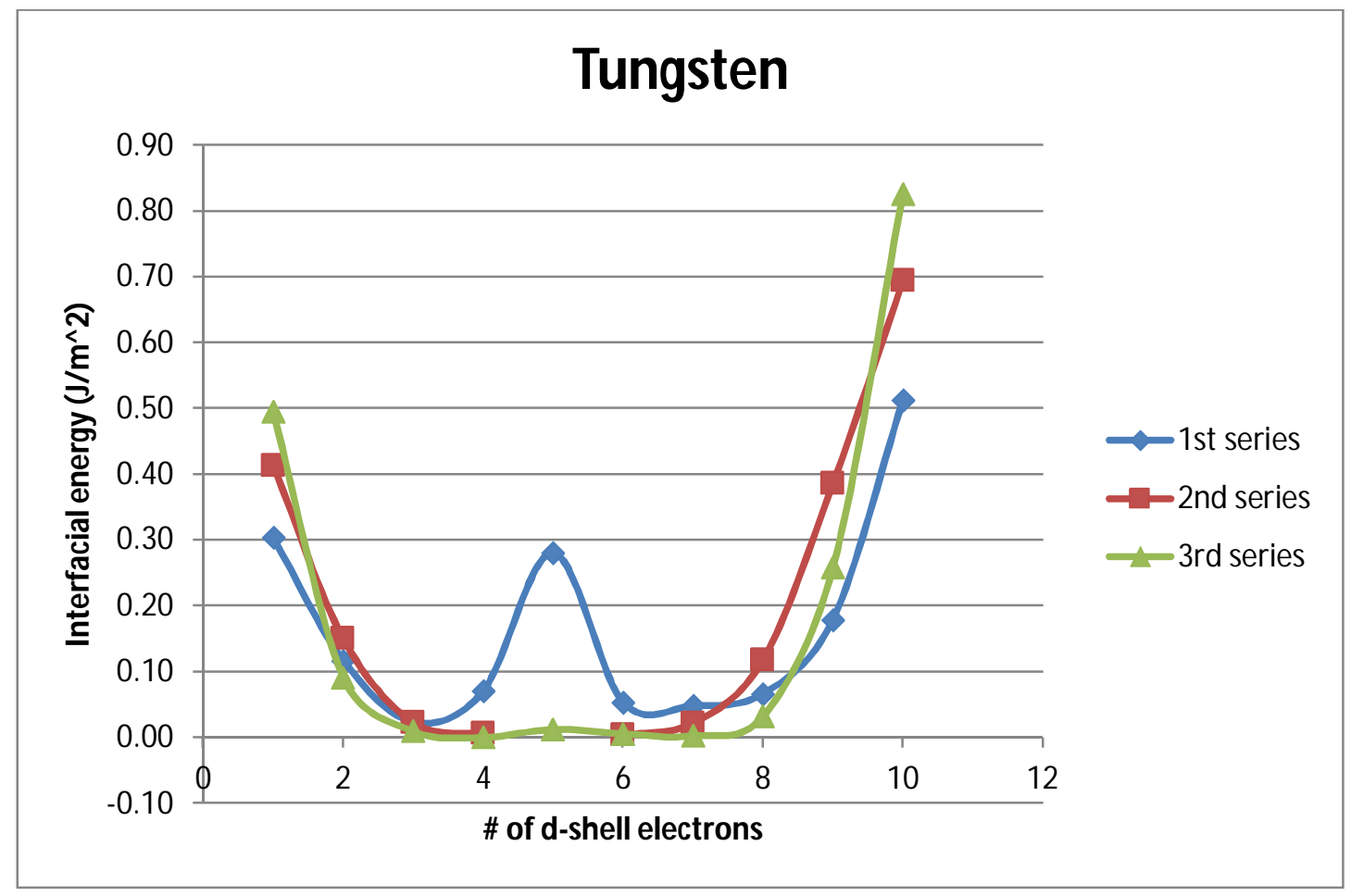

(c)

Figure 16: Graphs of molar volume model interfacial energies for (a) Chromium, (b) Molybdenum, and (c) Tungsten.

Because the interfacial energy is controlled by the difference in surface energies, the trends are somewhat similar to those predicted by the Physics model. This is because the cohesive and surface energies of metals are closely related and exhibit similar trends (Figure 17). Metals on the ends of the transition rows exhibit a parabolic relationship of interfacial energy; moving across a row, interfacial energy increases, reaches a maximum, then decreases, much like the individual surface energies. Metals in the middle of the transition rows, however, exhibit the opposite trend. This is expected according to Equation 8. 


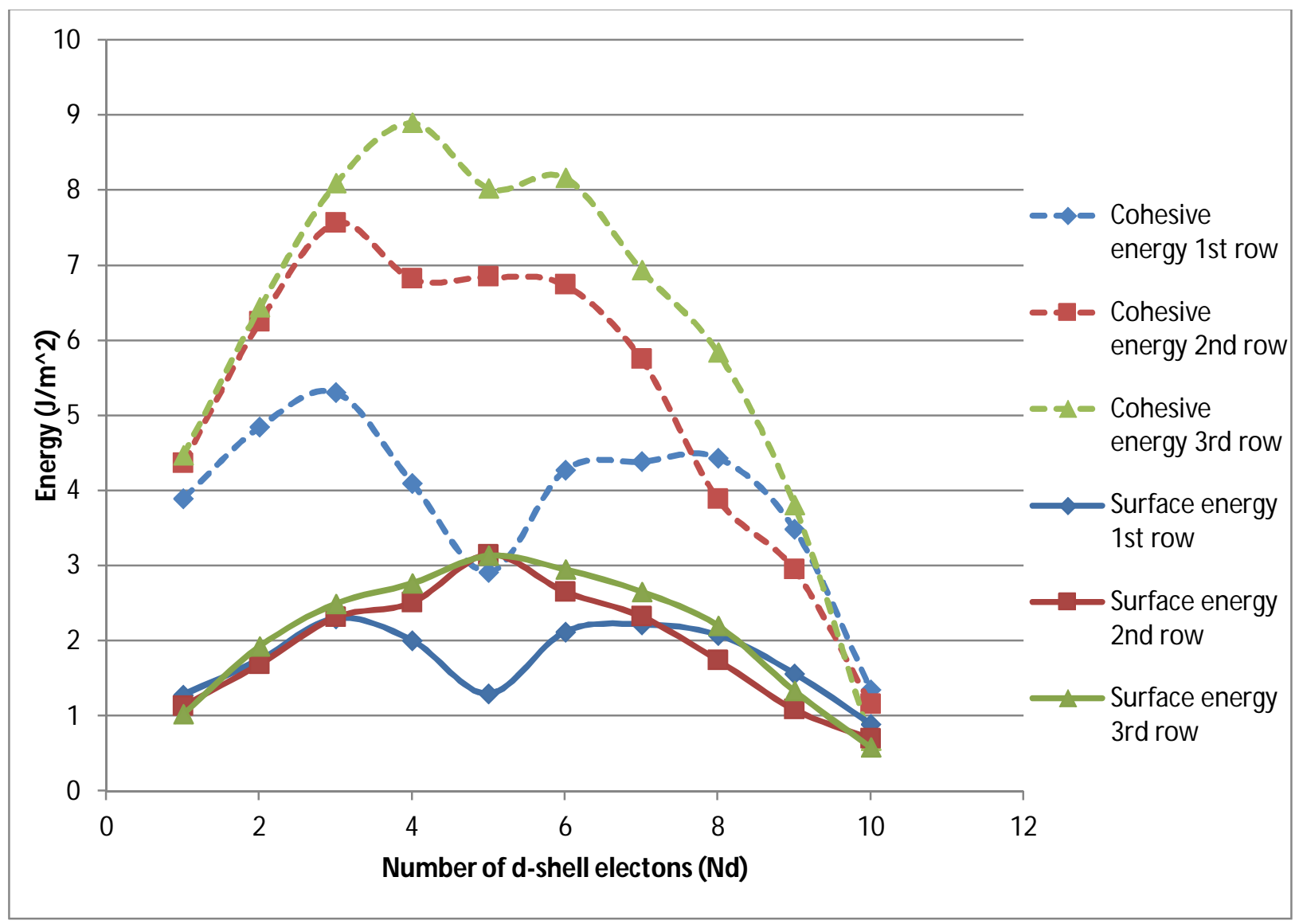

Figure 17: The cohesive and surface energies of the transition metals follow approximately the same trend.

\section{Cohesion Theory Model}

\section{Theory and Derivation}

A third model for predicting interfacial energy, called the Cohesion model, draws on the thermodynamics involved with alloy formation. The contributions to the enthalpy of alloy formation are identified and quantified and used to account for the enthalpy of formation of a solid-solid interface. The enthalpy of formation is simply the difference 
between the cohesive energies of alloys and their constituents in a metallic state. This model identifies two properties of metals that affect the enthalpy of alloy formation: the electron density at the boundary of the Wigner-Seitz cell, $\mathrm{n}_{\mathrm{ws}}$, and the chemical potential for electronic charge, $\varphi^{*}$. The latter has the same meaning as the work function $\varphi$, but is adjusted slightly to account for experimental uncertainty in measured values of $\varphi$. This model operates under the assumption that contact between two macroscopic pieces of metal can be modeled in the same way at the atomic scale. This assumption allows connections to be drawn between the atomic-scale interactions and macroscopic-scale enthalpies. This assumption is supported by the approximate proportionality between $\mathrm{n}_{\mathrm{ws}}$ and both $\gamma$, the surface energy of a solid metal and $\Delta \mathrm{H}^{\mathrm{vap}}$, the enthalpy of vaporization (de Boer, Boom, Mattens, Miedema, \& Niessen, 1988).

The derivation begins by considering the forces of attraction between two van der Waals substances. The interaction energy between these two substances is proportional to their polarizabilities. Because the surface energy of each substance is also proportional to their polarizabilities, the following expression can be written:

$$
\gamma_{A-B}^{\text {interface }}=\left[\sqrt{\gamma_{A}}-\sqrt{\gamma_{B}}\right]^{2}
$$

\section{Equation 12}

Where $\gamma_{\mathrm{AB}}, \gamma_{\mathrm{A}}$, and $\gamma_{\mathrm{B}}$ are the interfacial and surface energies, respectively. This is identical to Equation 11 seen in the Molar Volume model. If this result is applied on the atomic scale to a solid solution of $\mathrm{A}$ in $\mathrm{B}$, the enthalpy of vaporization per unit molar surface area $\Delta \mathrm{H}^{\mathrm{vap}} / \mathrm{V}^{2 / 3}$ can be used in place of interfacial energy. Next, the surface 
energies can be replaced by $\mathrm{n}_{\mathrm{ws}}$, since they are approximately proportional. This results in the following equation:

$$
\frac{\Delta H_{A-B}^{v d w}}{V_{A}^{2 / 3}}=Q\left[\left(n_{w s}^{1 / 2}\right)_{A}-\left(n_{w s}^{1 / 2}\right)_{B}\right]^{2}
$$

Where $\mathrm{Q}$ is a proportionality constant. For reasons that will become clear, it is useful to rewrite Equation 13 in the following form:

$$
\frac{\Delta H_{A-B}^{v d w}}{V_{A}^{2 / 3}}=Q^{\prime} \frac{\left[\left(n_{w s}^{1 / 3}\right)_{A}-\left(n_{w s}^{1 / 3}\right)_{B}\right]^{2}}{\left(n_{w s}^{-1 / 3}\right)_{A}+\left(n_{w s}^{-1 / 3}\right)_{B}}
$$

In addition to van der Waals interactions, an ionic contribution to interfacial energy must also be considered to account for the iconicity of metals. Similar to the theory presented in the Physics model, charge transfer will occur when metals of different chemical potential are brought into contact, creating a potential difference across the interface. This charge transfer also contributes to the enthalpy of alloy formation. Here, the modified work function $\varphi^{*}$ is used to quantify the chemical potential of each metal. This contribution is expressed by Equation 15:

$$
\Delta H_{A-B}^{\text {ionic }}=-P \frac{V_{A}^{2 / 3}}{\left(n_{w s}^{-1 / 3}\right)_{\text {avg }}}\left[\varphi_{A}^{*}-\varphi_{B}^{*}\right]^{2}
$$


Where $\mathrm{P}$ is an additional proportionality constant. When the ionic and van der Waals contributions to the interfacial enthalpy of formation are combined, the result is

\section{Equation 16:}

$$
\Delta H_{A-B}^{\text {interface }}=\frac{V_{A}^{2 / 3}}{\left(n_{w s}^{-1 / 3}\right)_{\text {avg }}}\left[-P\left(\Delta \varphi^{*}\right)^{2}+Q\left(\Delta n_{w s}^{1 / 3}\right)^{2}\right] \quad \text { Equation } 16
$$

Once the enthalpy of formation of the interface is known, it can be converted to interfacial energy by use of the following expression:

$$
\gamma_{\text {interface }}=\frac{\Delta H_{A-B}^{\text {interface }}}{c_{0} V_{A}^{2 / 3}}
$$

Where $\mathrm{c}_{0}$ is a proportionality constant with a value of $4.5 \times 10^{8}$. Because this term assumes an epitaxial interface, it will hereon be referred to as the Epitaxial term. Values for the variables on the right side of the equation are calculated and tabulated along with this model, allowing interfacial energy to be easily calculated. These results are shown graphically in Figure 18. 


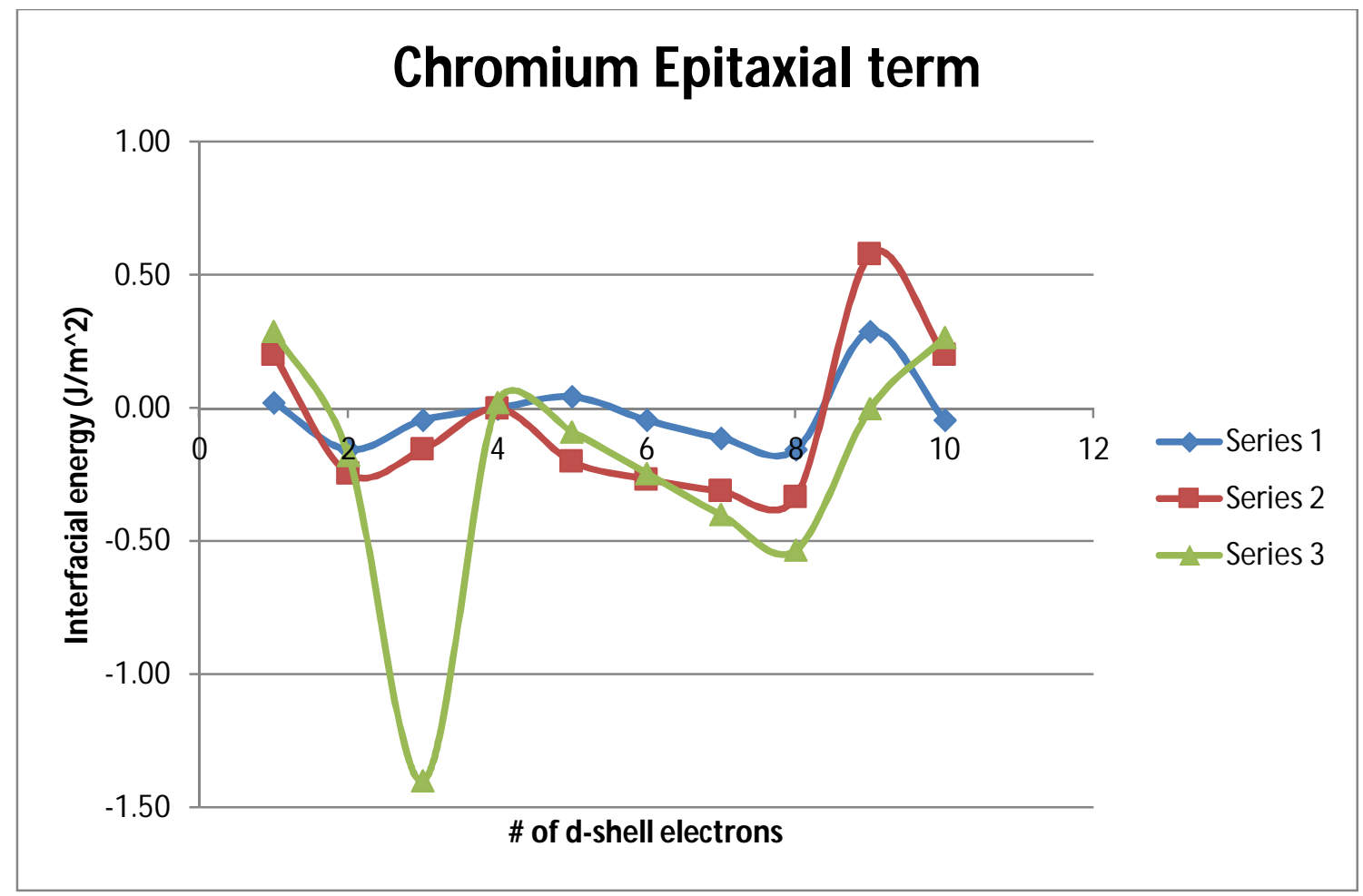

(a)

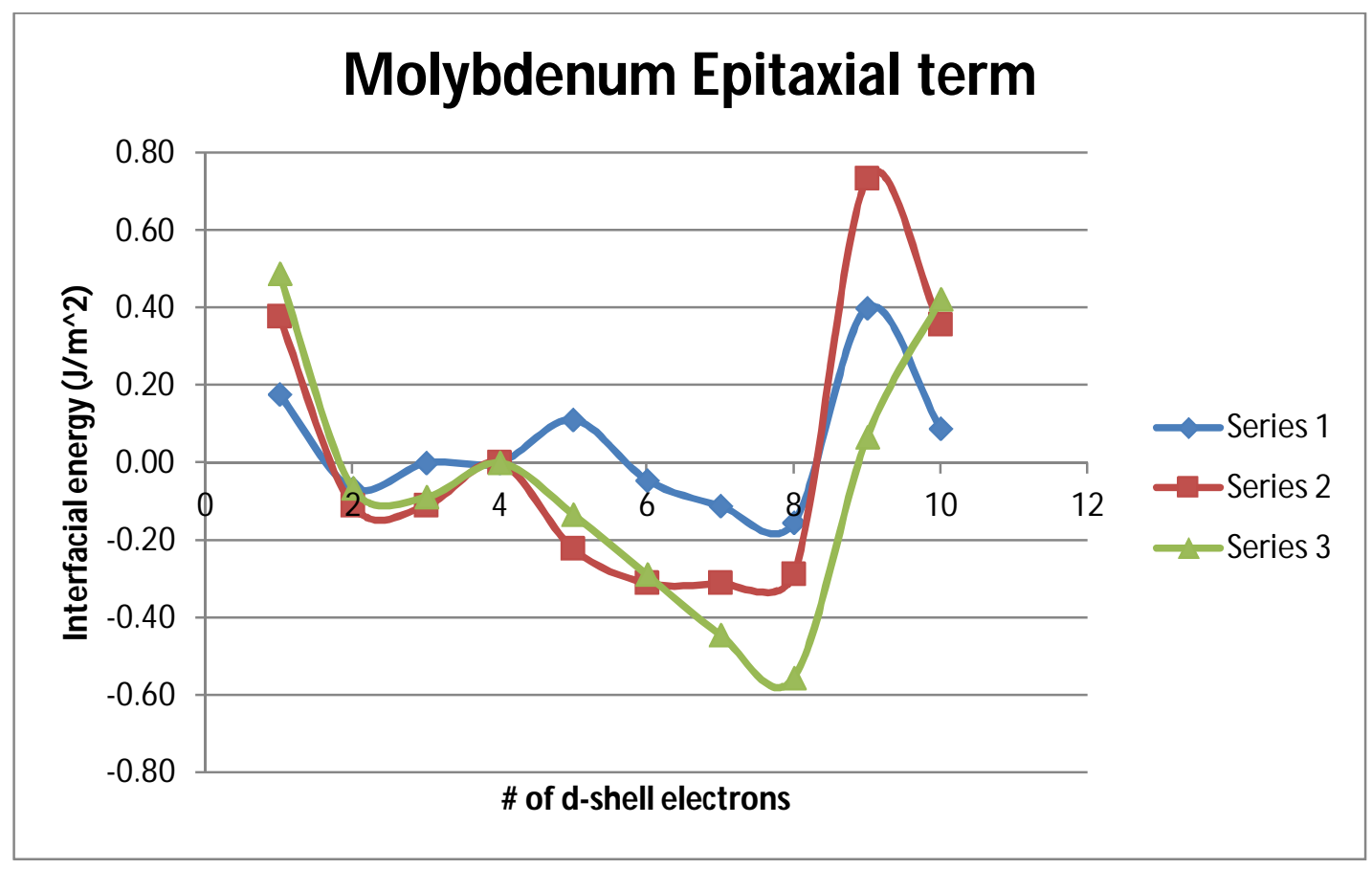

(b) 


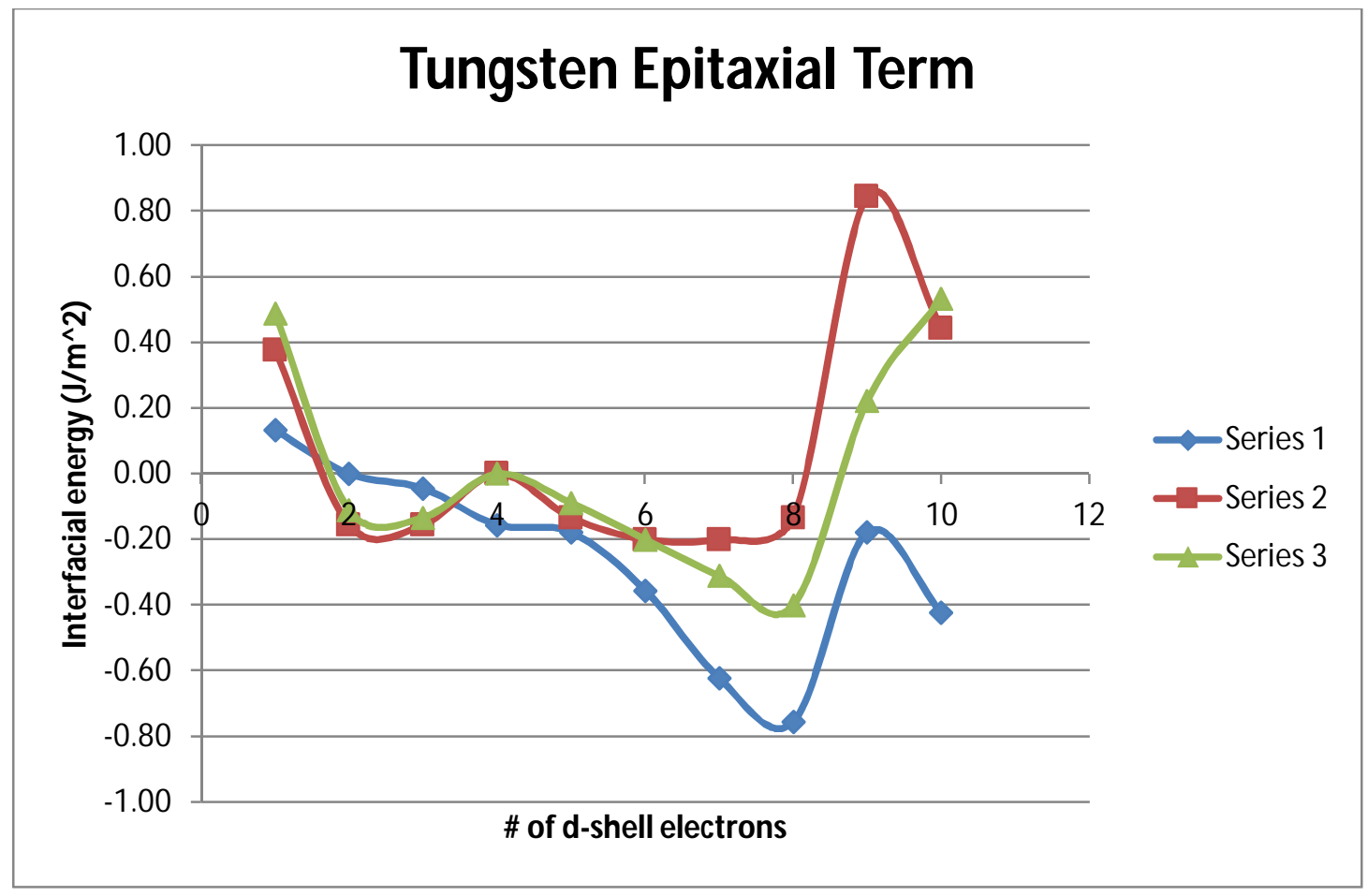

(c)

Figure 18: Epitaxial energy graphs for (a) Chromium, (b) Molybdenum, and (c) Tungsten. Assumptions and Additional Terms

As mentioned earlier, this model assumes a clean, epitaxial interface. Is does not include the contribution of elastic energies associated with solid solutions, such as lattice mismatch or differences in molar volume. The dislocation model of grain boundaries is used here to quantify the energy associated with lattice mismatch; it has been used successfully in the past to model the variation of boundary energy with crystal misorientation. In pure metals, the energy of mismatch resembles that of large-angle grain boundaries (Turnbull, 1955). Literature suggests that representative values of the energy of large-angle grain boundaries in pure metals are about one-third of their surface 
energy (Murr, 1975). If the average of the surface energies of the two constituents is used, the interfacial energy due to mismatch can be written as follows:

$$
\gamma_{A-B}^{\text {mismatch }}=0.15\left(\gamma_{A}+\gamma_{B}\right)
$$

Equation 18

Results for the mismatch contribution to interfacial energy are calculated using Equation 18 and are presented below:

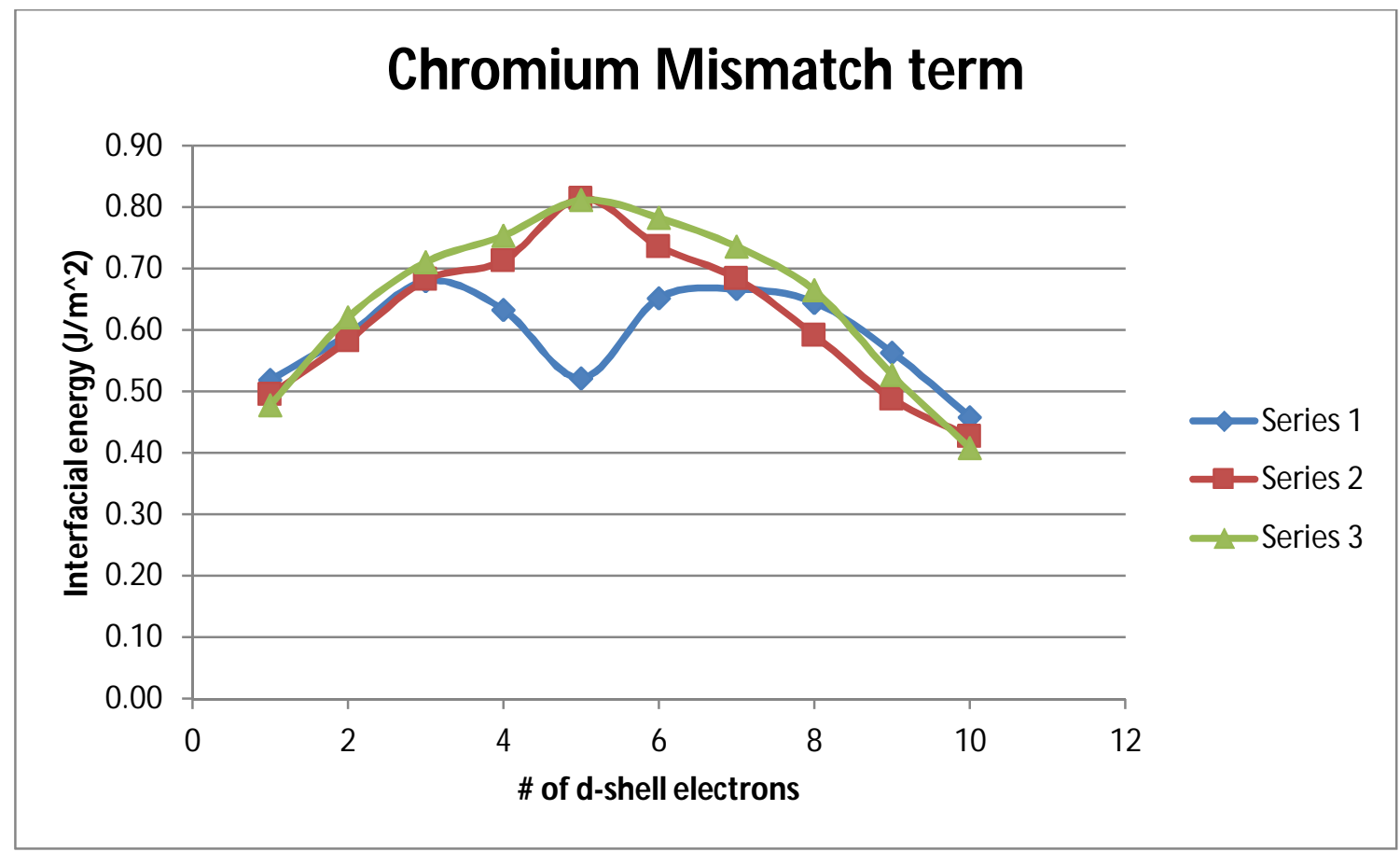

(a) 


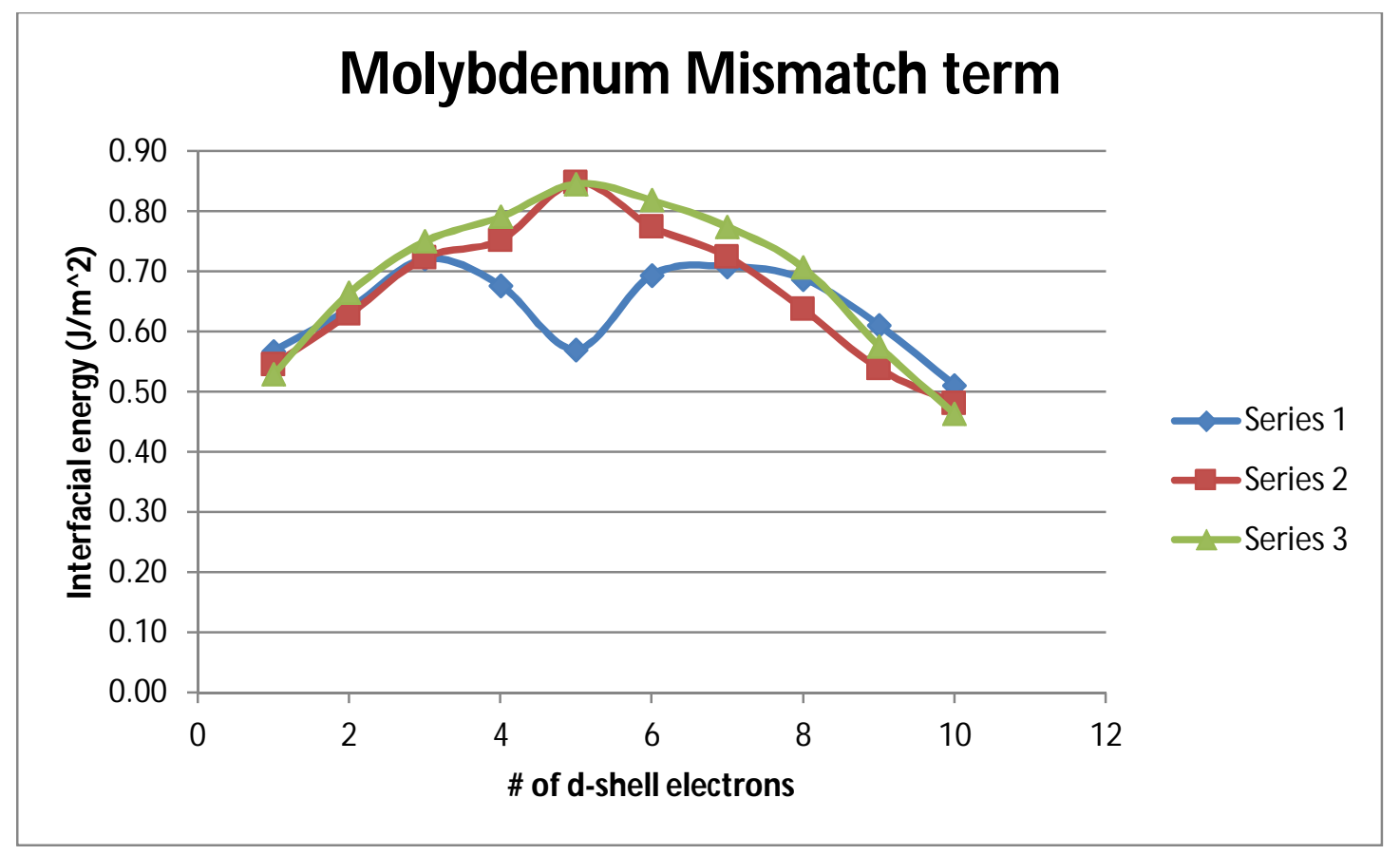

(b)

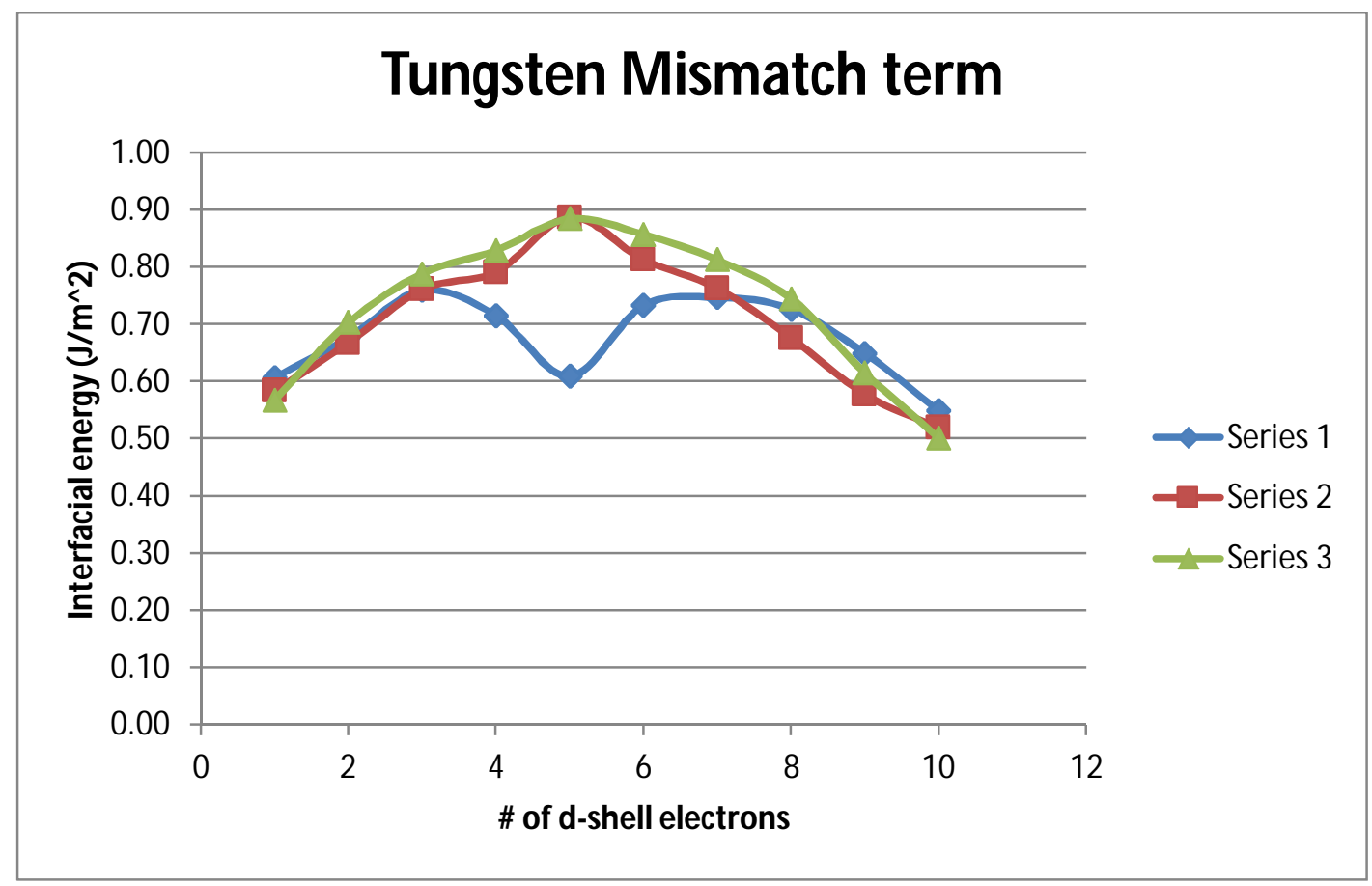

Figure 19: Mismatch energy graphs for (a) Chromium, (b) Molybdenum, and (c) Tungsten. 
Because the epitaxial and mismatch terms are essentially independent, they can be treated as additive contributions to the total interfacial energy of a system (Equation 19):

$$
\gamma_{A-B}^{\text {interface }}=0.15\left(\gamma_{A}+\gamma_{B}\right)+\frac{\Delta H_{A-B}^{\text {interface }}}{c_{0} V_{A}^{2 / 3}}
$$

Equation 19

The total energy is shown graphically in Figure 20:

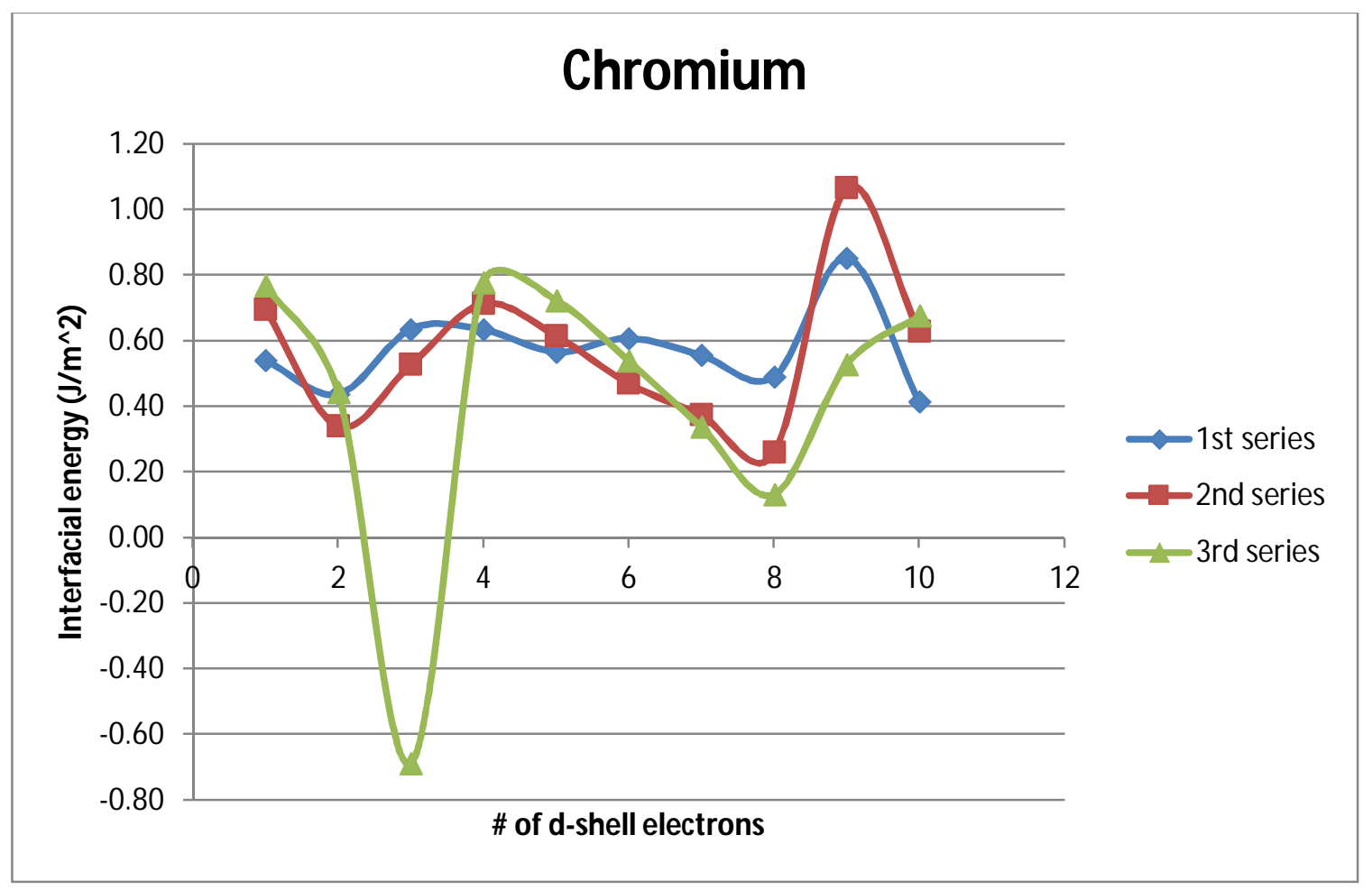

(a) 


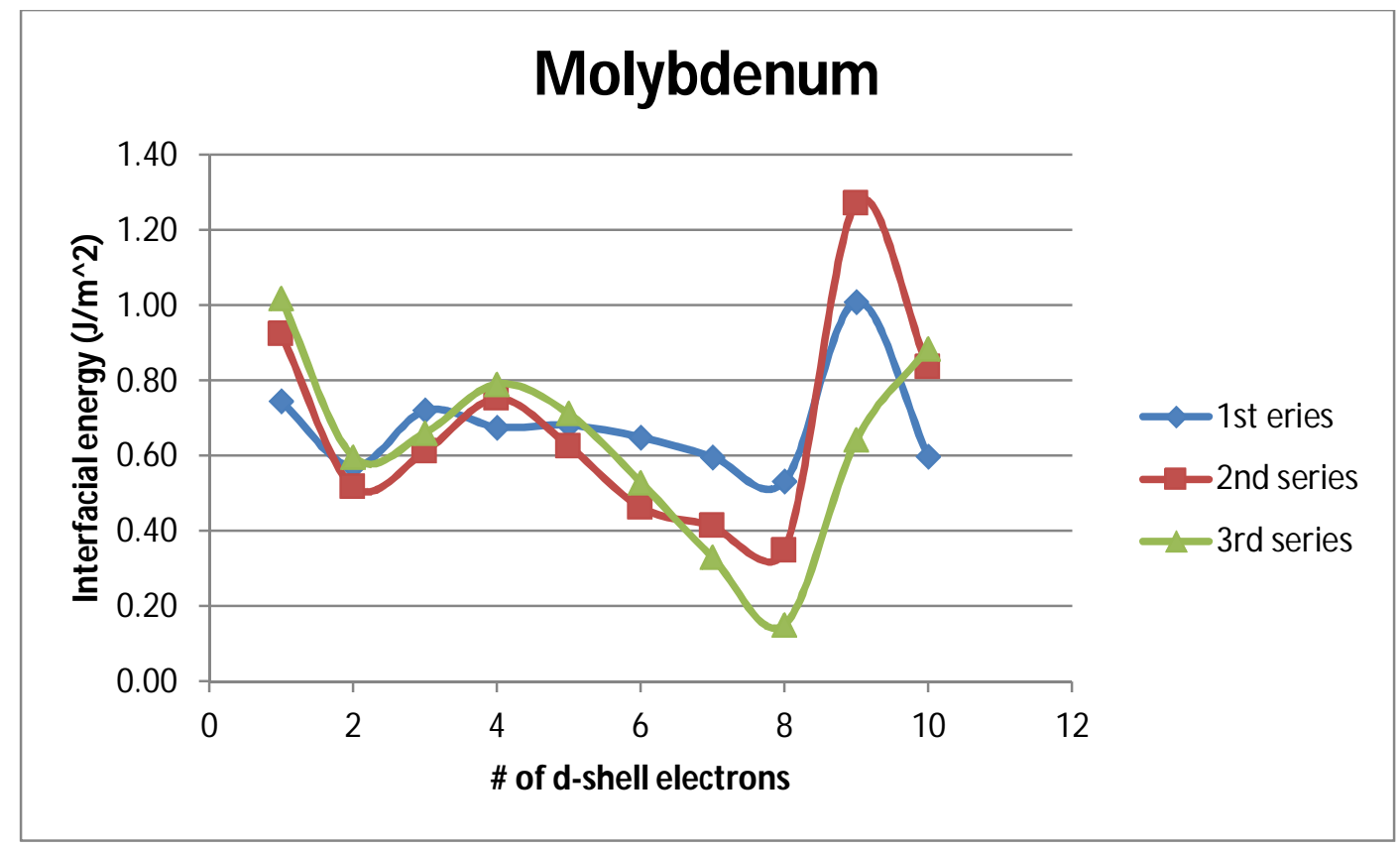

(b)

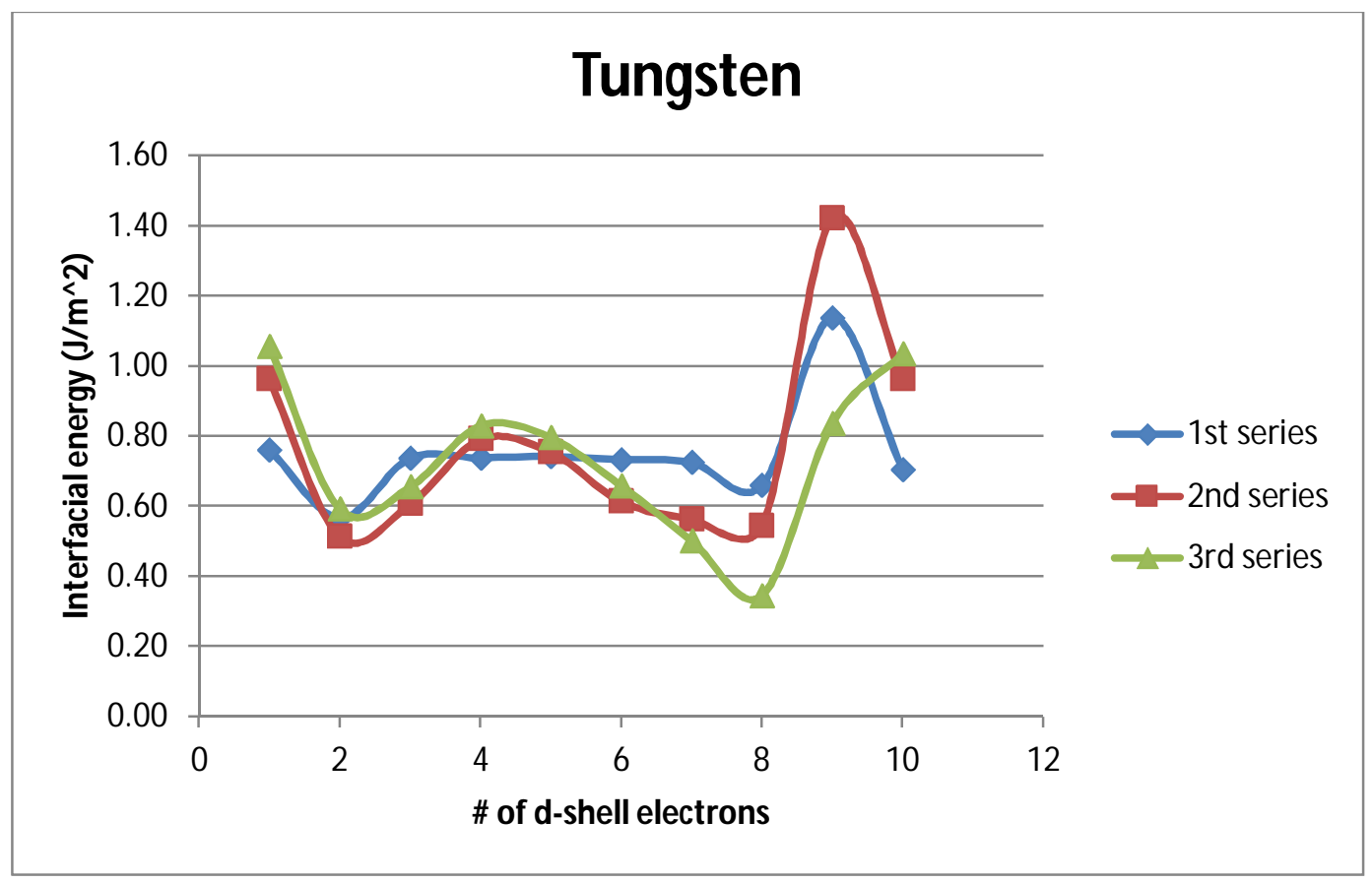

(c)

Figure 20: Graphs of total energy term for (a) Chromium, (b) Molybdenum, and (c) Tungsten. 


\section{Analysis of Variables and Trends}

The epitaxial and mismatch contributions are analyzed separately here. According to Equation 18, the mismatch energy is determined solely by the magnitude of the surface energies of the two constituents. It is not a difference term, as seen in other models. Clearly, then, the mismatch term follows a trend that is similar to that of the surface energy of metals (Figure 17). As surface energy increases, one expects the mismatch energy to increase as well. The epitaxial term is controlled by both $\Delta \mathrm{H}^{\text {interface }}$ and V. Molar volume does not vary much between these metals, so the dominant term is $\Delta H^{\text {interface }}$, the enthalpy of formation of the interface. Observation of the epitaxial term data reveals that each transition row seems to follow the same behavior moving across the row (Figure 18). In general, the trends for each metal resemble a cubic function, with a maximum and a minimum in between the two ends, which are all around zero. The relative position of the maximum and minimum appear to vary depending on the location of the metal within each transition row.

The value of $\Delta \mathrm{H}^{\text {interface }}$ is supposedly proportional to $\Delta \mathrm{n}_{\mathrm{ws}}{ }^{1 / 3}$. The difference in $\mathrm{n}_{\mathrm{ws}}$ represents the matching of electron densities at the interface and connects the physics of bonding with the thermodynamics presented in Equation 17. Values for $\mathrm{n}_{\mathrm{ws}}$ are not readily available, so direct analysis cannot be performed. However, inferences can be made based on what is known about the electronic structure of transition metals. If homogeneous bonding is considered neither favorable nor unfavorable, then the behavior exhibited by the epitaxial term suggests that certain alloy combinations are either less or 
more thermodynamically favorable. Some researchers hypothesize that metals can be classified as either hypoelectronic (electron acceptors) or hyperelectronic (electron donors) depending on their behavior during bonding (Czichos, 1972). This theory could explain the maxima and minima observed in the data. Because the behavior of $\Delta H^{\text {interface }}$ is consistent for all transition rows, one can infer that the relative favorability of bonding is due to the occupancy of the d-subshell. In general, it appears that bonds between metals that result in filled or unfilled d-subshells are more favorable and will have a lower, sometimes even less than zero, interfacial energy.

\section{Complete Model}

Analysis and comparison of the preceding three models reveals the complexity involved in the estimation of interfacial energy between two metals. On a fundamental level, though, there appears to be two contributions to interfacial energy: an electronic term, and a physical term. The electronic term, considered by the physics model and the Epitaxial term in the Cohesion Theory model, quantifies the effects of electronic structure on bonding. The physical term, considered by the Molar Volume model and the Mismatch term of the Cohesion Theory model, quantifies the thermodynamic effects of lattice mismatch and differences in molar volume. If it can be assumed that the electronic and physical contributions to interfacial energy are independent-an assumption made in the Cohesion Theory model (de Boer, Boom, Mattens, Miedema, \& Niessen, 1988)— then a "Complete" model can be formulated using the most appropriate model for each 
contribution. Comparison of the theory, derivation, and assumptions used in each model can help determine its applicability to a predictive model for KM coatings.

\section{Comparisons between Models}

\section{Physics Model versus Epitaxial Model}

Comparison of the Physics model and Epitaxial model reveals a similar dependence on electrochemical potential and free electron density. The physics model uses the work function, the Fermi level, the cohesive energy, and the relative variation of the density of states to quantify the effects of these parameters. The Epitaxial model uses the work function and electron density at the boundary of the Wigner-Seitz cell. The physics model is admittedly only semi-quantitative due to the assumptions made by the authors (Allan, Lannoo, \& Dobrzynski, 1974). Several additional approximations are needed to obtain useable output data from the model. Focusing on the model itself, it seems that the contribution of the electrochemical potential of the atom does not significantly factor into the interfacial energy. Instead, the cohesive energy is the dominant term in this model. The behavior of this model is also somewhat puzzling. It predicts an interfacial energy of near-zero for all same-row pairs of transition metals (Figure 13). Given the different electronic structure of these metals, one does not expect this to be so. In closer agreement with literature, the epitaxial term places significance on the electron density and the work function. These values are used to compute the enthalpy of formation of the interface, from which the interfacial energy can be calculated. This model uses a thermodynamic approach, but uses electronic properties of 
the metal in place of thermodynamic properties. The use of such properties is justified by the approximate proportionality between the electron density and surface energy (de Boer, Boom, Mattens, Miedema, \& Niessen, 1988). It is difficult to discern any trend in the data, but the observed behavior could perhaps be explained by the theory that metals can be classified as either hypo- or hyperelectronic. After considering the theoretical approach taken by each model, and the assumptions made in the process, it becomes evident that the epitaxial model better describes the electronic contribution to the interfacial energy.

\section{Molar Volume Model versus Mismatch Model}

The molar volume and mismatch models take different approaches to quantifying the physical contribution to the interfacial energy. The mismatch term of the Cohesion Theory model relates lattice mismatch at an interface to large-angle grain boundaries in pure metals, and then uses an estimation of grain boundary energy to quantify the mismatch energy (Turnbull, 1955; Murr, 1975). This term is dependent only on the magnitude of the surface energy of the two constituents (Equation 18). This model accounts for possible angular lattice misalignment at the interface, which is similar to that seen at grain boundaries. Despite the name, however, this model does not incorporate any "mismatch" in lattice parameter, molar volume, or surface energy between the two metals. Even for pairs of metals with similar sizes and surface energies, this model would still predict a non-zero value for interfacial energy (Figure 19). These results make one question the validity of the comparison between bimetallic interfaces and large-angle 
grain boundaries. The molar volume model, on the other hand, incorporates both differences in molar volume and surface energy into the expression for interfacial energy. This model is also more fully developed and more appropriate for this type of interface; it is derived by integrating the interaction energies between atoms across the separation distance (Girifalco \& Good, 1957). Pairs of metals with similar sizes and surface energies would have a near-zero interfacial energy, as one would expect (Figure 16). Given the theoretical basis and close agreement with expected results, it is clear that the Molar Volume model provides a better estimation of the physical contribution to interfacial energy.

\section{Analysis of Variables and Trends}

The resulting "Complete" model consists of the additive contributions of the Epitaxial model and the Molar Volume model, representing the electronic and physical contributions to interfacial energy, respectively. Interfacial energy values calculated using this model are presented below in Figure 21. The results are visually similar to those of the Cohesion theory model. This is because the magnitude of the epitaxial term is generally much larger than that of the Molar Volume term, suggesting that the electronic contribution to interfacial energy is more significant than the physical contribution. The values for interfacial energy vary from around -8 to $5 \mathrm{~J} / \mathrm{m}^{2}$, resulting in Work of Adhesion values that range from about 2 to $10 \mathrm{~J} / \mathrm{m}^{2}$. The sign of the interfacial energy term describes the thermodynamic favorability for the interfacial bond compared to a homogeneous bond; a negative term means the particular bimetallic bond is more 
favorable, and a positive term means it is less favorable. These results indicate that large Work of Adhesion values can be obtained by specific pairs of metals. According to literature, then, high interfacial toughness can be achieved by careful materials selection. The task is now to correlate interfacial energy and work of adhesion values with experimental results, and to determine how manipulation of the terms in the complete model affects interfacial toughness.

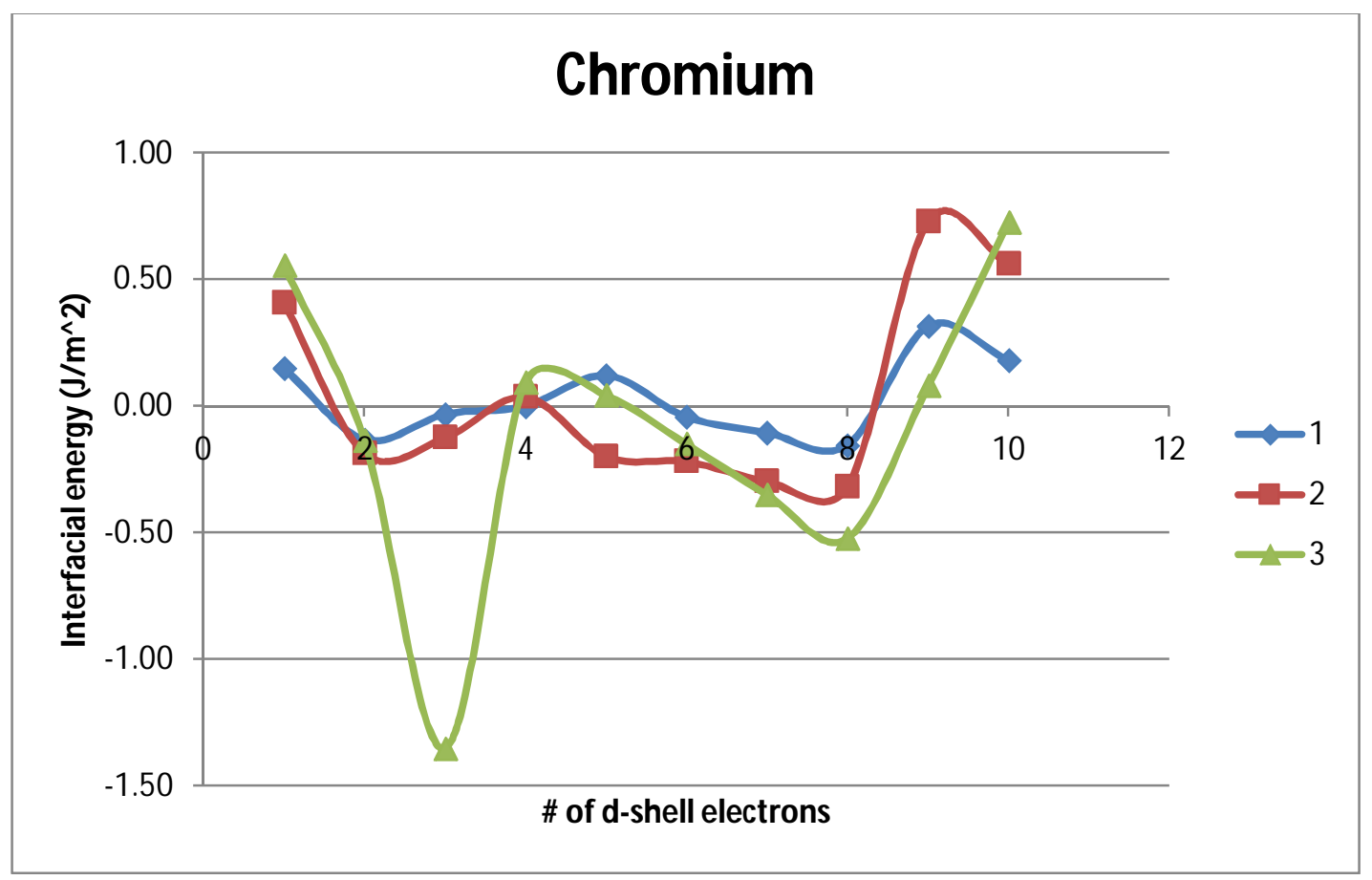

(a) 


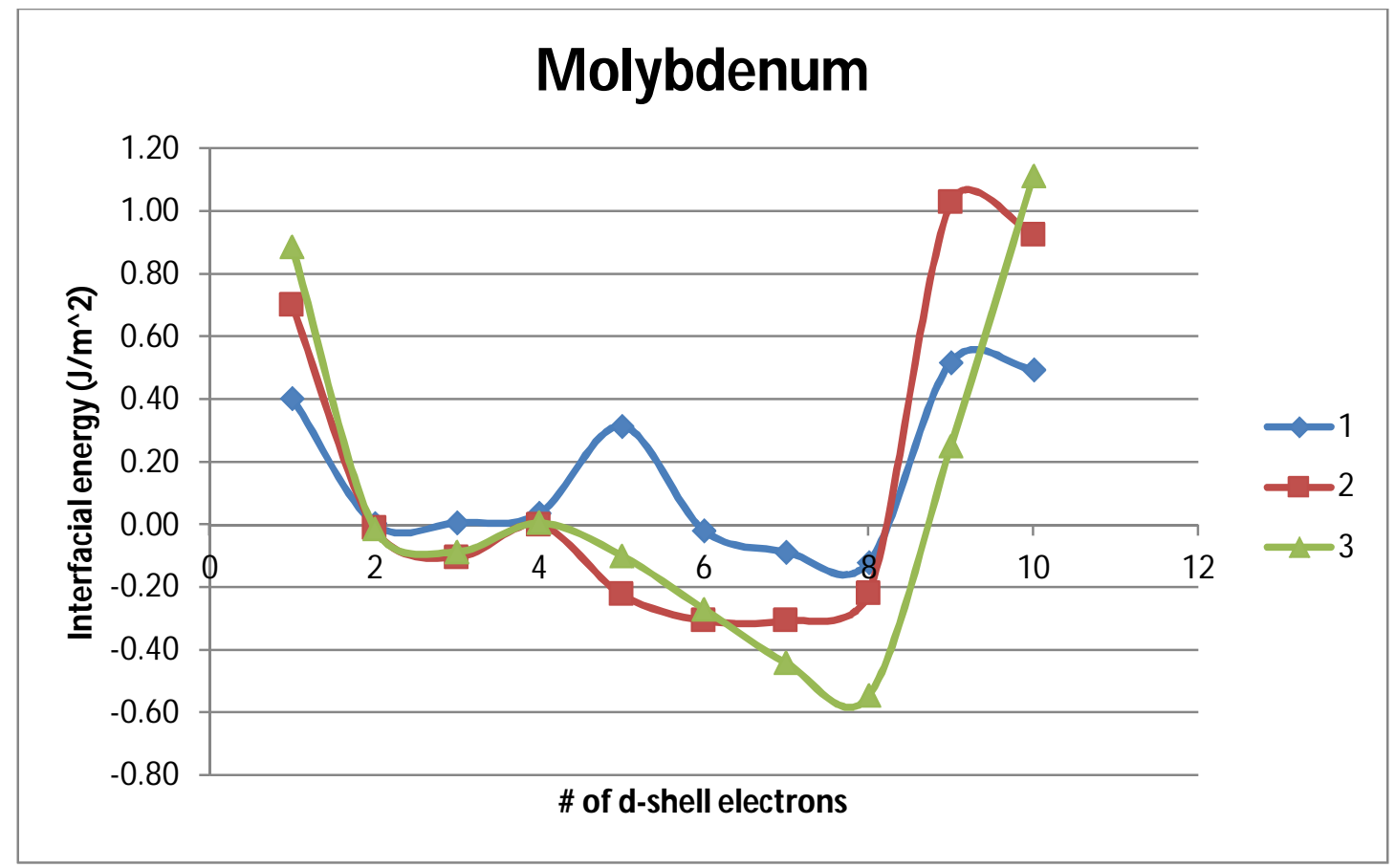

(b)

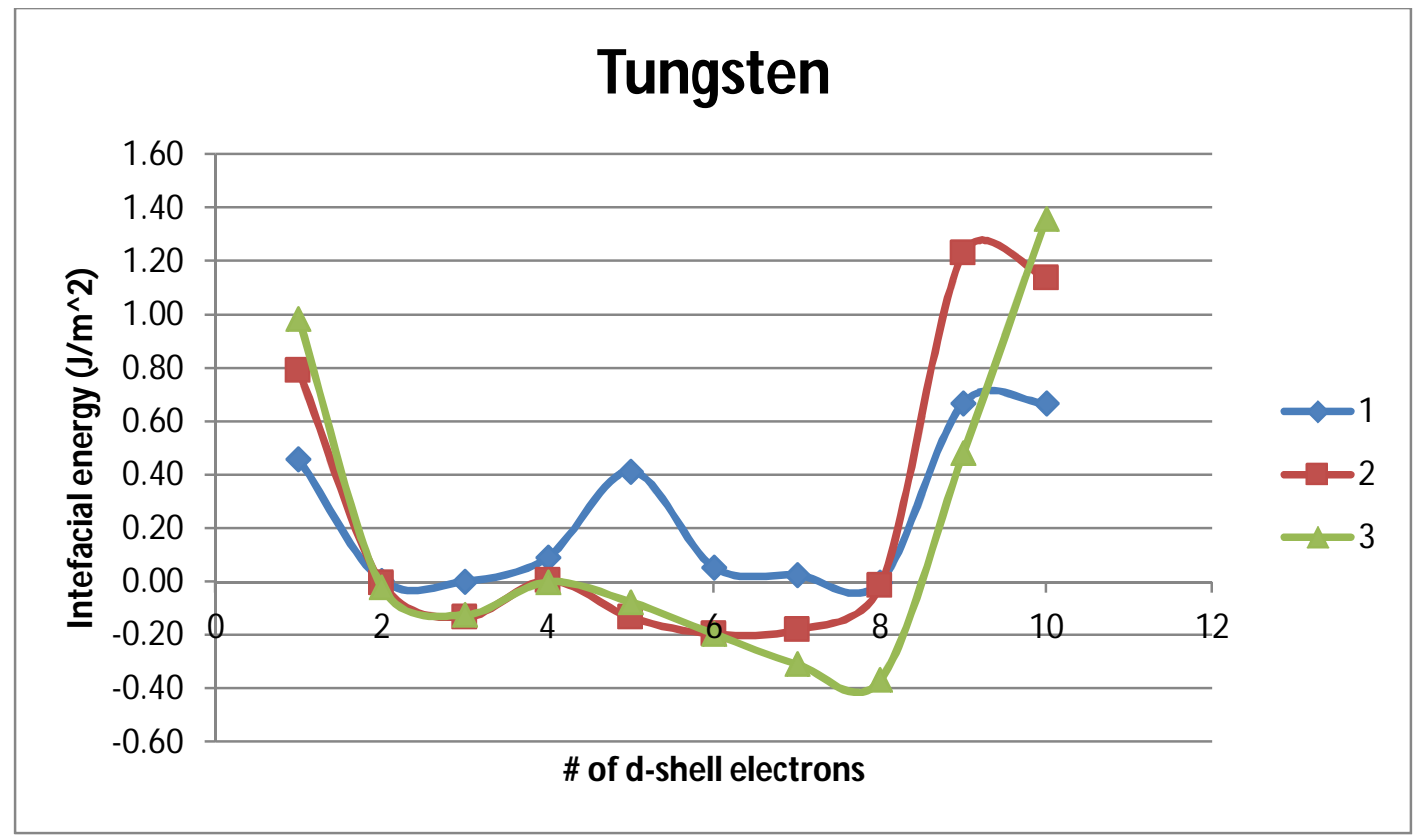

(c)

Figure 21: Complete model interfacial energies for (a) Chromium, (b) Molybdenum, and (c) Tungsten. 


\section{EXPERIMENTAL PROCEDURE}

\section{Test Method}

The theoretically calculated values for interfacial energy and work of adhesion are compared with experimentally measured values of interfacial toughness. As discussed previously, two quantitative indicators of the toughness of an interface are the critical strain energy release rate, $\mathrm{G}_{\mathrm{C}}$, and interfacial fracture toughness, $\mathrm{Kc}$. To measure these quantities, a modified Four-Point Bend Test procedure is followed. This method is based on ASTM D 6272: Standard Test Method for Flexural Properties of Unreinforced and Reinforced Plastics and Electrical Insulating Materials by Four-Point Bending (ASTM International, 2010). This test method is useful for analysis of stiff, brittle materials that are highly susceptible to flaws. It can be used to measure the flexural properties of homogeneous materials, but can also be used to determine the interfacial properties of KM coating systems. The general Four-point bending set-up is shown below in Figure 22. With this set-up, a uniform bending moment is exerted on the sample along the entire length of the support span. This makes Four-point bending less susceptible to inaccurate results due to premature failure caused by flaws in the test specimen. 


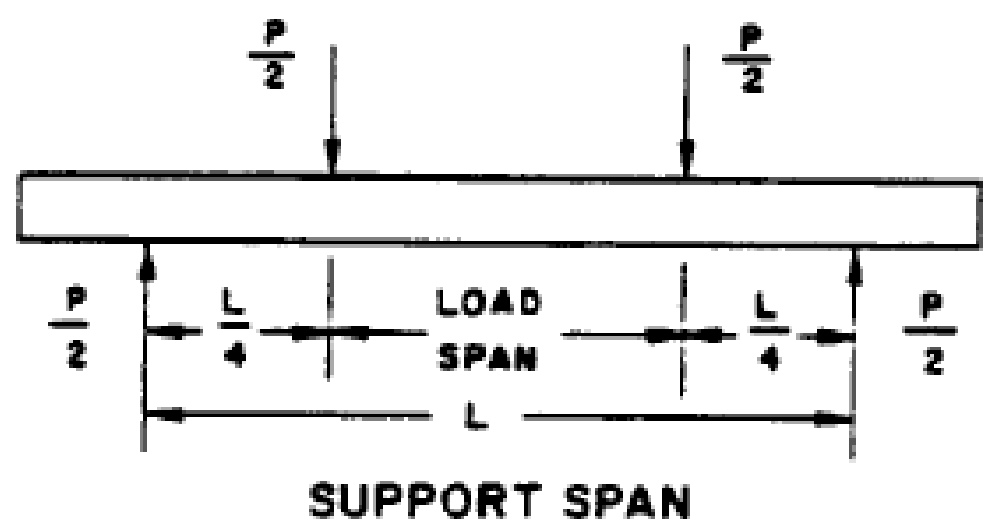

Figure 22: A typical four-point bend test fixture using a load span-support span ratio of 1:2 (ASTM International, 2010).

The ASTM standard test method is modified slightly to account for the heterogeneous nature of the KM test specimens. The goal of these experiments is to measure the properties of the interface, not those of the coating or the substrate. To ensure that interfacial failure occurs before bulk failure of either the coating or substrate, a notch is introduced in the coating at the midpoint of the test specimen (Figure 23). The notch introduces a flaw significantly larger than what is otherwise present in the specimen; this makes the failure location highly predictable and makes the failure process more controllable (Klingbeil \& Beuth, 1997; Katipelli, Agarwal, \& Dahotre, 2000). During loading, a crack initiates at this notch and propagates vertically down until it reaches the interface. At this point, the load is effectively transferred to the interface. At a critical load, coating delamination will occur. The measured critical load is then used to calculate the interfacial properties of the coating system. 


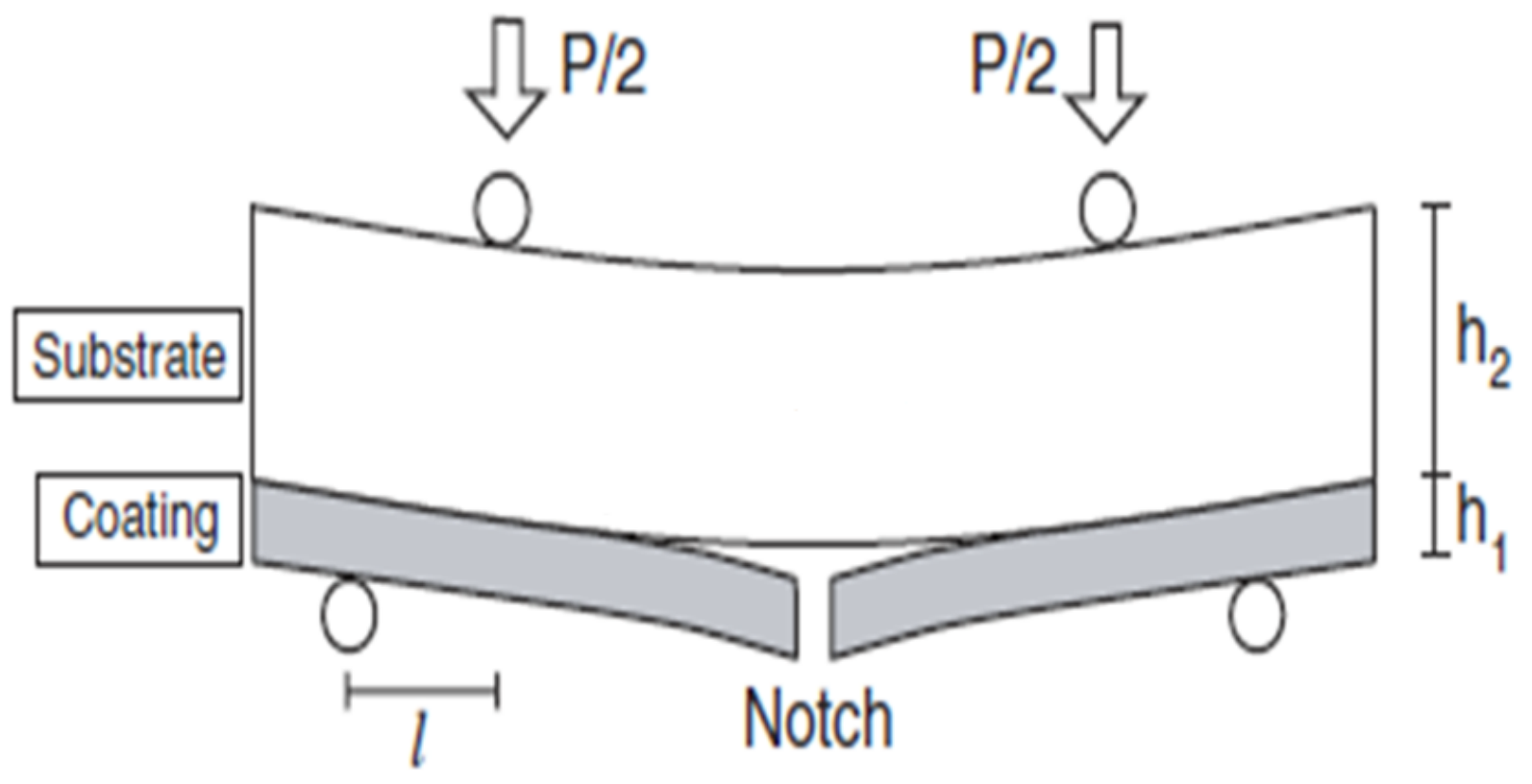

Figure 23: Modified Four-point Bend test specimen (Watanabe, Owada, Kuroda, \& Gotoh, 2006).

\section{Theory}

\section{Four-point Bending}

The modified Four-point bending test procedure operates under the assumptions made in Linear Elastic Fracture Mechanics (LEFM). The basic principle is that of an energy balance between the elastic energy stored during flexure and the energy released during coating delamination. Interfacial crack propagation occurs when the strain energy release rate $G_{S S}$ equals the critical strain energy release rate $G_{C}$ of the interface. Because there is a constant moment within the load span, and $\mathrm{G}_{\mathrm{sS}}$ is independent of crack length, $\mathrm{G}_{\text {ss }}$ can be easily determined. Once a critical load $\mathrm{P}_{\text {crit }}$ is reached, stead-state crack propagation will occur at the interface. The load remains constant as crack propagation 
proceeds. Gss is calculated by considering the difference in the moments of inertia between the cracked and un-cracked test specimen (Klingbeil \& Beuth, 1997).

$$
G_{S S}=\frac{P_{c r i t}^{2} l^{2}\left(1-v_{2}^{2}\right)}{8 b^{2} E_{2}} \cdot\left(\frac{1}{I_{2}}-\frac{\lambda}{I_{C}}\right)
$$

Equation 20

$$
\lambda=\frac{E_{2}\left(1-v_{2}^{2}\right)}{E_{1}\left(1-v_{1}^{2}\right)}
$$

Equation 21

Where $v_{1}, v_{2}, E_{1}$, and $E_{2}$ are the Poisson's ratios and Elastic moduli of the coating and substrate respectively, $\mathrm{P}_{\text {crit }}$ is the critical load at which delamination occurs, 1 is the length of the load span, $b$ is the width of the sample, $I_{2}$ is the moment of inertia of the specimen below the interfacial crack (essentially, the moment of inertia of the substrate), and $I_{C}$ is the moment of inertia of the entire specimen. $\mathrm{I}_{2}$ and $\mathrm{I}_{\mathrm{C}}$ are given by Equation 22 and

\section{Equation 23:}

$$
I_{2}=\frac{h_{2}^{3}}{12}
$$

Equation 22 


$$
I_{C}=\frac{h_{1}^{3}}{12}+\frac{\lambda h_{2}^{3}}{12}+\frac{\lambda h_{1} h_{2}\left(h_{1+} h_{2}\right)^{2}}{4\left(h_{1}+\lambda h_{2}\right)}
$$

Equation 23

Where $h_{1}$ and $h_{2}$ are the thickness of the coating and the substrate, respectively

(Watanabe, Owada, Kuroda, \& Gotoh, 2006). The critical stress intensity factor $\mathrm{K}_{\mathrm{C}}$ associated with the crack tip can also be determined from this test method. $\mathrm{K}_{\mathrm{C}}$ is related to $G_{C}$ by the following equations:

$$
\begin{gathered}
G_{C}=\frac{1}{16 \cosh ^{2}(\pi \epsilon)}\left(\frac{\chi_{1}+1}{\mu_{1}}+\frac{\chi_{2}+1}{\mu_{2}}\right) K_{C}^{2} \\
\varepsilon=\frac{1}{2 \pi} \ln \left[\frac{1-\beta}{1+\beta}\right] \\
\beta=\frac{1}{2} \frac{\mu_{2}\left(1-2 v_{1}\right)-\mu_{1}\left(1-2 v_{2}\right)}{\mu_{2}\left(1-v_{1}\right)+\mu_{1}\left(1-v_{2}\right)} \\
\chi_{i}=3-4 v_{i}
\end{gathered}
$$$$
\text { Equation } 24
$$

Equation 25

Equation 26

Where $\mu_{1}$ and $\mu_{2}$ are the shear moduli of the coating and substrate, respectively, $\varepsilon$ is a bimaterial constant and represents the elastic property mismatch between the two 
materials, and $\beta$ in a Dunders' Parameter (Schmauder \& Meyer, 1992). The previous equations are valid under plane strain conditions; here, plane strain conditions are assumed due to the fixed ends of the test specimen (Katipelli, Agarwal, \& Dahotre, 2000). It should be noted that these equations and the resulting values of $\mathrm{G}_{C}$ and $\mathrm{K}_{\mathrm{C}}$ are dependent on the phase angle of loading $\psi$. All reported values are in reference to the specified loading conditions. For four-point bending conditions, $\psi$ is approximately $45^{\circ}$ (Klingbeil \& Beuth, 1997). Although $\mathrm{K}_{\mathrm{C}}$ is a more widely used measure of toughness, this study will focus on $G_{C}$ because it is more directly related to the fracture mechanics involved with the test method and is more amenable to comparison with $\mathrm{W}_{\mathrm{AD}}$.

\section{Determination of $\mathbf{P}_{\text {crit }}$}

Under ideal conditions, $\mathrm{P}_{\text {crit }}$ is easy to identify. Consider the ideal loading scenario illustrated in Figure 24. For simplicity, assume that there is no plastic deformation of the test specimen; loading occurs completely within the elastic region. As the test fixture moves, the load on the specimen increases linearly. If one assumes that coating failure occurs instantaneously at $\mathrm{P}_{\text {crit }}$ via a vertical crack that propagates to the interface, and that the resulting load drop is negligible, then there will be a sharp transition in the load response of the specimen, as seen in Figure 24. Further movement of the test fixture will drive delamination, but will not result in an increase in load on the test specimen. 


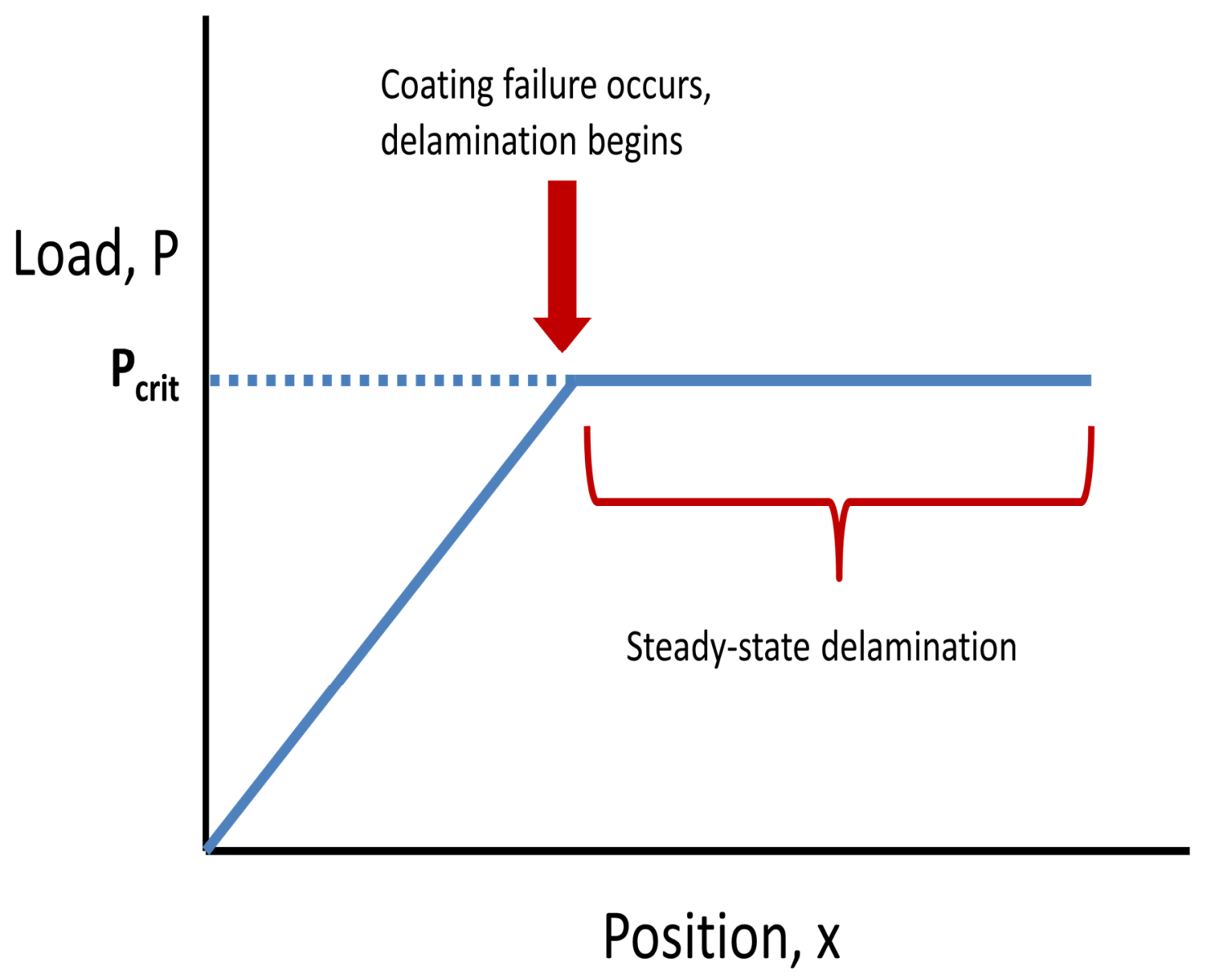

Figure 24: The load response of an ideal four point bending specimen. Under these conditions, $\mathbf{P}_{\text {crit }}$ is easy to determine.

The principles of the Gss calculation can be understood by further examining the energy balance associated with the test method. As the specimen is loaded, energy is stored in the form of elastic strain energy in the coating and substrate according to Equation 28: 


$$
U=\frac{M^{2} l}{2 E I^{2}}
$$

Equation 28

Where $\mathrm{U}$ is the elastic strain energy and $\mathrm{M}$ is the applied moment, which is proportional to the applied load. As $M$ increases, $U$ also increases. At $P_{\text {crit, }}$ the coating failure occurs and the specimen cracks, resulting in a reduction in I, the moment of inertia. The cracked specimen cannot store the elastic energy of the un-cracked specimen. The extra strain energy is released as the coating delaminates from the substrate. This extra energy is $\mathrm{G}_{\mathrm{C}}$, the critical strain energy release rate, and is equal to the difference in the stored elastic energy of the cracked and un-cracked specimens at $\mathrm{P}_{\text {crit }}$ (Figure 25). 


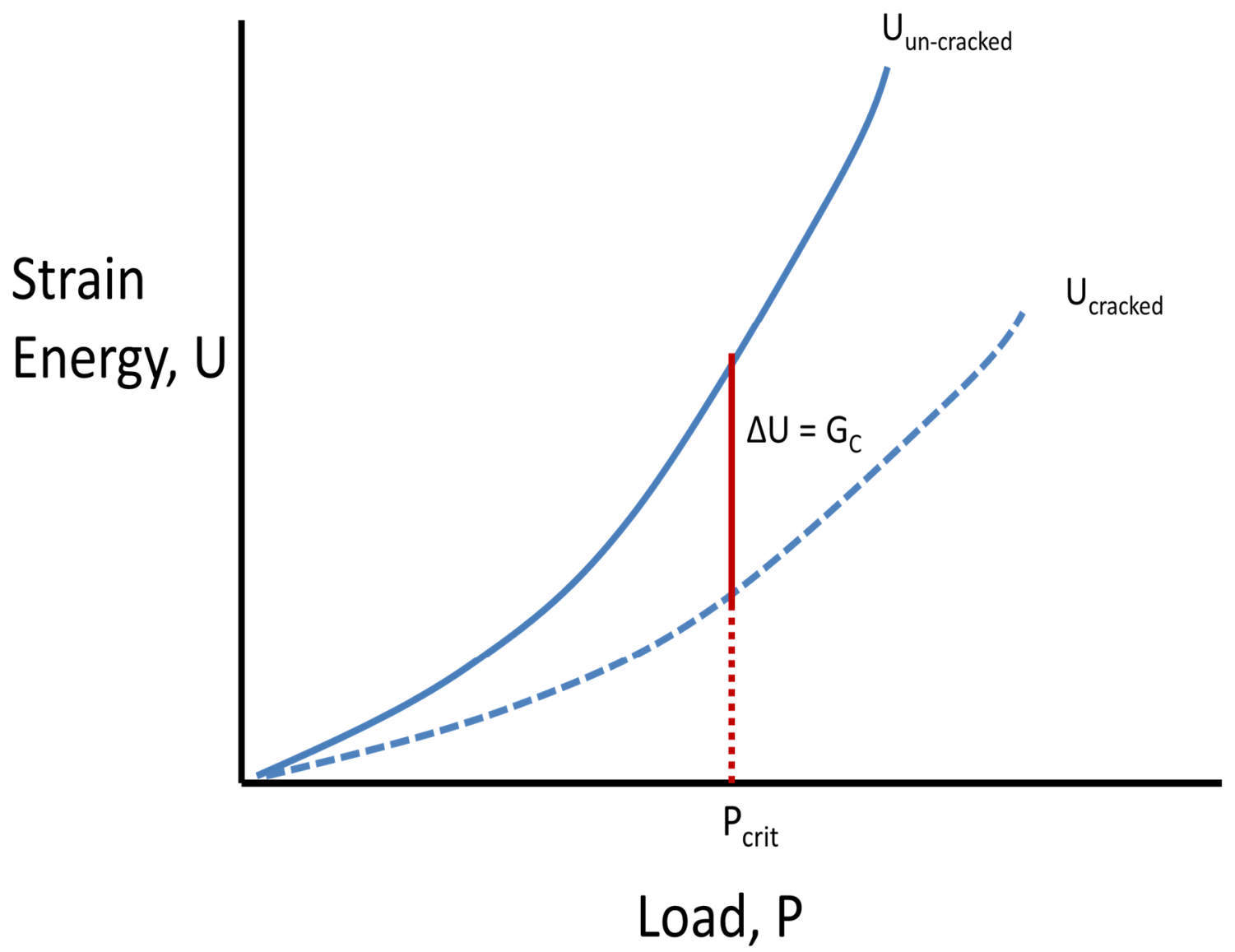

Figure 25: $G_{C}$ is calculated by considering the difference in stored strain energy between the cracked and un-cracked specimen at the critical load when delamination begins.

Clearly, accurate calculation of $\mathrm{G}_{\mathrm{ss}}$ requires a reliable method of determining $\mathrm{P}_{\text {crit. }}$

Unfortunately, preliminary testing suggests that plastic deformation does in fact occur, making it more difficult to identify the critical load. Further, the transition from elastic loading to delamination is not instantaneous, since it takes a finite amount of time for the crack to propagate through the coating to the interface. Preliminary tests yielded the following loading behavior: 


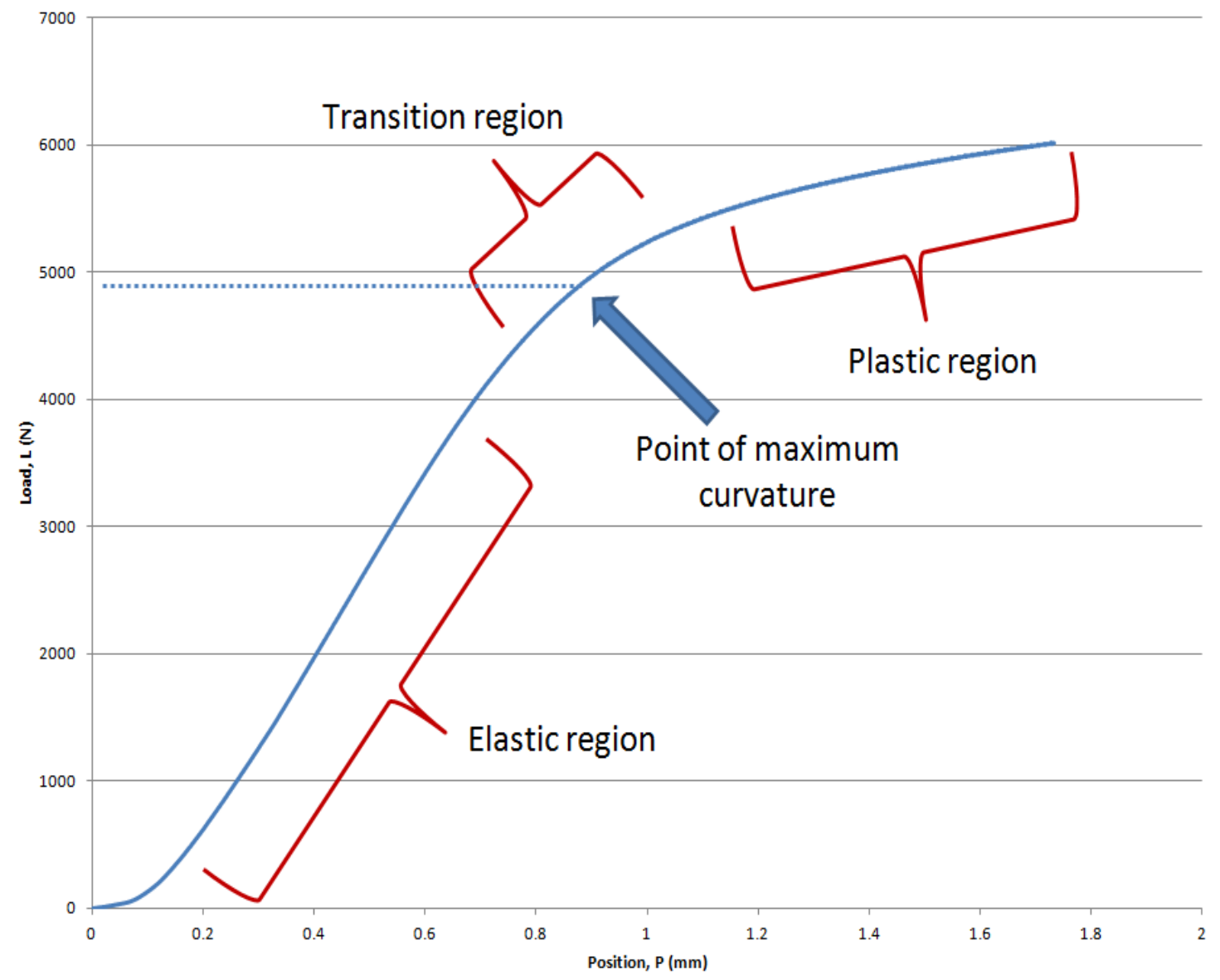

Figure 26: Preliminary testing resulted in loading behavior that deviated from the ideal, with three distinct load response regions.

Examination of the test data reveals three distinct load response behaviors: an initial linear elastic region, and a subsequent plastic region, with a transitional region between the two. As suspected, there is a gradual transition from the elastic to the plastic region. Comparison with the ideal loading scenario of Figure 24 suggests that coating delamination begins within this transition region. Unlike the ideal scenario, however, the load at which delamination occurs is not constant. The critical load is not easily identifiable. This is due to the energy absorbed by the substrate during plastic 
deformation, which necessitates an increase in load for delamination to continue. One way to estimate $\mathrm{P}_{\text {crit }}$ is to determine the load at which the curvature of the Load vs. Position plot reaches a maximum. The maximum curvature occurs where the second derivative of the plot reaches a minimum. Physically, this represents the middle of the transition region - the load at which the behavior of the specimen is changing most quickly. The point of maximum curvature is used to determine $\mathrm{P}_{\text {crit }}$ for all four-point bend tests.

\section{Materials}

The materials used for these tests were chosen such that they would provide a wide range of theoretical work of adhesion values so that correlation with experimental results could be performed. However, the choices of materials were limited by the capabilities of the predictive models, the availability of the materials, the funding available for this project, and the limitations of the KM deposition process. The final material choices are presented in Table 2 below. The use of low-carbon steel in place of pure Iron is necessary due to the reactive nature of pure Iron. In any case, the purity of the steel is on par with those of the other coating and substrate materials. It was mentioned earlier that the theoretical calculations assumed perfectly pure compositions, as any impurities could segregate to the interface and modify the work of adhesion according to the Gibbs adsorption isotherm (Equation 2). Studies have shown that alloying additions of as little as 1 at $\%$ can lead to significant changes in interfacial energy, but only if the alloying element is allowed to segregate to the interface (Wang \& 
Wynblatt, 1998; Gangopadhyay \& Wynblatt, 1994). Since these specimens are not subjected to appreciably high temperatures, no significant interfacial segregation can occur. Thus it is reasonable to assume that the modification of the work of adhesion due to impurities is minimal.

Table 2: Materials used for KM four-point bend specimens

\begin{tabular}{|c|c|c|}
\hline Constituent & Composition & Purity \\
\hline Coating & Nickel & $99.8 \%$ \\
\hline \multirow{3}{*}{ Substrate } & Copper & $99.9 \%$ \\
\cline { 2 - 3 } & Titanium & $98.9 \%$ \\
\cline { 2 - 3 } & Low-Carbon Steel & $99 \%$ \\
\hline
\end{tabular}

\section{Sample Preparation}

\section{KM Specimens}

Raw substrate specimens were received in 1 " by $1 / 8$ " bar form and cut to a length of approximately 4" using an abrasive cut-off saw. All sharp edges were ground down and burrs were removed by grinding. The side to be coated was then polished with an abrasive cloth and cleaned with methanol to remove surface contaminants. The nickel coating material was received in powder form, ready for KM deposition. The Inovati KM Production Coating System (PCS) was used to deposit the nickel coating onto the substrates (Figure 27). Thin coatings were produced in an attempt to minimize the effects of residual stresses. One run was performed on three specimens each of the copper, titanium, and steel substrates. Coating deposition was performed at an operating temperature of $920^{\circ} \mathrm{F}\left(493^{\circ} \mathrm{C}\right)$ and pressure of $90 \mathrm{psi}$. The powder feed rate and nozzle 
raster speed were controlled to produce a coating thickness of approximately 5 mils $(0.127 \mathrm{~mm})$.

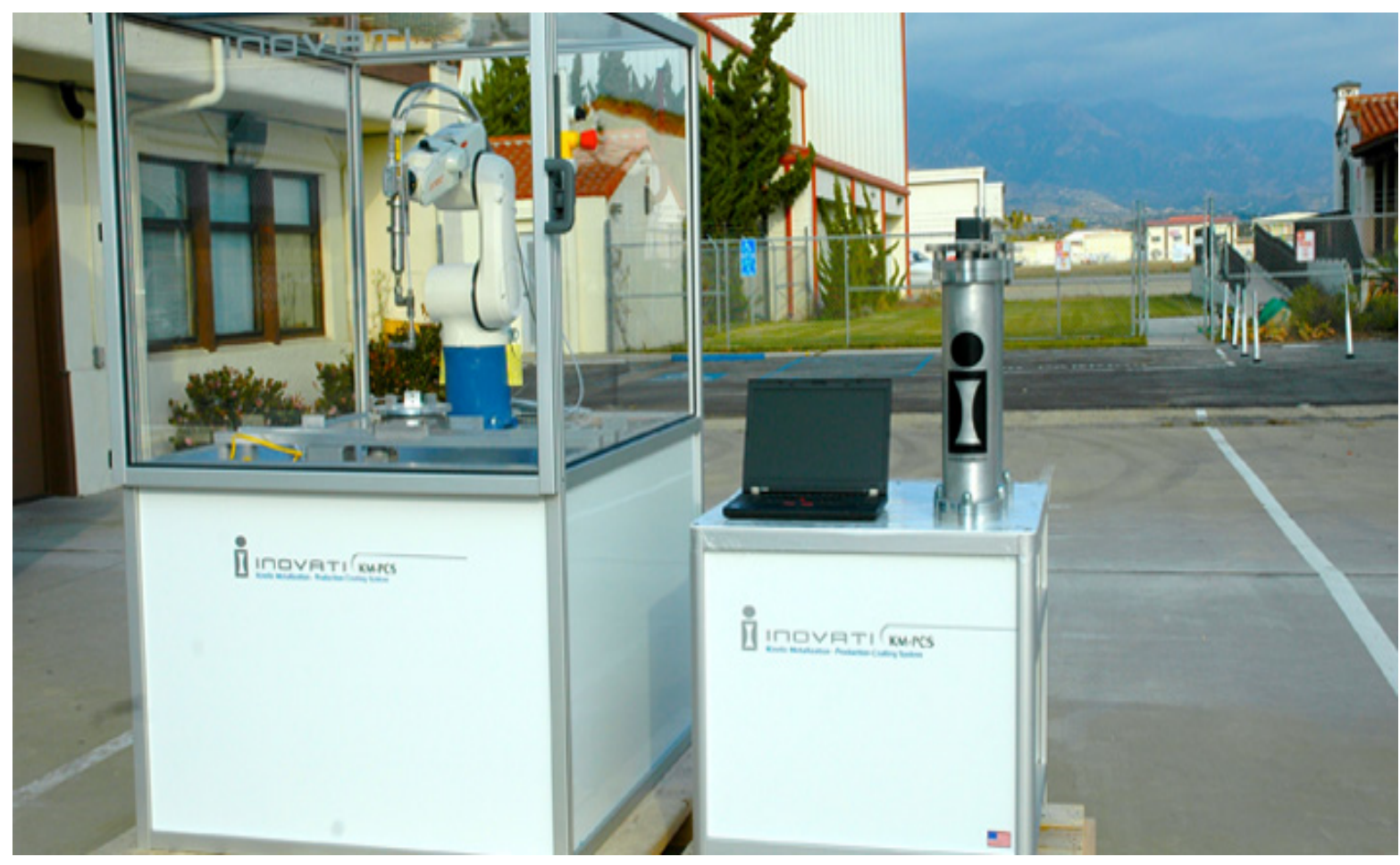

Figure 27: Inovati KM PCS equipment was used to produce the test specimens (Inovati, 2012).

\section{Notching}

A notch was made approximately at the midpoint of each test specimen to ensure failure within the load span. The depth of the notch is not critical because it merely acts as a stress concentration to promote crack nucleation and propagation. However, it is important that the interface is not damaged during introduction of the notch. For this reason, verification of coating thickness is required. Metallographic analysis was performed on one 5 mil specimen of each substrate type according to ASTM E1920: 
Standard Guide for Metallographic Preparation of Thermal Sprayed Coatings (ASTM International, 2008). Optical microscopy was used to determine the thickness of the coating (Figure 28). 10 measurements were taken of each specimen. The minimum coating thickness was used to determine the depth of the notch to be made. Since nowhere was the coating observed to be less than 4 mils, a notch depth of 3 mils was used. This nominal depth ensured that the notch would penetrate more than halfway through the coating while minimizing the risk of damaging the substrate during notching. A carbide-coated chamfer end mill was used to machine the notches in the test specimens. Precise specimen dimensions are necessary to ensure accuracy of $\mathrm{G}_{\mathrm{C}}$ calculations. All dimensions were measured with calipers and are included for reference in Table 3. 


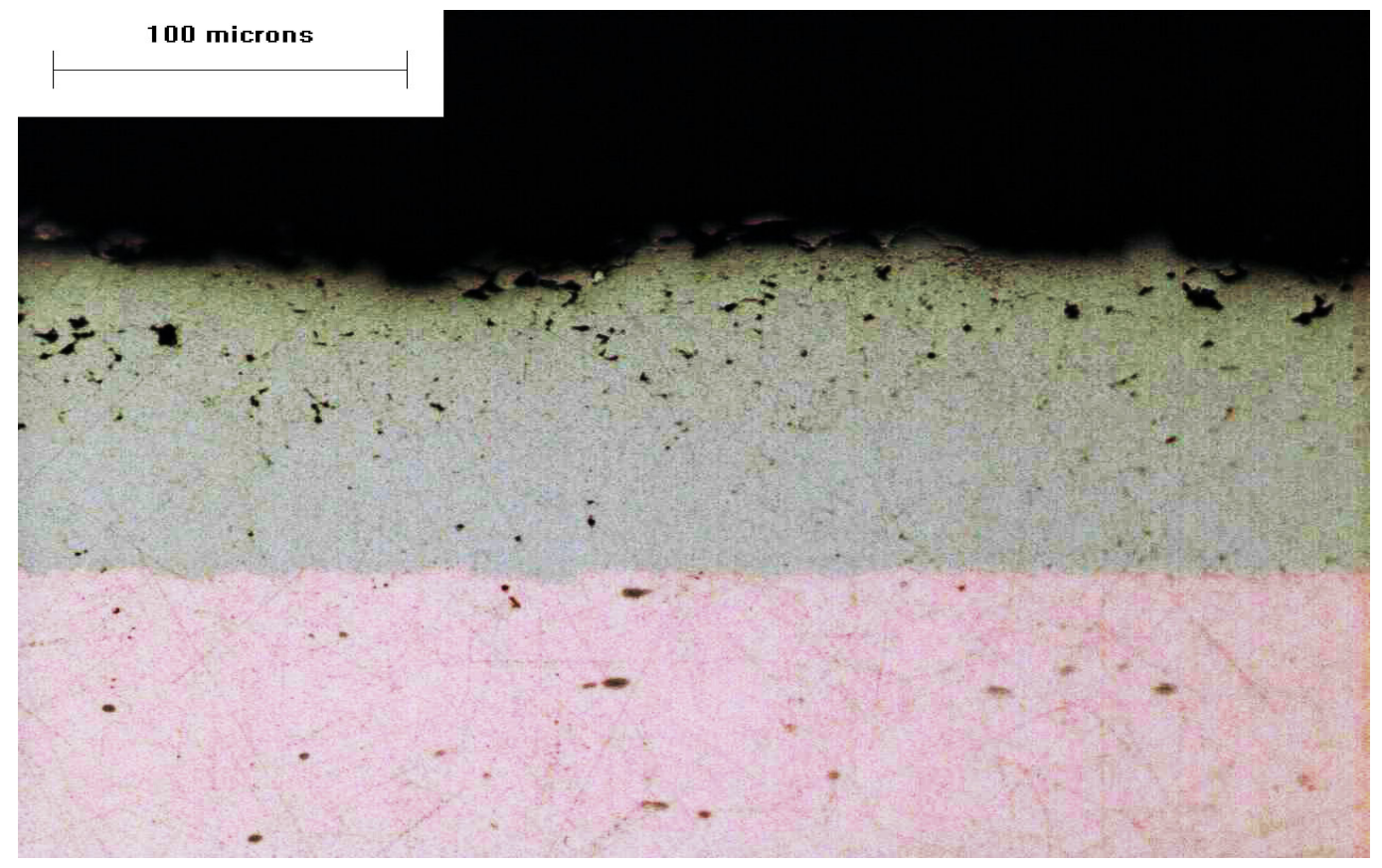

(a)

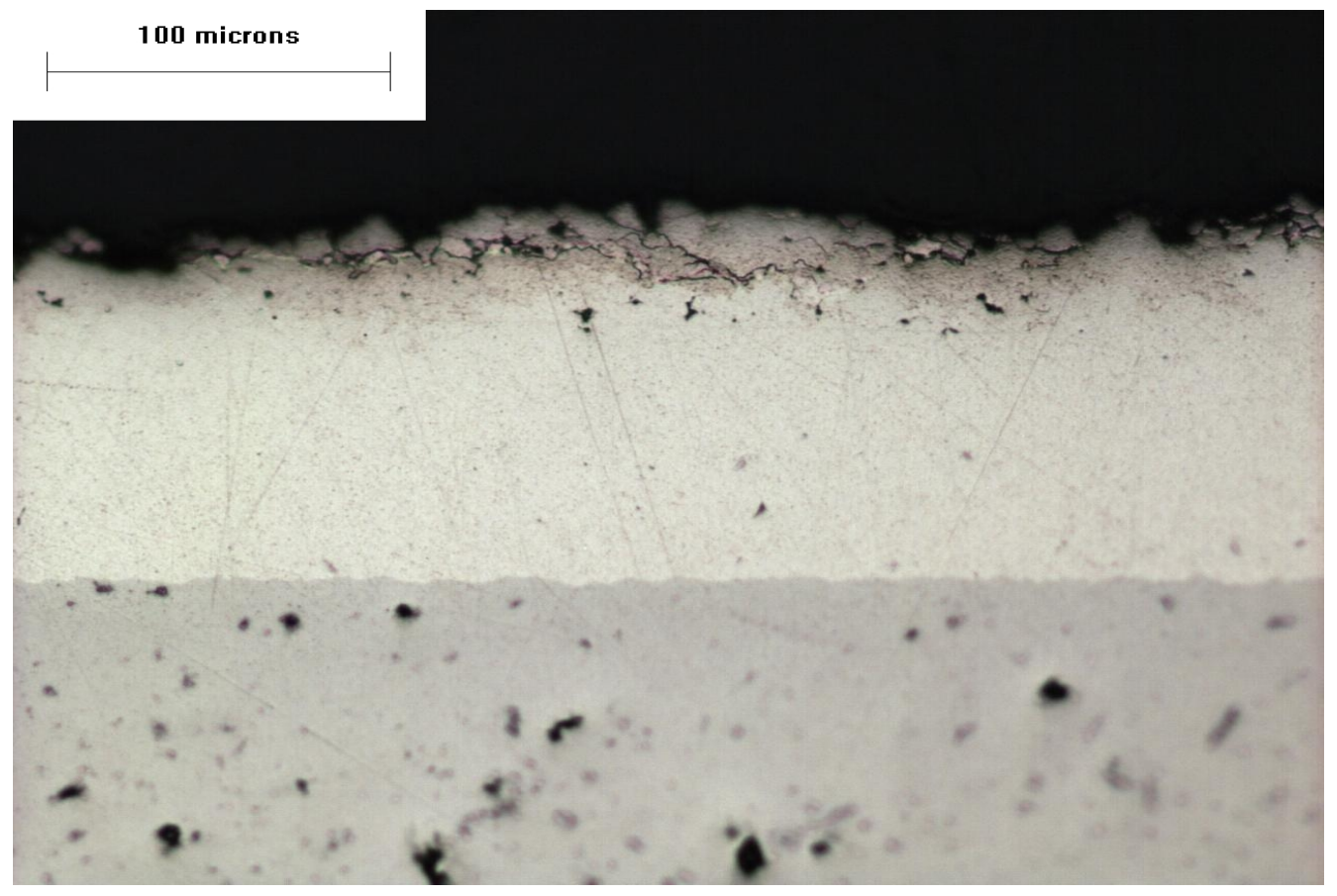

(b)

Figure 28: Optical microcopy was used to verify coating thickness: (a) Copper substrate (b) Titanium substrate 
Table 3: KM test specimen dimensions (mm)

\begin{tabular}{|c|c|c|c|c|}
\hline \multirow{2}{*}{ Substrate } & Specimen & Width & $\begin{array}{c}\text { Substrate } \\
\text { Thickness }\end{array}$ & $\begin{array}{c}\text { Coating } \\
\text { Thickness }\end{array}$ \\
\hline \multirow{3}{*}{ Copper } & $\mathrm{A}$ & 101.6 & 3.162 & 0.115 \\
\cline { 2 - 5 } & $\mathrm{B}$ & 101.6 & 3.222 & 0.115 \\
\cline { 2 - 5 } & $\mathrm{C}$ & 98.43 & 3.238 & 0.115 \\
\hline \multirow{3}{*}{ Titanium } & $\mathrm{A}$ & 101.6 & 3.129 & 0.133 \\
\cline { 2 - 5 } & $\mathrm{B}$ & 101.6 & 3.200 & 0.133 \\
\cline { 2 - 5 } & $\mathrm{C}$ & 101.6 & 3.144 & 0.133 \\
\hline
\end{tabular}

\section{Test Procedure}

Bend testing was conducted using an Instron 3369 tensile tester set up for fourpoint bending. Specimen dimensions were used to calculate the appropriate load span, support span, and crosshead movement rate. These values were calculated according to ASTM E1920 and are presented in Table 4 (ASTM International, 2008). Preliminary testing revealed that the crosshead movement rate calculated by this standard was too slow. This standard was developed for brittle-- not ductile-- materials. To account for this, the crosshead movement rate was increased.

Table 4: Paramters used for four-point bend testing

\begin{tabular}{|c|c|}
\hline Load Span & $27.5 \mathrm{~mm}$ \\
\hline Support Span & $55 \mathrm{~mm}$ \\
\hline Crosshead Movement Rate & $0.1 \mathrm{~mm} / \mathrm{s}$ \\
\hline
\end{tabular}

During loading, a pre-crack initiated at the notch and propagated vertically downward until it reaches the coating-substrate interface, at which point it deflected 
along the interface. This pre-crack is necessary for accurate results; it ensures delamination occurs before large-scale failure of the coating. After the pre-crack formed, loading was continued until coating delamination occurred. The load-displacement data was used to calculate $\mathrm{G}_{\mathrm{C}}$ as previously described. The material property values used in these calculations are listed below in Table 5. Property values for Cold Spray Nickel coatings were used to approximate the values for KM Nickel. After testing was complete, Scanning Electron Microcopy (SEM) was used to examine the fracture surface.

Table 5: Material property values used in $\mathbf{G}_{\mathrm{C}}$ calculations.

\begin{tabular}{|c|c|c|c|c|}
\hline \multirow{2}{*}{ Material } & \multicolumn{3}{|c|}{ Property } & \multirow{2}{*}{ Source } \\
\cline { 2 - 4 } & $\begin{array}{c}\text { Elastic } \\
\text { Modulus }\end{array}$ & $\begin{array}{c}\text { Poisson's } \\
\text { ratio }\end{array}$ & $\begin{array}{c}\text { Shear } \\
\text { Modulus }\end{array}$ & \\
\hline $\begin{array}{c}\text { Nickel (Cold } \\
\text { Spray) }\end{array}$ & $158 \mathrm{GPa}$ & 0.31 & $60 \mathrm{GPa}$ & (Davis, 2004) \\
\hline Copper (Bulk) & $130 \mathrm{GPa}$ & 0.345 & $47.5 \mathrm{GPa}$ & $\begin{array}{c}\text { (Granta Design, } \\
\text { Ltd., 2011) }\end{array}$ \\
\hline Titanium (Bulk) & $109.5 \mathrm{GPa}$ & 0.347 & $46.15 \mathrm{GPa}$ & $\begin{array}{c}\text { (Granta Design, } \\
\text { Ltd., 2011) }\end{array}$ \\
\hline
\end{tabular}




\section{RESULTS}

\section{Sample Preparation}

Preparations were made to deposit a $\mathrm{Ni} \mathrm{KM}$ coating on substrates of $\mathrm{Cu}$, $\mathrm{Ti}$, and Fe (with low-carbon steel used as an appropriate substitute). However, during the deposition process, it was observed that the Ni coating did not appear to adhere well to the steel substrate. During subsequent examination of the sprayed specimens, the coating easily flaked off the steel substrate, rendering them unacceptable for testing purposes. Due to budget and time constraints, no further efforts were made to coat the Fe specimens. For this reason, no further testing could be performed on the Ni-Fe coating system. All $\mathrm{Cu}$ and $\mathrm{Ti}$ specimens were acceptable in appearance. Theoretical results are presented for all three coating systems, but $\mathrm{G}_{\mathrm{C}}$ results are only presented for the $\mathrm{Ni}-\mathrm{Cu}$ and Ni-Ti coating systems.

\section{Theoretical Calculations}

As explained earlier, the Complete Model represents the most intuitively accurate method of calculating interfacial energies for pairs of metals. The following analysis uses the results from this model. Work of Adhesion $\left(\mathrm{W}_{\mathrm{AD}}\right)$ values were calculated for the each coating system using Equation 4. The numerical results are presented in Table 6.

Because $\mathrm{W}_{\mathrm{AD}}$ is dependent on the surface energies of each metal in addition to the interfacial energy, these values are shown for comparison. 
Table 6: Theoretical results for Work of Adhesion. All values are in units of $\mathrm{J} / \mathrm{m}^{2}$.

\begin{tabular}{|c|c|c|c|c|}
\hline $\begin{array}{c}\text { Coating } \\
\text { System }\end{array}$ & $\begin{array}{c}\text { Coating } \\
\text { Surface Energy, } \\
\sigma_{1}\end{array}$ & $\begin{array}{c}\text { Substrate Surface } \\
\text { Energy, } \sigma_{2}\end{array}$ & $\begin{array}{c}\text { Interfacial } \\
\text { Energy, } \sigma_{12}\end{array}$ & $\begin{array}{c}\text { Work of } \\
\text { Adhesion, } \mathrm{W}_{\mathrm{A}}\end{array}$ \\
\hline $\mathbf{N i}-\mathbf{C u}$ & 2.08 & 1.57 & $\mathbf{0 . 1 3}$ & $\mathbf{3 . 5 1}$ \\
\hline $\mathbf{N i}-\mathbf{T i}$ & 2.08 & 1.75 & $\mathbf{- 0 . 7 2}$ & $\mathbf{4 . 5 5}$ \\
\hline $\mathbf{N i}-\mathbf{F e}$ & 2.08 & 2.12 & $\mathbf{- 0 . 0 4}$ & $\mathbf{4 . 2 5}$ \\
\hline
\end{tabular}

Although the surface energies of $\mathrm{Ni}, \mathrm{Cu}, \mathrm{Fe}$ and $\mathrm{Ti}$ are not substantially different from each other, there is a large difference in the interfacial energies between the $\mathrm{Ni}-\mathrm{Cu}$ and $\mathrm{Ni}$ - Ti coating systems. The Ni-Cu system has a relatively small, positive value of $0.13 \mathrm{~J} / \mathrm{m}^{2}$, while the Ni-Ti system has a larger, negative value of $-0.72 \mathrm{~J} / \mathrm{m}^{2}$. The interfacial energy of the $\mathrm{Ni}-\mathrm{Fe}$ system lies between the other two at $-0.04 \mathrm{~J} / \mathrm{m}^{2}$, much smaller in magnitude compared to the other coating systems. The Ni-Ti system has the highest $\mathrm{W}_{\mathrm{AD}}$ of the three systems with a value of $4.55 \mathrm{~J} / \mathrm{m}^{2}$, due in part to the large, negative value of $\sigma_{12}$ for this system. Despite the fact that its constituents have higher surface energies, the Ni-Fe system has a lower $\mathrm{W}_{\mathrm{AD}}$ than $\mathrm{Ni}-\mathrm{Ti}$, with a value of $4.25 \mathrm{~J} / \mathrm{m}^{2}$. This is due to the small $\sigma_{12}$ of the Ni-Fe system. $\mathrm{W}_{\mathrm{AD}}$ of the $\mathrm{Ni}-\mathrm{Cu}$ system is $3.51 \mathrm{~J} / \mathrm{m}^{2}$, the lowest of the three systems. This is due in part to its small, positive $\sigma_{12}$ and the lower surface energy of $\mathrm{Cu}$ compared to Fe and Ti. 


\section{Gc and $K_{C}$ Testing}

\section{Quantitative Results}

The results of the Four-point bend tests are summarized in Figure 29:

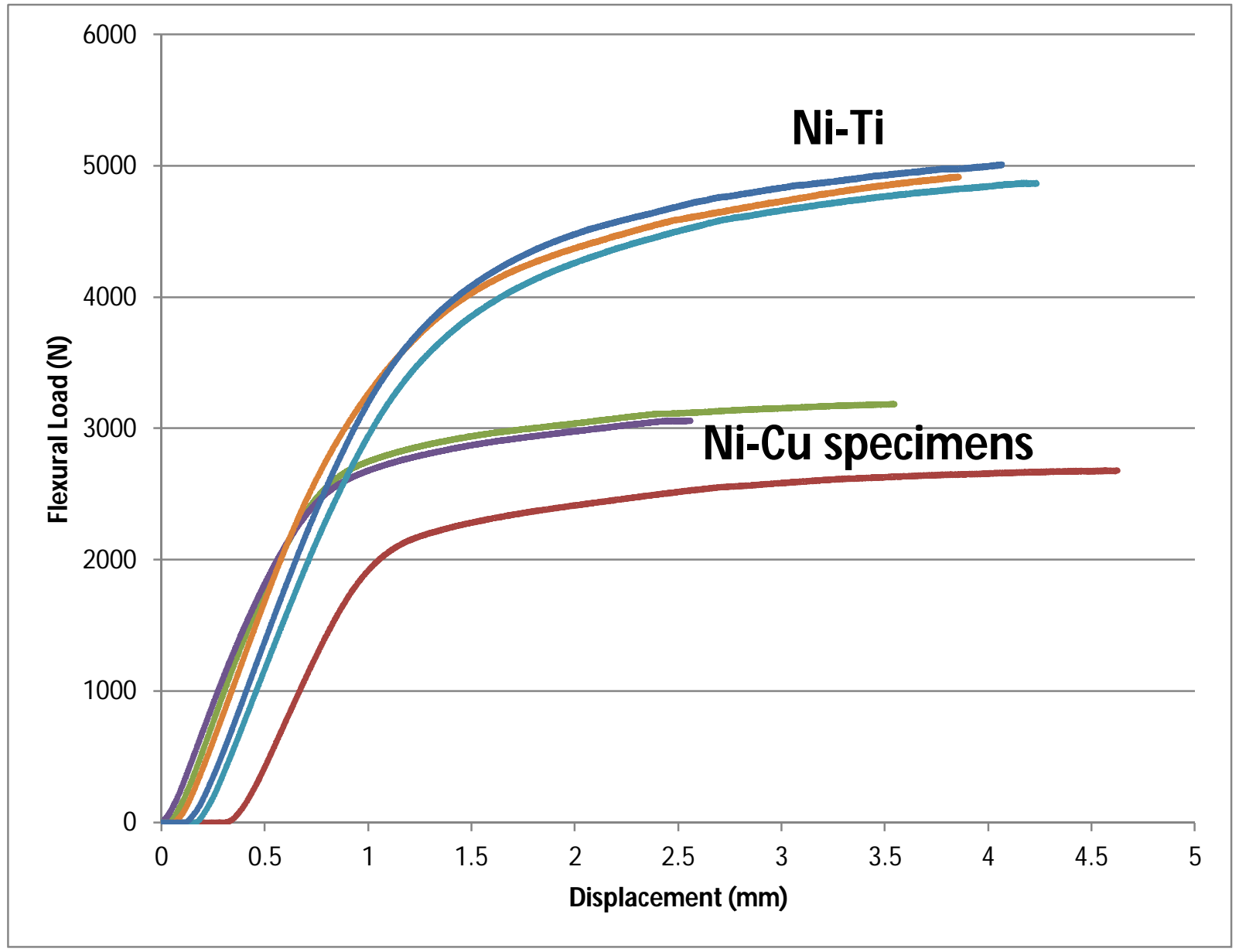

Figure 29: Four-point bend test results for Ni-Ti and Ni-Cu coating systems.

Both the Ni-Ti and the Ni-Cu specimens exhibited the non-ideal load response behavior discovered during preliminary testing: an initial linear elastic region, and a subsequent plastic region, with a transitional region between the two. The $\mathrm{Ni}-\mathrm{Cu}$ specimens exhibit linear elastic behavior up to a displacement of between 0.75 and 1.0 
$\mathrm{mm}$. The Ni-Ti specimens exhibit this behavior until a displacement of about $1.25 \mathrm{~mm}$. The point of maximum curvature was used to determine $\mathrm{P}_{\text {crit }}$ for all four-point bend tests, and $\mathrm{G}_{\mathrm{C}}$ values were calculated as described previously. The results are summarized in Table 7:

Table 7: $G_{C}$ and $K_{C}$ calculations from bend test results.

\begin{tabular}{|c|c|c|c|}
\hline $\begin{array}{c}\text { Coating } \\
\text { System }\end{array}$ & Specimen & $\begin{array}{c}\text { Critical Load, } \\
\mathrm{P}_{\text {crit }}(\mathrm{N})\end{array}$ & $\begin{array}{c}\text { Critical Strain Energy Release Rate, } \mathrm{G}_{\mathrm{C}} \\
\left(\mathrm{J} / \mathrm{m}^{2}\right)\end{array}$ \\
\hline \multirow{5}{*}{$\mathrm{Ni}-\mathrm{Cu}$} & $\mathrm{A}$ & 1829.7 & 30.68 \\
\cline { 2 - 4 } & $\mathrm{B}$ & 2409.0 & 62.42 \\
\cline { 2 - 4 } & $\mathrm{C}$ & 2377.0 & 59.67 \\
\cline { 2 - 4 } & Mean & $\mathbf{2 2 0 5 . 2}$ & $\mathbf{5 0 . 9 2}$ \\
\cline { 2 - 4 } & Std Dev & $\mathbf{3 2 5 . 6}$ & $\mathbf{1 7 . 5 9}$ \\
\hline \multirow{5}{*}{ Ni-Ti } & $\mathrm{A}$ & 3079.0 & 147.46 \\
\cline { 2 - 4 } & $\mathrm{B}$ & 2444.8 & 85.01 \\
\cline { 2 - 4 } & $\mathrm{C}$ & 3278.2 & 165.56 \\
\cline { 2 - 4 } & Mean & $\mathbf{2 9 3 4 . 0}$ & $\mathbf{1 3 2 . 6 8}$ \\
\cline { 2 - 4 } & Std Dev & $\mathbf{4 3 5 . 2}$ & $\mathbf{4 2 . 2 6}$ \\
\hline
\end{tabular}

The mean value of $\mathrm{P}_{\text {crit }}$ for the $\mathrm{Ni}-\mathrm{Cu}$ specimens was $2205.2 \mathrm{~N}$, which yielded mean values of $50.92 \mathrm{~J} / \mathrm{m}^{2}$ for $\mathrm{G}_{\mathrm{C}}$. For the Ni-Ti specimens, the mean $\mathrm{P}_{\text {crit }}$ was $2934.0 \mathrm{~N}$, corresponding to a mean of $132.68 \mathrm{~J} / \mathrm{m}^{2}$ for $\mathrm{G}_{\mathrm{C}}$. The standard deviation of these data was quite large. Closer examination of the data reveals that for each set of specimens, two data points were within about $20 \%$ of each other, but the third data point deviated significantly. 


\section{Qualitative Results}

SEM analysis of the failed test specimens revealed fracture morphology characteristic of thin coatings. Both coating systems exhibited similar behavior. Examination of the interface at the notch confirmed that a vertical crack did indeed initiate at the machined notch and propagate down to the interface (Figure 30). In addition to a crack initiated by the notch, several microcracks were observed to initiate on the coating surface and propagate to the interface. These cracks were regularly spaced about $1 \mathrm{~mm}$ apart (Figure 31). Upon reaching the interface, the cracks deflected along the interface, causing delamination (Figure 32). Similar fracture morphology was observed in a recent study that subjected $\mathrm{TiC}-\mathrm{Al}$ specimens to four-point bending (Katipelli, Agarwal, \& Dahotre, 2000). 


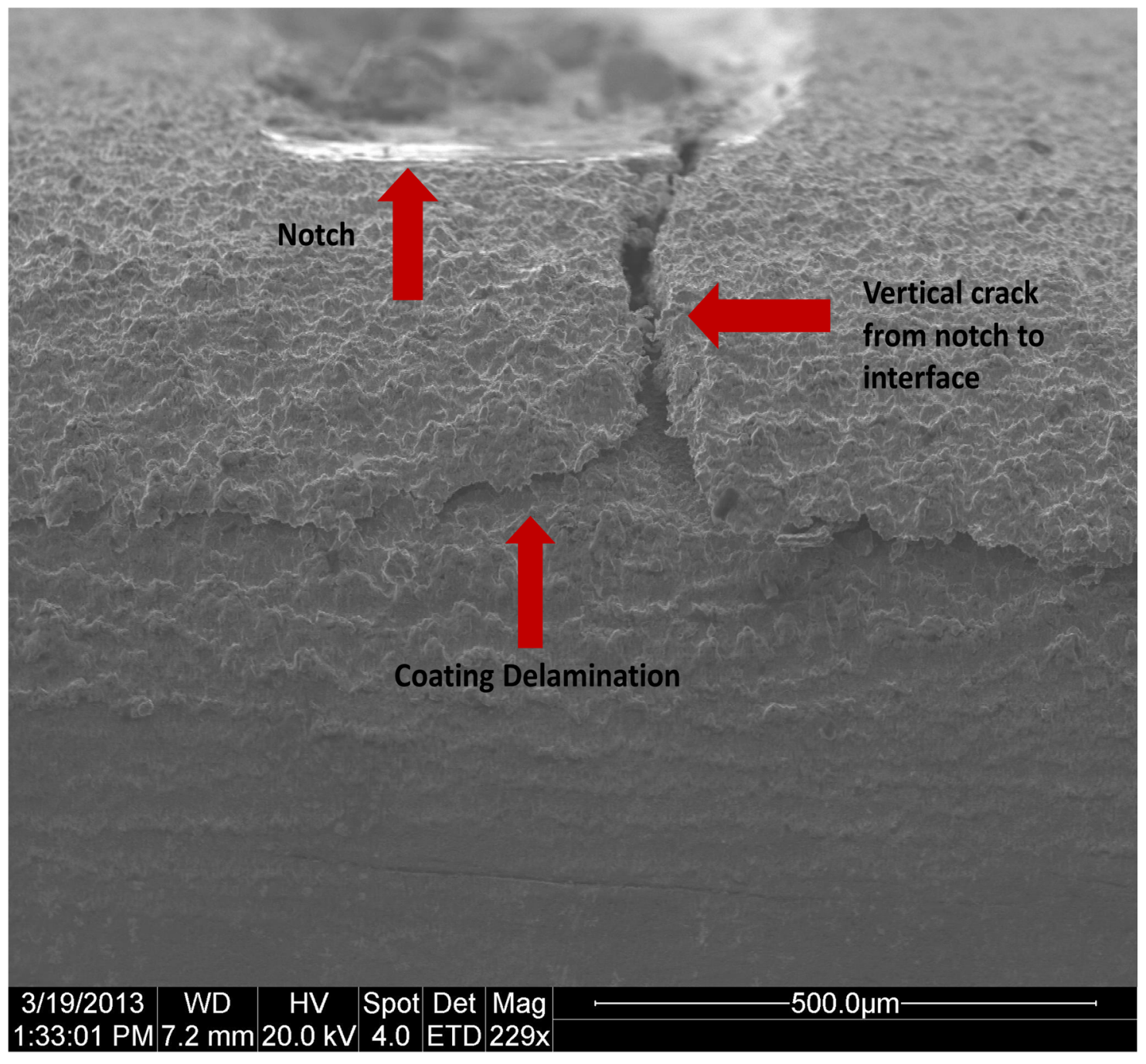

Figure 30: The notch acted as an initiation site for the vertical crack. 


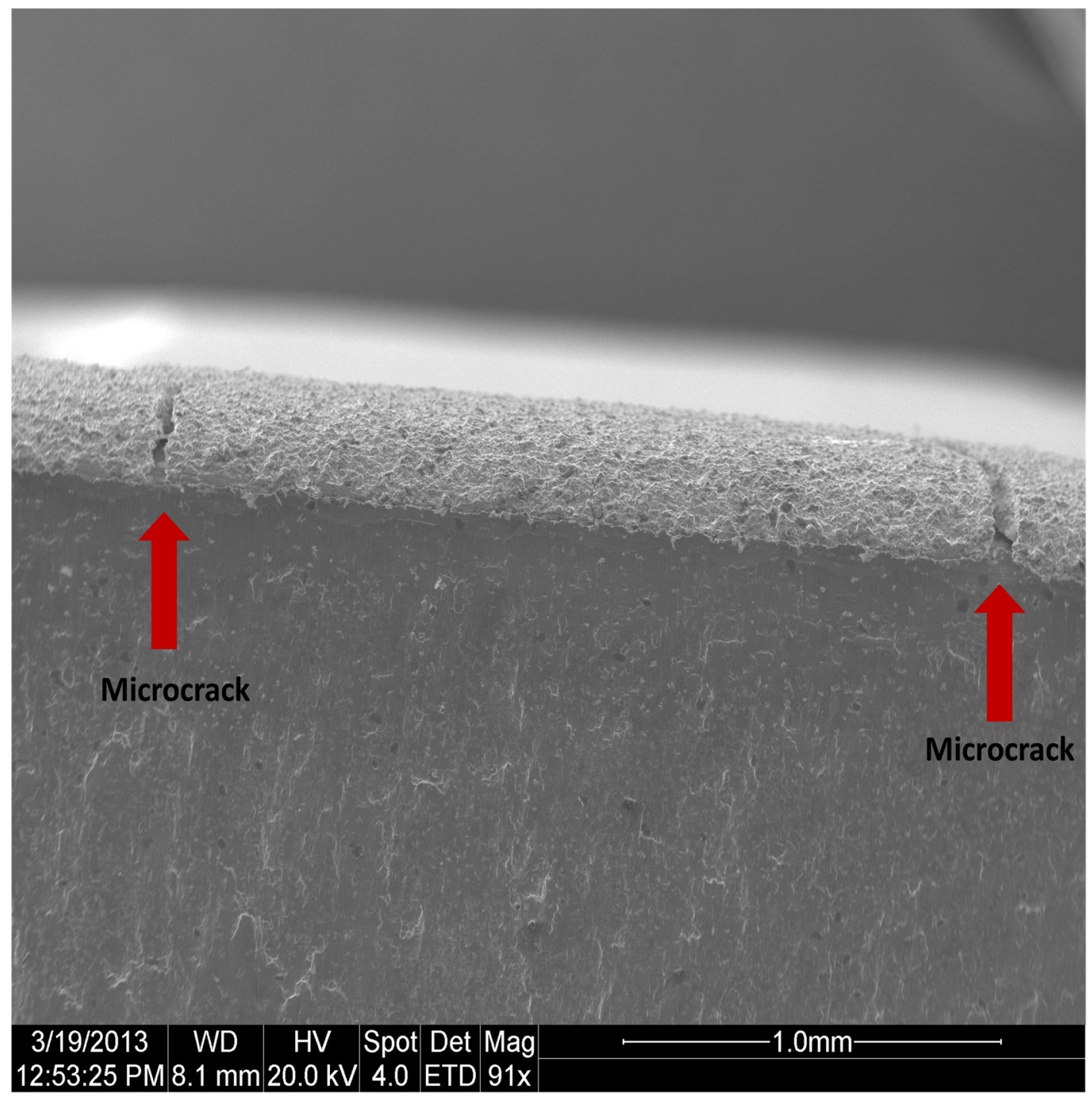

Figure 31: Microcracks initiated at the coating surface caused delamination, as seen in literature. 


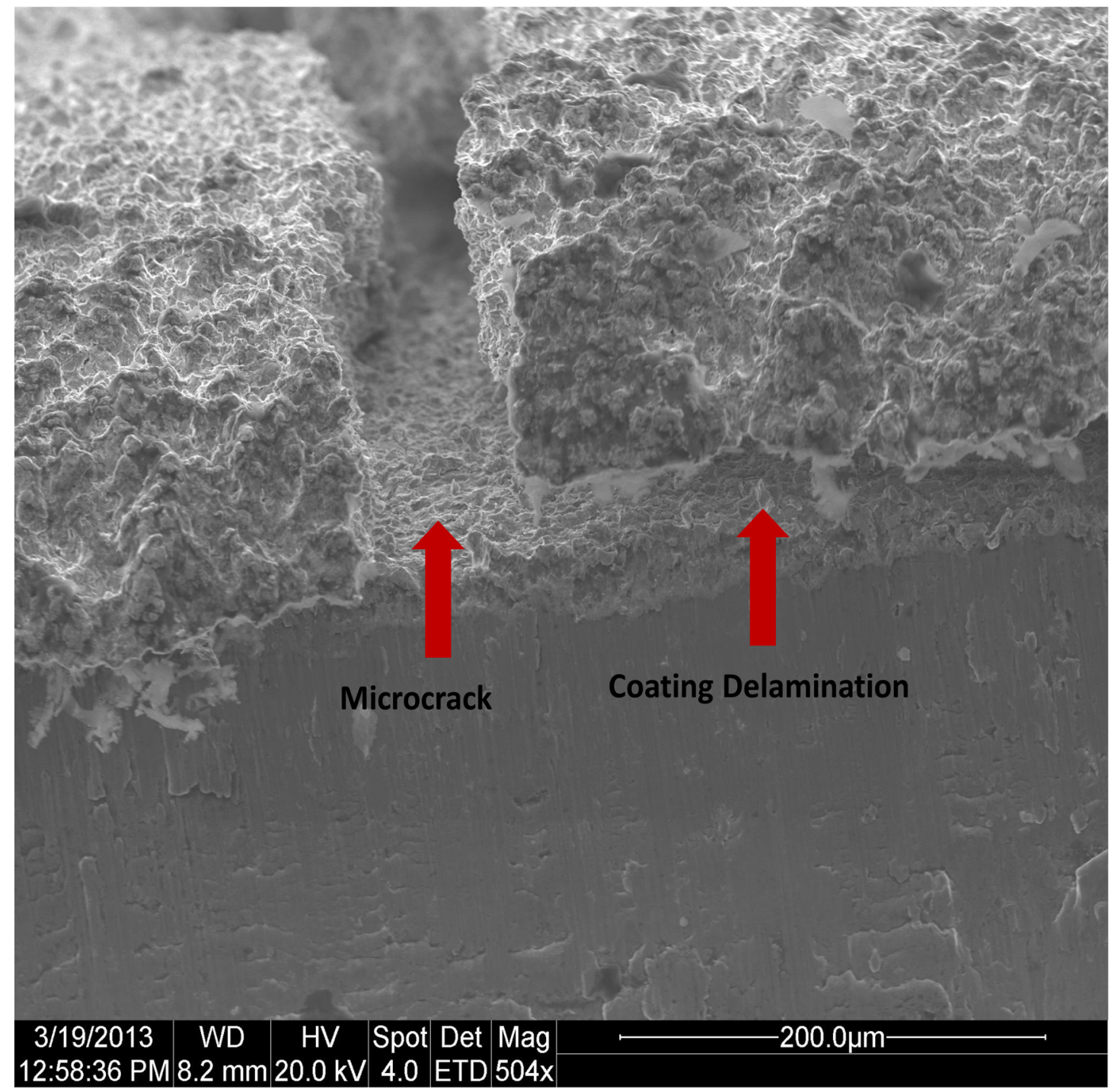

Figure 32: High-magnification view of a microcrack that deflected along the interface, causing delamination.

\section{$\mathrm{W}_{\mathrm{AD}}$ and $\mathrm{G}_{\mathrm{C}}$ Comparison}

It was theorized that the Work of Adhesion, $\mathrm{W}_{\mathrm{AD}}$, and the "toughness" of the interface should be related to each other. $\mathrm{W}_{\mathrm{AD}}$ and $\mathrm{G}_{\mathrm{C}}$ data for the $\mathrm{Ni}-\mathrm{Cu}$ and $\mathrm{Ni}-\mathrm{Ti}$ coating systems are summarized in Table 8 and shown graphically in Figure 33. 
Table 8: $W_{\mathrm{AD}}$ and $\mathrm{G}_{\mathrm{C}}$ values are compared to attempt to identify a relationship between the two.

\begin{tabular}{|c|c|c|}
\hline $\begin{array}{l}\text { Coating } \\
\text { System }\end{array}$ & $\begin{array}{l}\text { Work of Adhesion, } \mathrm{W}_{\mathrm{A}} \\
\left(\mathrm{J} / \mathrm{m}^{2}\right)\end{array}$ & $\begin{array}{l}\text { Critical Strain Energy Release Rate, } \mathrm{G}_{\mathrm{C}} \\
\qquad\left(\mathrm{J} / \mathrm{m}^{2}\right)\end{array}$ \\
\hline \multirow{3}{*}{$\mathrm{Ni}-\mathrm{Cu}$} & \multirow{3}{*}{3.51} & 30.68 \\
\hline & & 62.42 \\
\hline & & 59.67 \\
\hline \multirow{3}{*}{ Ni-Ti } & \multirow{3}{*}{4.55} & 147.46 \\
\hline & & 85.01 \\
\hline & & 165.56 \\
\hline
\end{tabular}

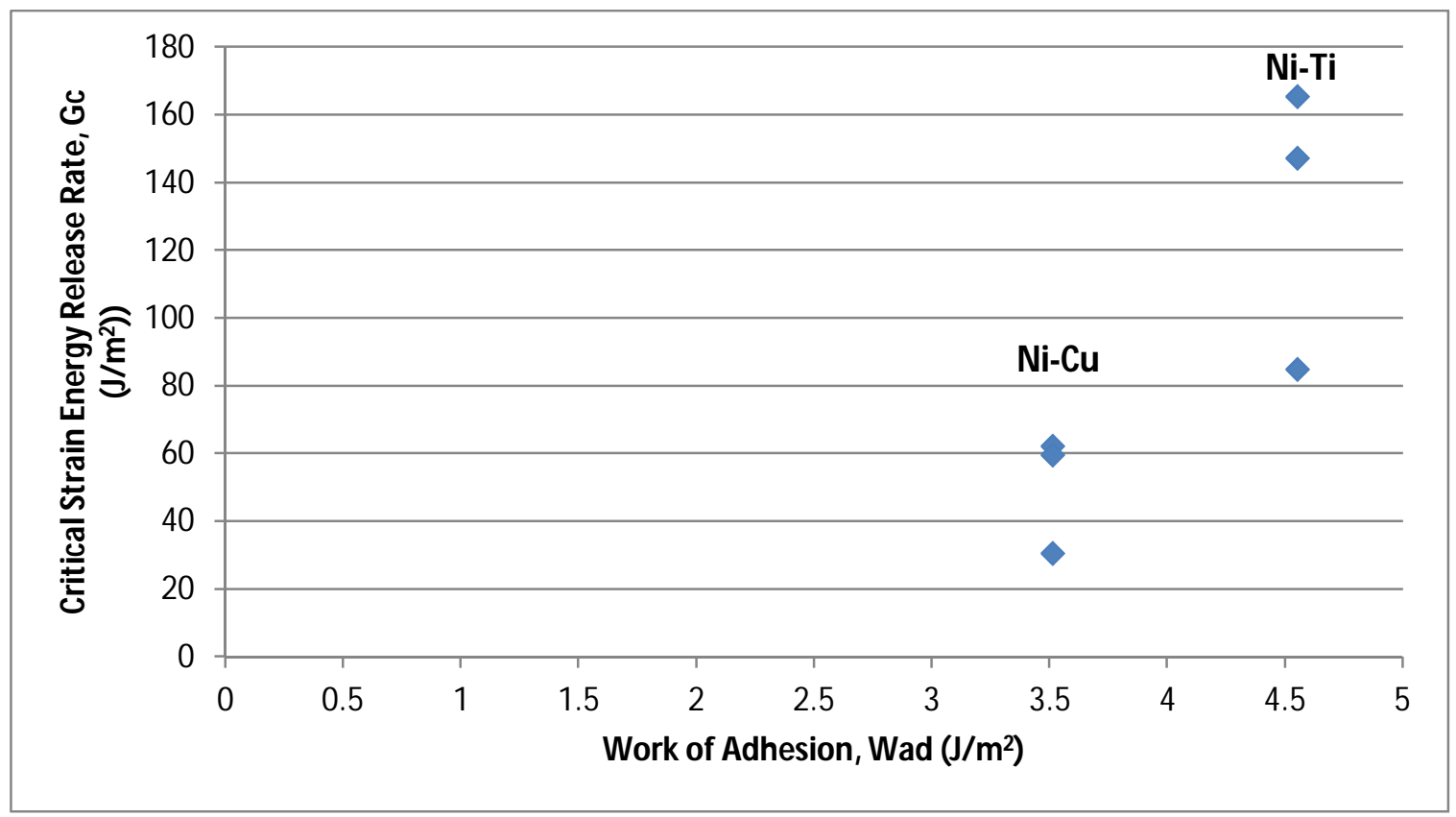

Figure 33: There appears to be a positive correlation between $W_{\mathrm{AD}}$ and $\mathbf{G}_{\mathrm{C}}$.

Since all specimens of the same coating system are theoretically identical, they all have the same value for Work of Adhesion. Differences in $\mathrm{G}_{\mathrm{C}}$ between specimens of the same coating system differ due to experimental error. When comparing the data for the two coating systems, it is clear that a difference exists. The Ni-Ti specimens have a higher $\mathrm{W}_{\mathrm{AD}}$ than the $\mathrm{Ni}-\mathrm{Cu}$ specimens; $\mathrm{G}_{\mathrm{C}}$ of the $\mathrm{Ni}-\mathrm{Ti}$ specimens was also higher. $\mathrm{W}_{\mathrm{AD}}$ 
accounted for $6.89 \%$ of the average measured $\mathrm{G}_{\mathrm{C}}$ for the $\mathrm{Ni}-\mathrm{Cu}$ specimens. For the Ni-Ti specimens, $\mathrm{W}_{\mathrm{AD}}$ accounted for $3.43 \%$ of the average measured $\mathrm{G}_{\mathrm{C}}$. 


\section{DISCUSSION}

\section{Sample Preparation}

The failure of the Ni coating to adhere to the Fe substrate could be due to one of several factors. The first logical explanation is that the calculated work of adhesion was insufficient to promote coating adherence. Sufficient interfacial quality is necessary to overcome the effects of residual stresses-- which tend to cause coating delamination-built up during the deposition process. Residual stresses have been shown to be among the most influential process parameters in determining coating adhesion (Davis, 2004). However, the results of this study show that the $\mathrm{Ni}-\mathrm{Cu}$ system had a higher value of $\mathrm{W}_{\mathrm{AD}}$ than the Ni-Fe system. Despite this, the Ni-Cu system demonstrated sufficient adhesion, and the Ni-Fe system did not. The theoretical approach taken in this study fails to explain this result. This suggests that the lack of adhesion of the Ni-Fe system is due to some other mechanism. These other mechanisms were previously disregarded due to the difficulties involved with quantifying their contribution to adhesion. These effects will now be reconsidered in an attempt to explain this result.

Another possible explanation is the formation of oxide layers on the substrate surface. It is likely that there was some oxide content on the surface of each of the $\mathrm{Cu}$, Fe, and Ti specimens, since the formation of each oxide is thermodynamically favorable under ambient conditions (Morita \& Miki, 2003). Although it is unlikely that all the oxide 
was removed during cleaning, any remaining oxide would likely have been removed during the KM deposition process, leaving a clean surface.

Mechanical interlocking can contribute significantly to the overall adhesion of a coating-substrate system, and surface roughness can enhance the degree to which interlocking occurs. However, for these experiments, all substrates underwent the same surface preparation procedure. This rules out differing surface finishes as a possible explanation. Some researchers have suggested that the relative hardness of the coating and substrate materials may influence the coating quality. (Fukanuma \& Ohno, 2004). It is possible that the high hardness of the steel substrate resulted in a large degree of plastic deformation in the Nickel coating particles. Plastic deformation can lead to the build-up of residual stresses which tend to delaminate the coating (Katipelli, Agarwal, \& Dahotre, 2000). Although further mechanical testing and experimentation with substrates of different hardness would be needed, experimental results from Inovati support this hypothesis (Inovati, 2012).

\section{Theoretical Calculations}

Comparing the magnitude of the interfacial energy to the individual surface energies for each coating system reveals the importance of the $\sigma_{12}$ term in calculating $\mathrm{W}_{\mathrm{AD}}$. For the sake of comparison, this ratio is presented along with $\sigma_{12}$ and $\mathrm{W}_{\mathrm{AD}}$ in Table 9. 
Table 9: Comparison of the magnitudes of interfacial and surface energies.

\begin{tabular}{|c|c|c|c|}
\hline \multirow{2}{*}{ Coating System } & $\begin{array}{c}\text { Interfacial Energy, } \\
\sigma_{12}\end{array}$ & $\begin{array}{c}\text { Work of Adhesion, } \\
\mathrm{W}_{\mathrm{A}}\end{array}$ & $\frac{\sigma_{12}}{\left(\sigma_{1}+\sigma_{2}\right)}$ \\
\hline $\mathbf{N i - C u}$ & 0.13 & 3.51 & $\mathbf{+ 3 . 6 \%}$ \\
\hline $\mathbf{N i}-\mathbf{T i}$ & -0.72 & 4.55 & $\mathbf{- 1 8 . 8 \%}$ \\
\hline $\mathbf{N i}-\mathbf{F e}$ & -0.04 & 4.25 & $\mathbf{- 1 . 0 \%}$ \\
\hline
\end{tabular}

The Ni-Cu system has a $\sigma_{12}$ of $0.13 \mathrm{~J} / \mathrm{m}^{2}, 3.6 \%$ of the sum of the surface energies of its constituents. The Ni-Fe system has a $\sigma_{12}$ of $-0.04 \mathrm{~J} / \mathrm{m}^{2}$, only $1 \%$ of the sum of the surface energies of its constituents. In contrast, the Ni-Ti system has a $\sigma_{12}$ of $-0.72 \mathrm{~J} / \mathrm{m}^{2}$, a value that is $18.8 \%$ of the sum of the surface energies of its constituents. These ratios represent the relative thermodynamic favorability of the interfaces. The relatively small values for the $\mathrm{Ni}-\mathrm{Cu}$ and $\mathrm{Ni}-\mathrm{Fe}$ systems suggests that these interfaces are only slightly more or less favorable than a homogeneous interface. In these cases, $\mathrm{W}_{\mathrm{AD}}$ is determined primarily by the surface energies of the two constituents. The relatively large, negative $\sigma_{12}$ value for the $\mathrm{Ni}-\mathrm{Ti}$ indicates that this interface is more favorable than either a $\mathrm{Ni}-\mathrm{Ni}$ or $\mathrm{Ti}-\mathrm{Ti}$ interface; that is, Ni and Ti would rather bond with each other than with themselves.

This behavior is easily explained by the theory that metals can be either hypo- or hyperelectronic, as discussed previously (Czichos, 1972). Ti has two d-shell electrons, and $\mathrm{Ni}$ has eight. According to this theory, when bonding occurs, a Ti atom would donate two electrons to a $\mathrm{Ni}$ atom, leaving the Ti atom's d-shell completely empty and the $\mathrm{Ni}$ atom's d-shell completely full. This is energetically more favorable than Ti-Ti or Ni-Ni bonding, in which the d-shells of each atom are neither completely empty nor completely 
filled. The negative sign of $\sigma_{12}$ for this coating system represents the favorability of the $\mathrm{Ni}$-Ti bond. Conversely, neither Ni-Cu nor Ni-Fe bonds result in completely empty or filled d-subshells. As a result, these heterogeneous bonds are not significantly more favorable or unfavorable than homogeneous bonds, and the interfacial energies of the interfaces are close to zero.

There is little experimental data for metal-metals pairs with which to compare these results, but some experimentally determined interfacial energy and work of adhesion values for other bimaterial interfaces are presented in Table 10 for comparison.

Table 10: Interfacial properties of other bimaterial interfaces. All values are in units of $\mathbf{J} / \mathbf{m}^{2}$.

\begin{tabular}{|c|c|c|c|}
\hline $\begin{array}{l}\text { Coating } \\
\text { System }\end{array}$ & $\begin{array}{c}\text { Interfacial } \\
\text { Energy, } \sigma_{12} \\
\end{array}$ & $\begin{array}{c}\text { Work of } \\
\text { Adhesion, } \mathrm{W}_{\mathrm{A}}\end{array}$ & Source \\
\hline $\begin{array}{c}\text { Au- } \\
\text { Graphite }\end{array}$ & 1.025 & -- & (Gangopadhyay \& Wynblatt, 1995) \\
\hline Au-SiC & -- & 0.445 & (Wang \& Wynblatt, 1998) \\
\hline Ge-SiC & -- & 0.820 & (Wang \& Wynblatt, 1998) \\
\hline $\mathrm{Pb}_{-\mathrm{SiO}_{2}}$ & -- & 0.869 & $\begin{array}{l}\text { (Sangiorgi, Muolo, Chatain, \& } \\
\text { Eustathopolous, 1988) }\end{array}$ \\
\hline Pt- $\mathrm{Al}_{2} \mathrm{O}_{3}$ & -- & 1.472 & (Li J. , 1992) \\
\hline $\mathrm{Au}-\mathrm{Al}_{2} \mathrm{O}_{3}$ & 2.52 & 0.12 & (Sadan \& Kaplan, 2006) \\
\hline $\mathrm{Ni}-\mathrm{Cu}$ & 0.13 & 3.51 & This work \\
\hline Ni-Ti & -0.72 & 4.55 & This work \\
\hline Ni-Fe & -0.04 & 4.25 & This work \\
\hline
\end{tabular}

Comparison of these results to interfacial properties of other bimaterial systems reveals that the interfacial energy metal-ceramic systems are much higher than the metal-metal systems examined in this study. Experiments for $\mathrm{Au}$-graphite and $\mathrm{Au}-\mathrm{Al}_{2} \mathrm{O}_{3}$ systems 
report interfacial energy values of $1.025 \mathrm{~J} / \mathrm{m}^{2}$ and $2.52 \mathrm{~J} / \mathrm{m}^{2}$, respectively. These high values of $\sigma_{12}$ result in low values of $\mathrm{W}_{\mathrm{AD}}$. Various studies cite experimental values of between 0.12 and $1.472 \mathrm{~J} / \mathrm{m}^{2}$, significantly lower than those calculated in this study.

Like metal-metal interfaces, the strength of metal-oxide interfaces has been shown to be a function of $n_{W S}$ of the metal, where $n_{W S}$ is the electron density at the boundary of the Wigner-Seitz cell. As $\mathrm{N}_{\mathrm{WS}}$ increases, so does $\mathrm{W}_{\mathrm{AD}}$ (Li J. , 1992). This is because more electrons are available for bonding. The difference in the strength of the two interfaces can be explained by their different electronic characteristics. Metals have no bandgap_electrons are driven across the interface as a result of the difference in the Fermi levels of the two metals (Czichos, 1972). Conversely, oxides have a bandgap. At a given temperature, only a fraction of electrons have sufficient energy to cross the bandgap and participate in bonding, resulting in interfaces that are generally weaker than metal-metal interfaces. This theory could also explain the low $\mathrm{W}_{\mathrm{AD}}$ values for other metal-nonmetal systems.

\section{Gc Testing}

$\mathrm{G}_{\mathrm{C}}$ values for the two interfaces are presented along with other interfacial toughness data in Table 11: 
Table 11: Interfacial toughness data for various bimaterial interfaces.

\begin{tabular}{|c|c|c|c|}
\hline $\begin{array}{c}\text { Coating } \\
\text { System }\end{array}$ & Bonding Technique & $\begin{array}{c}\mathrm{G}_{\mathrm{C}} \\
\left(\mathrm{J} / \mathrm{m}^{2}\right)\end{array}$ & Source \\
\hline Al-TiC & $\begin{array}{c}\text { Laser surface } \\
\text { engineered }\end{array}$ & 156 & (Katipelli, Agarwal, \& Dahotre, 2000) \\
\hline $\begin{array}{c}\text { NiAl- } \\
\text { Steel }\end{array}$ & Plasma spray & 52.4 & (Klingbeil \& Beuth, 1997) \\
\hline $\begin{array}{c}\text { Stainless } \\
\text { Steel-Cu }\end{array}$ & Microcasting & 387 & (Klingbeil \& Beuth, 1997) \\
\hline Ni-Cu & KM & 50.92 & This work \\
\hline Ni-Ti & KM & 132.68 & This work \\
\hline
\end{tabular}

It is evident from this data that the toughness values determined in this study are within the range of other bimetallic interfaces created using a variety of bonding techniques. Depending on the constituents and the bonding technique, $\mathrm{G}_{\mathrm{C}}$ ranges from approximately 50 to $400 \mathrm{~J} / \mathrm{m}^{2}$ for these bimaterial interfaces. For homogeneous materials, $\mathrm{G}_{\mathrm{C}}$ can range from as low as $5 \mathrm{~J} / \mathrm{m}^{2}$ for perfectly brittle cleavage to about $300 \mathrm{~J} / \mathrm{m}^{2}$ for ductile steel (Katipelli, Agarwal, \& Dahotre, 2000).

Inovati has hypothesized that solid-state wetting at the interface may account for the improved adhesion observed in certain material combinations. Although there was a large difference in $\mathrm{G}_{\mathrm{C}}$ between the $\mathrm{Ni}-\mathrm{Cu}$ and $\mathrm{Ni}-\mathrm{Ti}$ specimens, with limited data available, it is difficult to assess the validity of these claims. Nevertheless, comparison of $\mathrm{G}_{\mathrm{C}}$ values from Table 11 reveals that $\mathrm{KM}$ interfaces are at least as tough as other thermal spray coatings, and almost as strong as a laser surface engineering coating-a more 
expensive process (Katipelli, Agarwal, \& Dahotre, 2000). Overall, the $\mathrm{G}_{\mathrm{C}}$ values calculated in this work suggests that KM produces fairly strong interfaces.

\section{$\mathrm{W}_{\mathrm{AD}}$ and $\mathrm{G}_{\mathrm{C}}$ Comparison}

Although there is little data for metal-metal systems, $\mathrm{W}_{\mathrm{AD}}$ and $\mathrm{G}_{\mathrm{C}}$ for several metal-ceramic coating systems are compared to the KM results in Table 12:

Table 12: $G_{C}$ results for several metal-metal and metal-nonmetal interfaces.

\begin{tabular}{|c|c|c|c|}
\hline $\begin{array}{l}\text { Coating } \\
\text { System }\end{array}$ & $\mathrm{W}_{\mathrm{AD}}\left(\mathrm{J} / \mathrm{m}^{2}\right)$ & $\begin{array}{c}\mathrm{G}_{\mathrm{C}} \\
\left(\mathrm{J} / \mathrm{m}^{2}\right)\end{array}$ & Source \\
\hline $\mathrm{Ni}-\mathrm{Al}_{2} \mathrm{O}_{3}$ & $0.2-0.8$ & $0-60$ & (Kosolapova, 1990) \\
\hline Fe-TiB 2 & 2.85 & 255 & (Agarwal \& Dahotre, 1990) \\
\hline Al-TiC & 0.485 & 156 & (Katipelli, Agarwal, \& Dahotre, 2000) \\
\hline $\mathrm{Ni}-\mathrm{Cu}$ & 3.51 & 50.92 & This work \\
\hline Ni-Ti & 4.55 & 132.68 & This work \\
\hline
\end{tabular}

On average, $G_{C}$ values for the $\mathrm{KM}$ interfaces studied in this work were 15 to 30 times greater than the corresponding value of $\mathrm{W}_{\mathrm{AD}}$. Results from other studies show even larger discrepancies between $\mathrm{W}_{\mathrm{AD}}$ and $\mathrm{G}_{\mathrm{C}}$. This difference is likely due to one or more of several factors that are not accounted for in the theoretical model. Many of these factors were identified and discussed in previous chapters. These include: plastic deformation of the coating or substrate during delamination, residual stresses formed during coating deposition, impurities present at the interface, and the degree of roughness of the substrate surface. Literature suggests that plastic deformation and surface roughness are likely the main reasons for the large discrepancy between $\mathrm{G}_{\mathrm{C}}$ and $\mathrm{W}_{\mathrm{AD}}$ (Evans, Ruhle, 
Dalgleish, \& Charalambides, 1989). Plastic deformation and work hardening absorb a large amount of energy, and surface roughness can increase the amount of surface area available for bonding and allow mechanical interlocking to occur-both result in higher interfacial toughness (Katipelli, Agarwal, \& Dahotre, 2000).

\section{Statistical Analysis}

The goal of this study is to identify a possible relationship between the Work of Adhesion and interfacial toughness, quantified by $\mathrm{G}_{\mathrm{C}}$. Unfortunately, limited time and resources available for this study meant that only a small number of interfaces could be examined, and only a small number of experimental replicates could be tested. It was determined that the best way to proceed would be to examine the difference in $\mathrm{G}_{\mathrm{C}}$ between the Ni-Ti and Ni-Cu samples. A difference in $\mathrm{G}_{\mathrm{C}}$ would then be associated with a difference in $\mathrm{W}_{\mathrm{AD}}$. This analysis was done using a 2-sample t-test. The input variables and results of this test are summarized below in Table 13. Detailed statistical analysis is included in Appendix A.

Table 13 : 2-sample t-test for the difference in mean $\mathbf{G}_{\mathrm{C}}$ between the Ni-Ti and Ni-Cu specimens.

\begin{tabular}{|c|c|c|}
\hline Variable & Value & Interpretation \\
\hline $\mathbf{H}_{\mathbf{0}}$ & $\mu_{\mathrm{Ni}-\mathrm{Ti}}-\mu_{\mathrm{Ni}-\mathrm{Cu}}=0$ & $\begin{array}{c}\text { There is no difference in the mean toughness of } \\
\text { the two interfaces }\end{array}$ \\
\hline $\mathbf{H}_{\mathbf{a}}$ & $\mu_{\mathrm{Ni}-\mathrm{Ti}}-\mu_{\mathrm{Ni}-\mathrm{Cu}}>0$ & $\begin{array}{c}\text { The mean toughness of the Ni-Ti interface is } \\
\text { greater than the mean toughness of the Ni-Cu } \\
\text { interface }\end{array}$ \\
\hline $\boldsymbol{\alpha}$ & 0.05 & Confidence level of $95 \%$ \\
\hline $\mathbf{t}$ & 3.09 & $\mathrm{p}<0.05$, reject $\mathrm{H}_{0}$ \\
\hline $\mathbf{p}$ & 0.018 & $\mathrm{t}$-test statistic \\
\hline
\end{tabular}


With a p-value of 0.018 , we reject the null hypothesis and conclude that the mean toughness of the Ni-Ti interface is, in fact, greater than the mean toughness of the $\mathrm{Ni}-\mathrm{Cu}$ interface. This difference is statistically significant at the 0.05 significance level. The mean difference was found to be $81.8 \mathrm{~J} / \mathrm{m}^{2}$. With $95 \%$ confidence, the lower bound of the difference in mean $\mathrm{G}_{\mathrm{C}}$ was found to be $25.4 \mathrm{~J} / \mathrm{m}^{2}$.

These results seem to support the hypothesis made earlier-that interfacial toughness of an interface is positively associated with its Work of Adhesion. However, given the limited about of data available, it would be difficult to make any strong claims about the true nature of the relationship between $\mathrm{G}_{\mathrm{C}}$ and $\mathrm{W}_{\mathrm{AD}}$. The fact that only two coating systems were tested means that linear regression cannot be conducted. As a result, the true nature of the relationship between $\mathrm{W}_{\mathrm{AD}}$ and $\mathrm{G}_{\mathrm{C}}$ is still unknown. Collecting data for more interfaces — which would entail testing more coating systemswould be necessary for this model to have any predictive capabilities. More data would possibly allow for linear regression, a much more accurate way of describing the effect of $\mathrm{W}_{\mathrm{AD}}$ on $\mathrm{G}_{\mathrm{C}}$. 


\section{CONCLUSIONS}

It is possible to construct a theoretical model that can calculate the interfacial energy, $\sigma_{12}$, at a bimetallic interface of two transition metals. This "complete" model draws on the concepts of intermolecular forces and alloy formation and uses known material properties to calculate $\sigma_{12}$, from which the Work of Adhesion, $\mathrm{W}_{\mathrm{AD}}$, can also be calculated. There are essentially two additive contributions to interfacial energy: a physical term and an electronic term. The physical term is a function of the molar volume, $\mathrm{V}$, and surface energy, $\gamma$, of each metal. The electronic term is a function of molar volume, $\mathrm{V}$, and the enthalpy of alloy formation, $\Delta \mathrm{H}^{\text {interface. }} \Delta \mathrm{H}^{\text {interface }}$ is a function of molar volume, $\mathrm{V}$, the work function, $\varphi$, and the electron density at the boundary of the Wigner-Seitz cell, $\mathrm{n}_{\mathrm{ws}}$. Because each of these properties is known or can readily be determined, $\sigma_{12}$ and $\mathrm{W}_{\mathrm{AD}}$ can be calculated without experimentation. However, this "complete" model has not been verified experimentally. Solid-state wetting experiments are recommended to assess the accuracy of this model.

Inovati has hypothesized that solid-state wetting at the interface may account for the improved adhesion observed in certain material combinations. More data is needed to assess the validity of these claims. Four-point bend tests conducted in this study yielded mean $\mathrm{G}_{\mathrm{C}}$ values of 50.92 and $132.68 \mathrm{~J} / \mathrm{m}^{2}$ for $\mathrm{Ni}-\mathrm{Ti}$ and $\mathrm{Ni}-\mathrm{Cu}$ specimens, respectively. These KM interfaces are at least as tough as other thermal spray coatings, and almost as tough as a laser surface engineering coating. Overall, the $G_{C}$ values calculated in this work suggests that KM produces fairly strong interfaces. 
On average, $\mathrm{W}_{\mathrm{AD}}$ for the $\mathrm{KM}$ interfaces studied in this work represented about $5 \%$ of the measured $\mathrm{G}_{\mathrm{C}}$ values. Plastic deformation of the coating or substrate during delamination, residual stresses formed during coating deposition, impurities present at the interface, and the degree of roughness of the substrate surface could have caused the observed differences between $\mathrm{W}_{\mathrm{AD}}$ and $\mathrm{G}_{\mathrm{C}}$. Literature suggests that plastic deformation and surface roughness are likely the main reasons for the large discrepancy between $\mathrm{G}_{\mathrm{C}}$ and $\mathrm{W}_{\mathrm{AD}}$.

The Ni-Ti specimens have a higher $\mathrm{W}_{\mathrm{AD}}$ than the $\mathrm{Ni}-\mathrm{Cu}$ specimens; $\mathrm{G}_{\mathrm{C}}$ of the $\mathrm{Ni}-$ Ti specimens was also significantly higher. These results appear to support the hypothesis made earlier - that interfacial toughness of an interface is positively associated with its Work of Adhesion. However, given the limited about of data available, it would be difficult to make any strong claims about the true nature of the relationship between $\mathrm{G}_{\mathrm{C}}$ and $\mathrm{W}_{\mathrm{AD}}$. The fact that only two coating systems were tested means that regression cannot be conducted. As a result, the true nature of the relationship between $\mathrm{W}_{\mathrm{AD}}$ and $\mathrm{G}_{\mathrm{C}}$ is still unknown. Admittedly, there are other limitations associated with this analysis. The theoretical model is only valid for interfaces between two pure transition metals. Several other contributing factors to interfacial toughness were omitted from this model. Despite these limitations, the results of these tests are encouraging, and should warrant further testing. 


\section{FUTURE WORK}

\section{Model Verification: Solid-State Wetting Experiments}

Solid-state wetting experiments could be used to experimentally verify the interfacial energy values calculated by the "complete" model. By manipulating the Young and Dupré equations, an alternate form of the Young-Dupré equation can be written:

$$
\gamma_{i n t}=\gamma_{s}-\gamma_{m} \cos \theta
$$

Equation 29

Where $\gamma_{\text {int }}$ is the interfacial energy, $\gamma_{S}$ is the surface energy of the substrate, $\gamma_{M}$ is the surface energy of the metallic particle, and $\theta$ is the contact angle, as shown below.

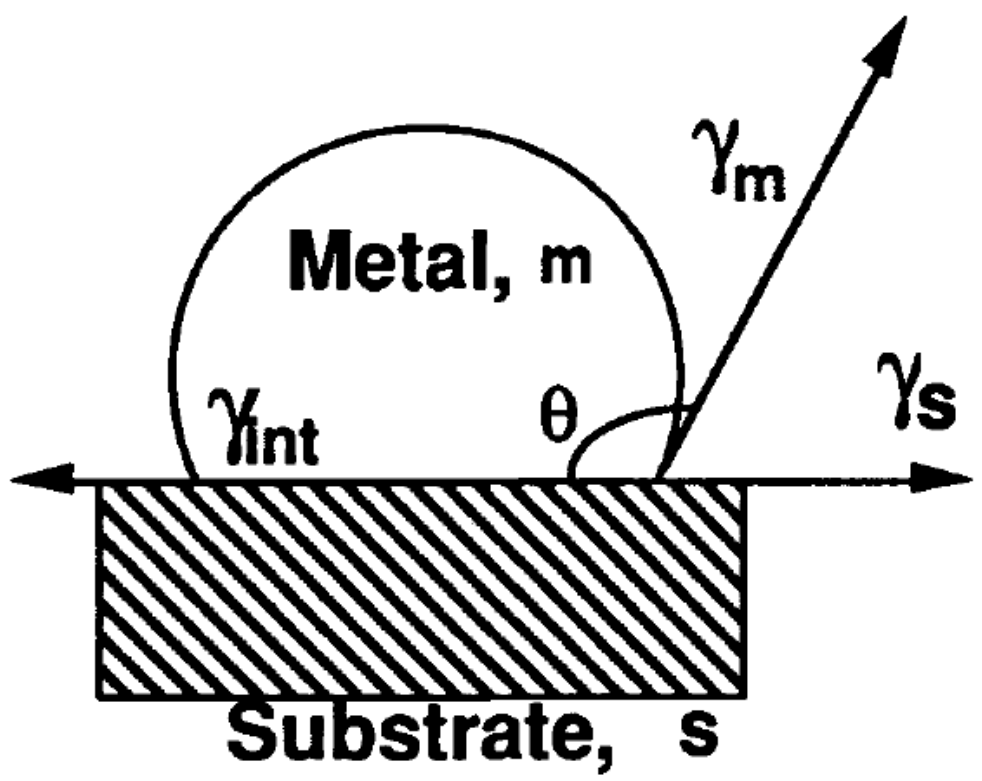

Figure 34: An alternate form of the Young-Dupré equation can be used to calculate interfacial energy experimentally. 
Contact angle can be measured experimentally, and values for the surface energies of metals are well known, meaning the interfacial energy of bimetallic interfaces can be calculated using Equation 29.

Solid-state wetting experiments can be used to measure the contact angle of these bimetallic interfaces. However, the accuracy of these experimental results relies upon the purity of the metals and the overall cleanliness of the procedure. Typically, a thin film of approximately $1000 \mathrm{~nm}$ of one metal is deposited onto a clean and smooth specimen of the other metal. Deposition can be accomplished by one of several techniques, including evaporation and sputtering. The melting point of the film should be lower than that of the substrate. Then, the coating-substrate specimen is heated under UHV conditions to slightly above $T_{\text {melt }}$ of the coating. The coating then de-wets to form spherical droplets. Upon subsequent cooling, these droplets solidify. By holding the specimen at a temperature just below $\mathrm{T}_{\text {melt }}$, these particles are able to assume their equilibrium shape (Heyraud \& Metois, 1983; Gangopadhyay \& Wynblatt, 1995; Gangopadhyay \& Wynblatt, 1994). It is the measured contact angle between the equilibrated particle and the substrate that is used in Equation 29 to calculate interfacial energy. Contact angle can be measured using SEM, AFM, or TEM in conjunction with FIB (van der Straten, Zhu, Rullan, Dunn, \& Kaloyeros, 2006; Delannay, Froyen, \& Deruyttere, 1987) 


\section{Determination of Elastic Properties of Coating}

Due to the significant microstructural differences observed between bulk form and KM deposited coatings, one would expect their elastic properties to be different as well (Davis, Handbook of Thermal Spray Technology, 2004). Accurate values of the elastic modulus as well as Poisson's ratio of the coating are required to calculate $\mathrm{G}_{\mathrm{C}}$ of the interface. Because these values cannot be easily calculated, they must be determined experimentally by means of a slightly difference test procedure. Un-notched specimens are placed in a four-point bending configuration as described previously, but with strain gauges placed on the outer surfaces of the coating and substrate. Using elementary beam theory, the ratio of the elastic moduli can be determined from:

$$
n=\frac{E_{1}}{E_{2}}=\frac{\left(2 h_{1} h_{2}+h_{2}^{2}\right) \frac{\varepsilon_{2}}{\varepsilon_{1}}-h_{2}^{2}}{h_{1}^{2}\left(1-\frac{\varepsilon_{2}}{\varepsilon_{1}}\right)+2 h_{1} h_{2}}
$$

Where $\mathrm{E}, \varepsilon$, and h represent the elastic modulus, measured strain, and thickness of each layer. The subscripts 1 and 2 refer to the top and bottom layer, respectively. Since the elastic modulus of the substrate is known, the elastic modulus of the coating can be calculated. In addition, Poisson's ratio of the coating can be calculated directly from the strain gauge measurements (Klingbeil \& Beuth, 1997).

For these tests, un-notched specimens would be set up under a four-point bending configuration and loaded to a predetermined point such that elastic strain was induced. Two strain gauges would be used to simultaneously measure the displacement of the 
coating and the substrate under a given load. The load-displacement data would then be used to calculate the elastic modulus and Poisson's ratio of the coating. Since the coating was the same for each test specimen, the results would provide a measure of the variability of the coating's properties. 


\section{REFERENCES}

Agarwal, A., \& Dahotre, N. B. (1990). Surface Coating Technology. (L. R. Katipelli, Interviewer)

Ajdelsztajn, L., Zuniga, A., Jodoin, B., \& Lavernia, E. J. (2006). Cold gas dynamic spraying of a high temperature Al alloy. Surface and Coatings Technology, 21092116.

Allan, G., Lannoo, M., \& Dobrzynski, L. (1974). Simple self-consistent theory of adhesion at a bimetallic interface. Philisophical Magazine, 33-45.

ASTM International. (2008). ASTM C 633: Standard Test Method for Adheison or Cohesion Strength of Thermal Spray Coatings. West Conshohocken: ASTM International.

ASTM International. (2008). ASTM E1920: Standard Guide for Metallographic Preparation of Thermal Sprayed Coatings. West Conshohocken: ASTM International.

ASTM International. (2010). ASTM D 6272: Standard Test Method for Flexural Properties of Unreinforced and Reinforced Plastics and Electrical Insulating Materials by Four-Point Bending. West Conshohocken: ASTM International.

Atkins, P., \& de Paula, J. (2009). Physical Chemistry. Gordonsville: W. H. Freeman.

Berndt, M. L., \& Berndt, C. C. (2003). Thermal Spray Coatings. ASM International.

Blazynski, T. (1983). Explosive Welding, Forming, and Compaction. New York: Applied Science Publishers.

Butt, H., Graf, K., \& Kappl, M. (2006). Physics and Chemistry of Interfaces. Weinheim: Wiley-VCH Verlag GmbH and Co.

Callister, J. W. (2003). Materials Science and Engineering: An Introduction. New York: John Wiley \& Sons.

Campbell, S. A. (2008). Fabrication Engineering at the Micro- and Nanoscale. New York: Oxford University Press.

Chalker, P. R., Bull, S. J., \& Rickerby, D. S. (1991). A review of the methods for the evaluation of coating-substrate adhesion. Materials Science and Engineering, 583-592. 
Czichos, H. (1972). The mechanism of the metallic adhesion bond. Journal of Physics D: Applied Physics, 1890-1897.

Davis, J. R. (2002). Hardfacing, Weld Cladding, and Dissimilar Metal Joining. ASM International.

Davis, J. R. (2004). Handbook of Thermal Spray Technology. Materials Park: ASM International.

de Boer, F. R., Boom, R., Mattens, W. C., Miedema, A. R., \& Niessen, A. K. (1988). Cohesion in Metals: Transition Metal Alloys. New York: North Holland.

Delannay, F., Froyen, L., \& Deruyttere, A. (1987). The wetting of solids by molten metals and its relation to the preparation of metal matrix composites. Journal of Materials Science, 1-16.

Devore, J., \& Farnum, N. (2005). Applied Statistics for Engineers and Scientists. Belmont: Thomson Brooks/Cole.

Evans, A. G., Hutchinson, J. W., \& Wei, Y. (1999). Interface Adhesion: Effects of Plasticity and Segregation. Acta Metallurgica, 4093-4113.

Evans, A. G., Ruhle, M., Dalgleish, B. J., \& Charalambides, P. G. (1989). The Frature Eenergy of Bimaterial Interfaces. Materials Science and Engineering, 53-64.

Fukanuma, H., \& Ohno, J. (2004). A Study of Adhesive Strength of Cold Spray Coatings. Thermal Spray 2004: Advances in Technology and Applications (ASM International), 329-334.

Gangopadhyay, U., \& Wynblatt, P. (1994). Solid-state Wetting of Graphite by $\mathrm{Pb}$ and PbNi Alloys. Metallurgical and Materials Transactions A, 607-615.

Gangopadhyay, U., \& Wynblatt, P. (1995). Modification of the gold/graphite interfacial energy by interfacial adsorption of nickel. Journal of Materials Science, 94-100.

Girifalco, L. A., \& Good, R. J. (1957). A theory for estimation of surface and interfacial energies I: Derivation and application to interfacial tension. The Journal of Physical Chemistry, 904-909.

Good, R. J., \& Girifalco, L. A. (1960). A theory for estimation of surface and interfacial energies III: Estimation of surface energies of solids from contact angle data. The Journal of Physical Chemistry, 561-565. 
Good, R. J., Girifalco, L. A., \& Kraus, G. (1958). A theory for estimation of surface and interfacial energies II: Application to surface thermodynamics of teflon and graphite. The Journal of Physical Chemistry, 1418-1421.

Granta Design, Ltd. (2011). CES Edupack. Granta Design, Ltd.

Gross, D., \& Seelig, T. (2011). Fracture Mechanics: With an Introduction to Micromechanics. New York: Springer.

Grujicic, M., Saylor, J. R., Beasley, D. E., DeRosset, W. S., \& Helfritch, D. (2003). Computational analysis of the interfacial bonding between feed-powder particles and the substrate in the cold-gas dynamic-spray process. Applied Surface Science, 211-227.

Hermanek, F. (2002). Thermal Spraying: What it Was and What it Has Become. The International Journal of Powder Metallurgy, 35-44.

Heyraud, J. C., \& Metois, J. J. (1983). Equilibrium Shape and Temperature; Lead on Graphite. Surface Science, 334-342.

Hussain, T., McCartney, D. G., Shipway, P. H., \& Zhang, D. (2009). Bonding Mehanisms in Cold Spraying: The Contributions of Metallurgical and Mechanical Components. Journal of Thermal Spray Technology, 364-379.

Inovati. (2012, January). Kinetic Metallization: Coatings Once Thought Impossible. Retrieved from Inovati: http://inovati.com

Kajar, F., \& Mizia, J. (1977). Energy of Cohesion in Transition Metals. Journal of Physics F: Metal Physics, 1115-1126.

Kasap, S. O. (2007). Principles of Electronic Materials and Devices. New York: The McGraw-Hill Companies.

Kashani, H., Amadeh, A., \& Ghasemi, H. M. (2007). Room and high tempetrature wear behaviors of nickel and cobalt base weld overlay coatings on hot forging dies. Wear, 800-806.

Katipelli, L. R., Agarwal, A., \& Dahotre, N. B. (2000). Interfacial strength of laser surface engineered TiC coating on $6061 \mathrm{Al}$ using four-point bend test. Materials Science and Engineering A, 34-40.

Kinloch, A. J. (1980). The Science of Adhesion Part 1: Surface and Interfacial Aspects. Journal of Materials Science, 2141-2166. 
Klingbeil, N. W., \& Beuth, J. L. (1997). Interfacial Fracture Testing of Deposited Metal Layers Under Four-Point Bending. Enginering Fracture Mechanics, 113-126.

Kosolapova, T. Y. (1990). Handbook of High Temperature Compounds: Properties, Production, Applications. New York: Hemisphere Publishing Corporation.

Ksiazak, M., Sobczak, N., Mikulowski, B., Radziwill, W., \& Surowiak, I. (2002). Wetting and bonding strength in $\mathrm{Al}-\mathrm{Al} 2 \mathrm{O} 3$ system. Materials Science and Engineering, 162-167.

Kurochkin, Y. V., Demin, Y. N., \& Soldatenkov, S. I. (2002). Demonstration of the Method of Cold Gasdynamic Spraying of Coatings. Chemical and Petroleum Engineering, 245-248.

Lee, L. (1991). Fundamentals of Adhesion. New York: Plenum Press.

Li, C., Li, W., \& Liao, H. (2006). Examination of the Critical Velocity for Deposition of Particles in Cold Spraying. Journal of Thermal Spray Technology, 212-222.

Li, J. (1992). Wetting and Interfacial Bonding of Metals with Ionocovalent Oxides. Journal of the American Ceramic Society, 3118-3126.

Lin, C. K., \& Berndt, C. C. (1994). Measurement and Anlaysis of Adhesion Strength for Thermally Sprayed Coatings. Journal of Thermal Spray Technology, 75-104.

Liu, G. W., Muolo, M. L., Valenza, F., \& Passerone, A. (2010). Survey on wetting of SiC by molten metals. Ceramics International, 1177-1188.

McMahon, J. C. (2004). Structural Materials. Philadelphia: Merion Books.

Mittal, K. L., \& Pizzi, A. (1999). Adhesion Promotion Techniques: Technological Applications. New York: Marcel Dekker, Inc.

Morita, K., \& Miki, T. (2003). Thermodynamics of solar-grade-silicon refining. Intermetallics, 1111-1117.

Moskowitz, L. N. (1992). Application of HVOF thermal spraying to solve corrosion problems in the petroleum industry. Thermal Spray: International Advances in Coatings Technology, 611-618.

Murr, L. E. (1975). Interfacial Phenomena in Metals and Alloys (from cohesion in metals). Reading: Addison-Wesley Publishing Company.

Packham, D. E. (2003). Surface energy, surface topography, and adhesion. International Journal of Adhesion and Adhesives, 437-448. 
Papyrin, A. N. (2003). Modeling of Particle-Substrate Adhesive Interaction Under the Cold Spray Process. International Thermal Spray Conference (pp. 27-35). Materials Park: ASM International.

Papyrin, A., Kosarev, V., Klinkov, S., Alkimov, A., \& Fomin, V. (2007). Cold Spray Technology. New York: Elsevier.

Sadan, H., \& Kaplan, W. D. (2006). Au-Sapphire (0001) solid-solid interfacial energy. Journal of Materials Science, 5099-5107.

Sangiorgi, R., Muolo, M. L., Chatain, D., \& Eustathopolous, N. (1988). Wettability and Work of Adhesion of Nonreactive Liquid Metals on Silica. Journal of the American Ceramic Society, 742-748.

Schmauder, A., \& Meyer, M. (1992). Correlation between Dunders' Parameters and Elastic Constants. Zeitschrift fur Metallkunde, 524-527.

Schmidt, T., Assadi, H., Gartner, F., Richter, H., Stoltenhoff, T., Kreye, H., \& Klassen, T. (2009). From ParticleAcceleration to Impact and Bonding in Cold Spraying. Journal of Thermal Spray Technology, 794-808.

Shen, W., Wang, F., Fan, Q., Ma, Z., \& Yang, W. (2011). Finite element simulation of tensile bond strength of atmospheric plasma spraying thermal barrier coatings. Surface and Coatings Technology, 2964-2969.

Shepeleva, L., Medres, B., Kaplan, W. D., Bamberger, M., \& Weisheit, A. (2000). Laser cladding of turbine blades. Surface and Coatings Technology, 45-48.

Skriver, H. L., \& Rosengaard, N. M. (1992). Surface energy and work function of elemental metals. Physical Review B, 7157-7168.

Stoltenhoff, T., Kreye, H., \& Richter, H. J. (2001). An Analysis of the Cold Spray Process and Its Coatings. Journal of Thermal Spray Technology, 542-550.

Tro, N. J. (2011). Chemistry: A Molecular Approach. Upper Saddle River: Pearson Education.

Turnbull, D. (1955). Impurities and Imperfections. Thirty-Sixth National Metal Congress and Exposition. Chicago: American Society for Metals.

Tvergaard, V., \& Hutchinson, J. W. (1993). The Influence of Plasticity on Mixed Mode Interface Toughness. Journal of the Mechanics and Physics of Solids, 1119-1135. 
van der Straten, O., Zhu, Y., Rullan, J., Dunn, K., \& Kaloyeros, A. E. (2006). Study of copper-refractory metal interfaces via solid-state wetting for emerging nanoscale interconnect applications. Journal of Materials Research, 255-262.

Wang, Z., \& Wynblatt, P. (1998). Wetting and Energetics of Solid Au and Au-Ge/SiC Interfaces. Acta Materialia, 4853-4859.

Watanabe, M., Owada, A., Kuroda, S., \& Gotoh, Y. (2006). Effect of WC size on interface fracture toughness of WC-Co HVOF sprayed coatings. Surface and Coatings Technology, 619-627.

Weiss, H. (1995). Adhesion of advanced overlay coatings: mechanisms and quantitative assessment. Surface and Coatings Technology, 201-207.

Wu, J., Fang, H., Yoon, S., Kim, H., \& Lee, C. (2006). The rebound phenomenno in kinetic spraying deposition. Scripta Materialia, 665-669.

Wu, J., Yang, J., Fang, H., Yoon, A., \& Lee, C. (2006). The bond strength of Al-Si coating on mild steel by kinetic spray deposition. Applied Surface Science, 78097814.

Wynblatt, P. (2000). The Effects of Interfacial Segregation on Wetting in Solid Metal-onMetal and Metal-on-Ceramic Systems. Acta Materialia, 4439-4447. 


\section{APPENDICES}

\section{Appendix A: Statistical Analysis of Gc Data}

Ideally, linear regression could be conducted in an attempt to correlate $\mathrm{W}_{\mathrm{AD}}$ with $\mathrm{G}_{\mathrm{C}}$. However, with only two interfaces to examine, its usefulness would be limited. From the current data, there is no way of knowing whether the relationship between $\mathrm{W}_{\mathrm{AD}}$ and $\mathrm{G}_{\mathrm{C}}$ is linear or nonlinear. Regression can only be used on two linearly related data sets; although the data can be transformed to make it linear, it is impossible to know which transformation is correct. This is because data was only collected for two interfaces. More data points are needed to determine the linearity_ or lack thereof—of a data set.

Instead, only the difference in mean $\mathrm{G}_{\mathrm{C}}$ between the $\mathrm{Ni}-\mathrm{Cu}$ and $\mathrm{Ni}-\mathrm{Ti}$ interfaces was analyzed. In this case, $\mathrm{W}_{\mathrm{AD}}$ is essentially treated as a categorical variable, with $\mathrm{G}_{\mathrm{C}}$ as a quantitative response. If a significant difference between the two groups exist, then one can infer that there is an association between $\mathrm{G}_{\mathrm{C}}$ and $\mathrm{W}_{\mathrm{AD}}$.

\section{Test for Difference between Means}

To determine if the difference in $\mathrm{G}_{\mathrm{C}}$ values between the $\mathrm{Ni}-\mathrm{Ti}$ and $\mathrm{Ni}-\mathrm{Cu}$ specimens is significant, a 2-sample t-test is used. In order to use these tests, several conditions must be met. Firstly, the data must be from two independent, random samples. Randomization was used in the design of the $\mathrm{G}_{\mathrm{C}}$ experiments, assuring that this condition is met. A second condition is that the data come from a normal distribution. To determine 
if this condition is met, normality tests on the two groups are performed. The results of these tests are shown in Figure 35. Normality tests return p-values of 0.113 and 0.290 for the $\mathrm{Ni}-\mathrm{Cu}$ and $\mathrm{Ni}-\mathrm{Ti}$ samples, respectively. This means that both distributions are approximately normal at any reasonable significant level (Devore \& Farnum, 2005).

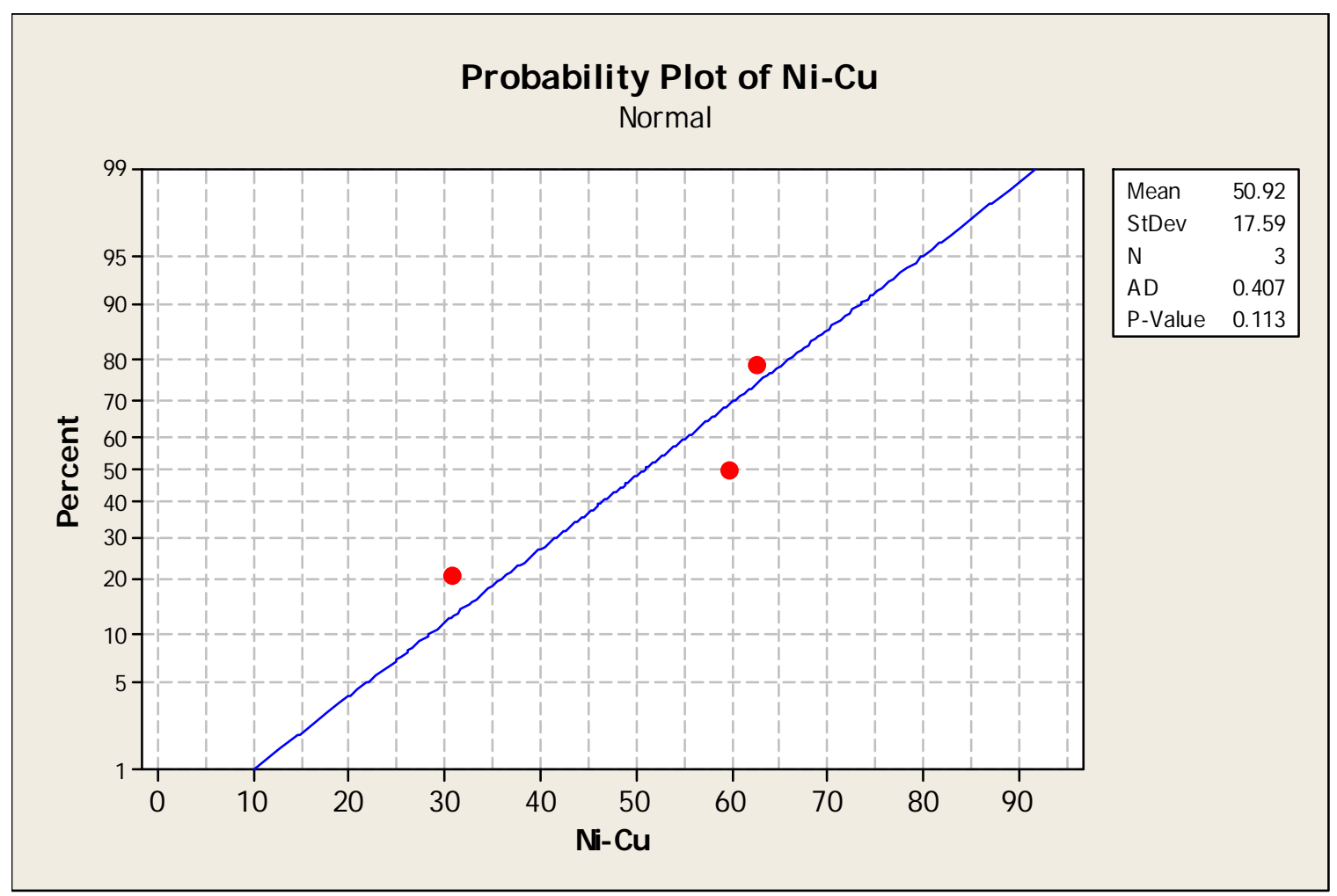

(a) 


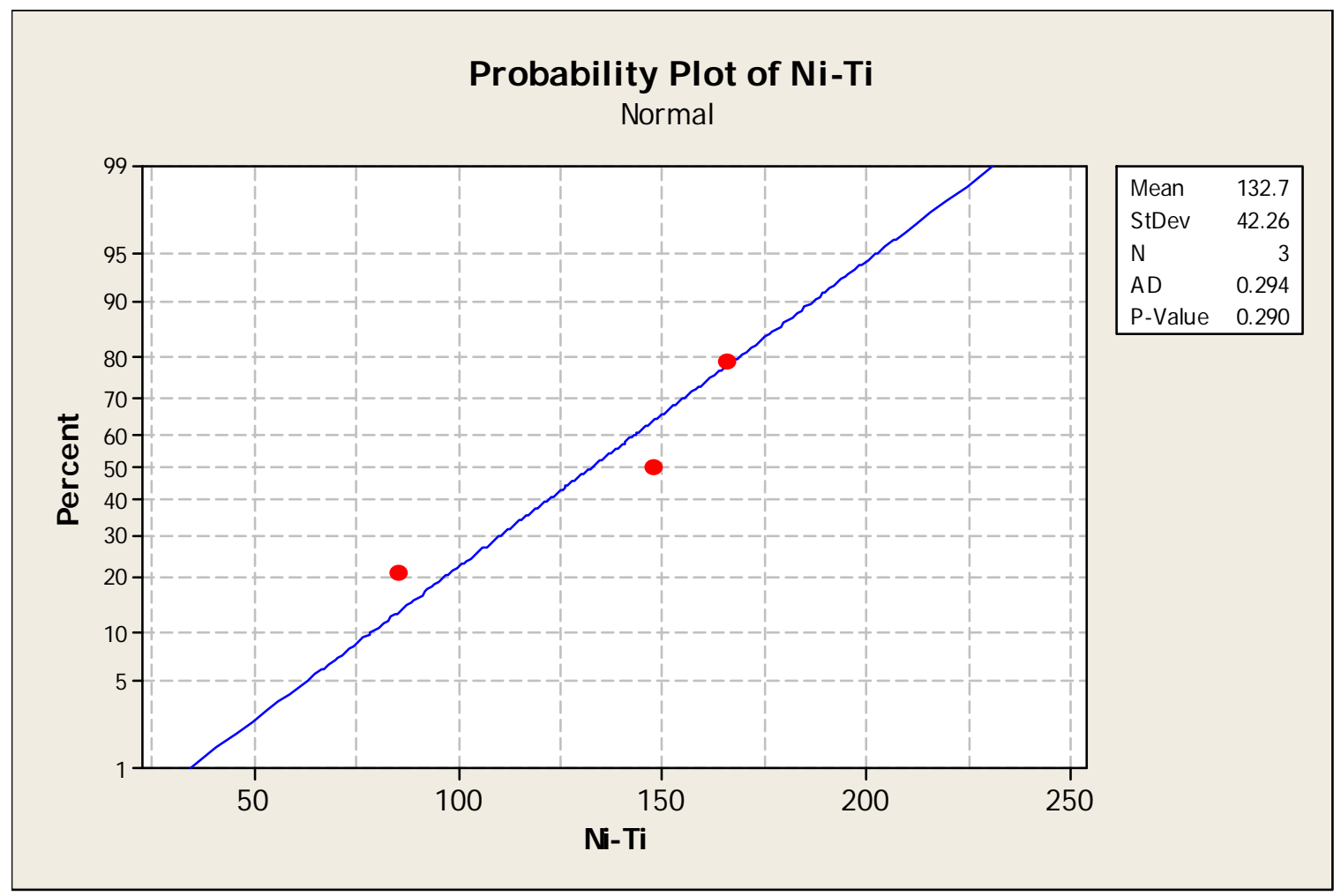

(b)

Figure 35: Normal Probablility plots of the (a) Ni-Cu and (b) Ni-Ti data. Normality tests suggest that the data is approximately normal.

Since both conditions are met, testing can proceed. However, the type of t-test used depends upon whether the two samples have equal variances. This can be determined using an F-test or Levene's test. The Minitab output of these tests is shown in Figure 36 . P-values for both tests are greater than 0.05 , indicating that there is no significant difference between the variances of the two samples at the $95 \%$ confidence level. 


\section{Test and $\mathrm{Cl}$ for Two Variances: $\mathrm{Ni}-\mathrm{Cu}, \mathrm{Ni}-\mathrm{Ti}$}

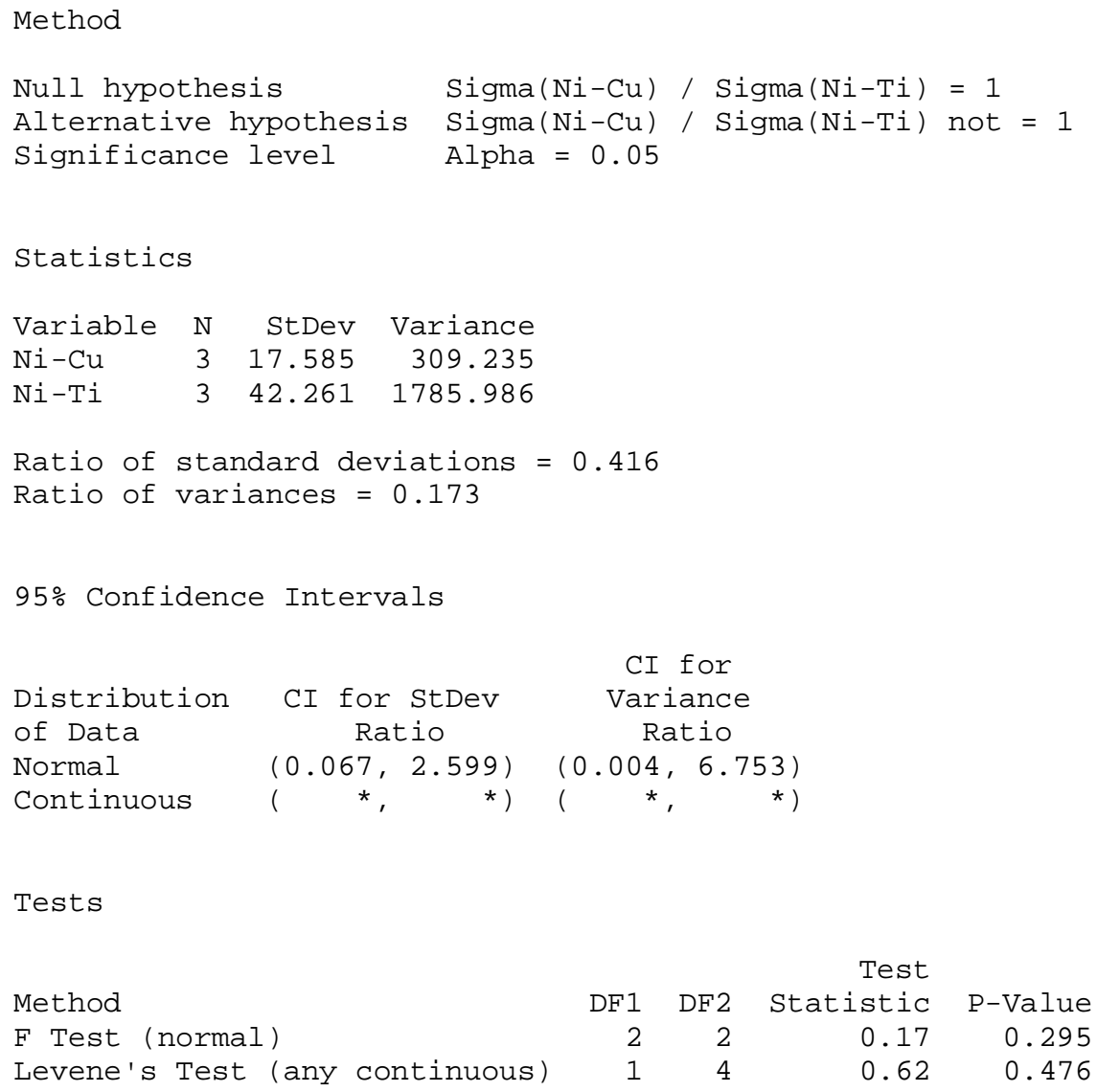

Figure 36: Both the tests return p-values $>0.05$, suggesting that there is no significant difference between the variances of the two samples.

Because there is no significant difference between the variances of the two samples, the pooled standard deviation of the two groups can be used in the 2-sample ttest. Theoretical results suggests that $\mathrm{G}_{\mathrm{C}}$ of the Ni-Ti specimens should be higher than that of the Ni-Cu specimens, so a one-tailed test is used. The Minitab output of this test is included below in Figure 37. The results of the test indicate that there is a significant difference in mean $\mathrm{G}_{\mathrm{C}}$ between the two groups. At the $95 \%$ significant level, the mean $\mathrm{G}_{\mathrm{C}}$ of the Ni-Ti specimens is significantly greater than the mean $\mathrm{G}_{\mathrm{C}}$ of the $\mathrm{Ni}-\mathrm{Cu}$ specimens. 
Minitab also computed the $95 \%$ lower bound for the difference in mean $\mathrm{G}_{\mathrm{C}}$ : this value was $25.4 \mathrm{~J} / \mathrm{m}^{2}$.

Two-Sample T-Test and $\mathrm{Cl}$ : $\mathrm{Ni}-\mathrm{Ti}, \mathrm{Ni}-\mathrm{Cu}$

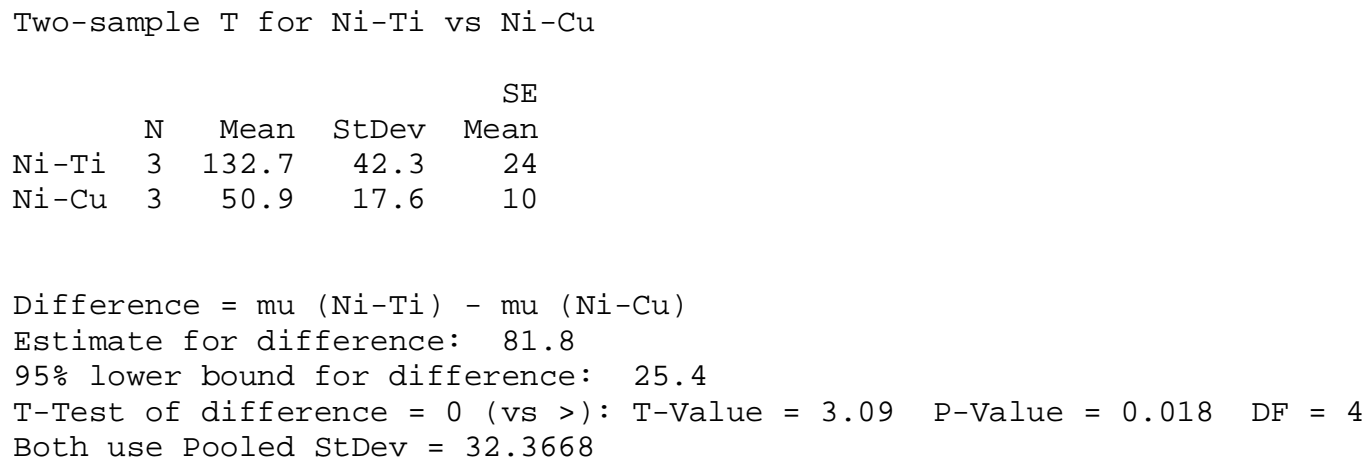

Figure 37: A 2-sample t-test using a pooled standard deviation indicates that the mean $\mathbf{G}_{\mathrm{C}}$ of the Ni-Ti specimens is significantly greater than the mean $\mathrm{G}_{\mathrm{C}}$ of the $\mathrm{Ni}-\mathrm{Cu}$ specimens. 